Guilherme Marques Dias

\title{
Heurística paralela para solução do problema de cobertura de rotas em larga escala
}

Dissertação apresentada à Escola Politécnica da Universidade de São Paulo para obtenção do Título de Mestre em Engenharia. 


\title{
Guilherme Marques Dias
}

\section{Heurística paralela para solução do problema de cobertura de rotas em larga escala}

\author{
Dissertação apresentada à Escola Po- \\ litécnica da Universidade de São Paulo \\ para obtenção do Título de Mestre em \\ Engenharia. \\ Área de concentração: \\ Engenharia de Controle e Automação \\ Mecânica \\ Orientador: \\ Prof. Dr. Marcos de Sales Guerra Tsuzuki
}


Este exemplar foi revisado e alterado em relação à versão original, sob responsabilidade única do autor e com anuência de seu orientador. São Paulo, 21 de Julho de 2013.

Assinatura do autor.

Assinatura do orientador.

Ficha Catalográfica

Dias, Guilherme Marques

Heurística paralela para solução do problema de cobertura de rotas em larga escala. São Paulo, 2013. 107 p.

Dissertação (Mestrado) — Escola Politécnica da Universidade de São Paulo. Departamento de Engenharia Mecatrônica.

1. Logística 2. Pesquisa operacional 3. Heurística I. Universidade de São Paulo. Escola Politécnica. Departamento de Engenharia Mecatrônica. II. Título. 
Dedico esta dissertação a minha mãe, por ter dedicado uma vida aos sonhos de seus filhos, incluindo este sonho. 


\section{Agradecimentos}

Ao meu Deus pela vida, esperança, energia, fé e por tudo que tenho e sou.

Ao amigo e orientador Marcos Tsuzuki pelo direcionamento do trabalho, revisões, incentivo e paciência.

Aos meus pais Clayton e Helena pelo apoio, pelo incentivo, pelo amor e pela compreensão pelas inúmeras vezes que deixei de visitá-los em prol do desenvolvimento deste trabalho.

Às minhas irmãs Ana Paula e Nathália pelo amor, zelo e incentivo.

À minha noiva Janaína, pela paciência e apoio nos momentos difíceis e pela compreensão pelos momentos que deixamos de passar juntos em prol deste trabalho. 
Everything Should Be Made as Simple as Possible, But Not Simpler

Albert Einstein 


\section{Resumo}

Empresas estão procurando reduzir seus custos e aumentar seu desempenho e competitividade. Neste cenário de redução de custos, a logística colaborativa pode ser uma aliada. Numa rede complexa, onde embarcadores muitas vezes nem sabem da existência de outros embarcadores com demandas complementares, existe um potencial de sinergia e redução de custos através da diminuição de deslocamentos de veículos sem carga, ou seja, deslocamentos para reposicionar os veículos. Visando essa redução, o Problema de Cobertura de Rotas (PCR), que tem como objetivo cobrir rotas no mínimo custo, une as demandas de frete de vários embarcadores e tenta minimizar os deslocamentos sem cargas (reposicionamentos), reduzindo assim o custo total de toda a rede dos embarcadores envolvidos.

Esta pesquisa propõe um modelo e uma heurística para resolver, em grande escala através de programação paralela, uma expansão do PCR.

Palavras-chave: Problema de Cobertura de Rotas, Programação Paralela, Logística Colaborativa. 


\section{Abstract}

Companies are looking to reduce costs and improve performance and competitiveness. In this cost-cutting scenario, collaborative logistics can be an ally. In a complex network where shippers often do not know of the existence of other shippers with complementary demands, there is potential for synergy and cost savings by reducing unloaded travelling of vehicles, i.e, the distance and time to reposition the vehicles'. Towards that reduction, the Lane Covering Problem (LCP), which aims to cover at least cost routeslinks the various shippers' demands of freight and tries to minimize operations without loads (repositioning), thus reducing the total cost of the entire network for involved shippers.

This research proposes a model and an heuristic to solve, in large-scale through parallel programming, an expansion of the PCR.

Keywords: Lane Covering Problem, Parallel Programming, Collaborative Logistics. 


\title{
Conteúdo
}

\section{Lista de Figuras}

\author{
Lista de Tabelas
}

\section{Lista de Abreviaturas}

1 Introdução 1

1.1 Objetivo da Dissertação . . . . . . . . . . . . . . . . . 2

1.2 Delineamento do Trabalho . . . . . . . . . . . . . . . . 2

2 Conceitos Preliminares 4

2.1 Modelagem de Custos de Transporte . . . . . . . . . . . . . . 4

2.1.1 Fatores que influenciam o custo e o preço do transporte . . 4

2.1.2 Componentes do Custo . . . . . . . . . . . . 5

2.2 Problemas de Roteamento . . . . . . . . . . . . . . . . . . 8

2.2.1 Caracterização dos Problemas de Roteamento . . . . . . . 8

2.2.2 Problemas Clássicos de Roteamento . . . . . . . . . . . . . 12

2.3 Programação Linear Inteira . . . . . . . . . . . . . . . . 16

2.3.1 Algoritmo Branch-and-Bound . . . . . . . . . . . 18

2.3.2 Algoritmo Branch-and-Cut . . . . . . . . . . . 18

2.3.3 Matriz Totalmente Unimodular (TUM) e Algoritmos de Relaxação . . . . . . . . . . . . . . . . 20

3 O Problema de Cobertura de Rotas $\quad 21$

3.1 Cobertura por Ciclos (Circuitos Logísticos) . . . . . . . . . . . 25

3.2 Cobertura por Rotas Spot (Terceirização de Frota) . . . . . . . . 27 
3.3 Modelagens e Abordagens de Solução para o PCRCR ..... 29

3.4 Gerador de Caminhos . . . . . . . . . . . . . . . . . . . 30

3.4.1 Geração Combinatória de Caminhos . . . . . . . . . . . 31

3.4.2 Geração de Caminhos Guiada pela Junção de Ciclos . . . . 35

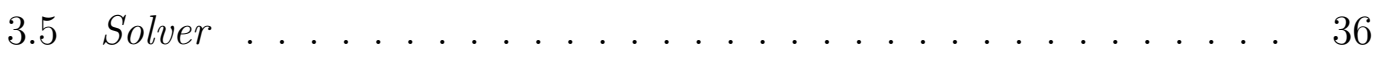

3.5.1 Programação Linear Inteira - PLI . . . . . . . . . . . . 36

3.5.2 Heurísticas. . . . . . . . . . . . . . . . . . 39

$\begin{array}{lll}4 & \text { Proposta } & 41\end{array}$

4.1 Delimitação da modelagem proposta . . . . . . . . . . . . . . 43

4.2 Modelagem do Custo de Rotas . . . . . . . . . . . . . . . . 44

4.2.1 Cálculo do Custo de Rotas . . . . . . . . . . . . . . 44

4.2.2 Comparação entre rota $\mathrm{C} 0$ e circuito $\mathrm{C} 1 \ldots$. . . . . . 46

4.2.3 Classificação dos custos de operação de uma rede . . . . . 48

4.3 Gerador de Caminhos Guiada por Raio de Investimento . . . . . . 49

4.3 .1 Raio de Investimento . . . . . . . . . . . . . . 50

4.3.2 Algoritmo Paralelo de Geração de Caminhos . . . . . . . . 55

4.4 Solver: Heurística de Priorização de Caminhos . . . . . . . . . . 58

4.4.1 Priorização por Dimensionamento de Frota . . . . . . . 59

4.4.2 Priorização por Eficiência do Ciclo . . . . . . . . . . . 62

4.4.3 Priorização por Melhor Custo . . . . . . . . . . . 62

4.5 Comparação entre Abordagens . . . . . . . . . . . . . . 62

4.6 Aplicações Relevantes para a Proposta . . . . . . . . . . . . . 65

5 Resultados Experimentais e Discussões $\quad 67$

5.1 Gerador de Instâncias . . . . . . . . . . . . . . . . . 67

5.2 Parâmetros de Custo e Operação . . . . . . . . . . . . . 68

5.3 Instâncias, Configurações e Linhas de Análise . . . . . . . . . . . 69

5.4 Aplicação do Gerador de Caminhos . . . . . . . . . . . . . . . 72 
5.4.1 Análise do Total de Ciclos Gerados . . . . . . . . . . . 72

5.4.2 Análise do Tempo de Execução . . . . . . . . . . . . . 76

5.4.3 Análise da Qualidade dos Caminhos Gerados . . . . . . . . 80

5.4.4 Discussões sobre o Gerador de Caminhos . . . . . . . . . 83

5.5 Aplicação do Solver . . . . . . . . . . . . . . . . . . . . . . 84

5.5.1 Análise do Tempo de Execução . . . . . . . . . . . . . . 84

5.5.2 Análise da Qualidade de Solução . . . . . . . . . . . . 86

5.5.3 Discussões sobre o Solver. . . . . . . . . . . . . . 87

$\begin{array}{llr}6 & \text { Conclusões } & 89\end{array}$

6.1 Trabalhos Futuros . . . . . . . . . . . . . . . . 90

$\begin{array}{ll}\text { Referências } & 91\end{array}$

Apêndice A - Aplicação da Proposta ao Transporte Colaborativo 94

A.1 Exemplo de aplicação em Transporte Colaborativo . . . . . . . . . 95

Apêndice B - Aplicação da Proposta à Modelo com Dados FIPE/I$\begin{array}{lr}\text { DET } & 98\end{array}$

Premissas e Parâmetros . . . . . . . . . . . . . . . . . . . . . . . 99

Aplicação das Heurísticas e Análise dos Resultados . . . . . . . . . . . 100

Anexo A - Tabelas de Movimentação de Cargas FIPE/IDET em Jan/2010 e PIB da Região Norte (2010) 103 


\section{Lista de Figuras}

1.1 Fluxograma Metodologia. . . . . . . . . . . . . . . . 3

2.1 Problemas de Roteamento de Veículos. . . . . . . . . . . . . . . 13

2.2 Cobertura de Nós através da solução do PCV (adaptado de Wolfram.com) . . . . . . . . . . . . . . . . . 14

2.3 Ciclos Hamiltonianos (WEISSTEIN ${ }^{[1]}$ ). . . . . . . . . . . . . 14

2.4 Transformação das sete pontes de Königsberg em um grafo por Euler (Gomes et al, 2009) ${ }^{[2]} \ldots$. . . . . . . . . . . . . . 15

2.5 Exemplo ilustrativo do algoritmo $B \mathscr{E} B$ (adaptado de ${ }^{[3]}$ ) . . . . . 18

2.6 Simplex e Kamarkar $\left(\right.$ retirado de $\left.{ }^{[4]}\right) \ldots \ldots \ldots$

2.7 Abordagem Cutting Plane (retirado de ${ }^{[4]}$ ). . . . . . . . . . . . . 19

2.8 Grupos de domínios para o B\&B (retirado de ${ }^{[4]}$ ). . . . . . . . . 19

3.1 Problema do Carteiro Chinês. . . . . . . . . . . . . . . . . . . 21

3.2 Problema de Cobertura de Rotas. . . . . . . . . . . . . . . . . 22

3.3 Problema Abordado neste trabalho. . . . . . . . . . . . . . . . 22

3.4 Problema de Cobertura de Rotas e suas principais vertentes. . . . 25

3.5 Exemplo de Logística Colaborativa promovendo economia com Circuitos Logísticos (retirado de Savelsbergh, Ergun e Kuyzu ${ }^{[5]}$ ). . 26

3.6 Exemplos de Circuitos Fechados. (Fonte: Ilustração CEL/Coppead) 27

3.7 Classificação das rotas (conjunto de arcos com demandas conectados, também chamados circuitos). . . . . . . . . . . . . . . 27

3.8 Caminhoneiros aguardando para acessar o Terminal de Cargas da Fernão Dias (Foto retirada do site: revistaocarreteiro.com.br, em 02 de Janeiro de 2013) . . . . . . . . . . . . . . . . . . . . . . 28

3.9 Estrutura geral das abordagens do PCRCR. . . . . . . . . . . . . 29 
3.10 Algoritmo para Geração de Caminhos - Extrapolado de (STRINGHER, 2004). . . . . . . . . . . . . . . . . . . 31

3.11 Exemplo: Permutações possíveis para formar um circuito C3. . . . 32

3.12 Crescimento do Número de Circuitos. . . . . . . . . . . . . . . 34

3.13 A rede representada na figura inclui quatro demandas entre três cidades $(\mathrm{A}, \mathrm{B}$ e $\mathrm{C}) . \mathrm{A}=\mathrm{A} \rightarrow \mathrm{B}, \mathrm{B} \rightarrow \mathrm{C}, \mathrm{C} \rightarrow \mathrm{B}, \mathrm{C} \rightarrow \mathrm{A} \ldots 37$

3.14 Circuitos gerados a partir da configuração da rede dada na Fig. (3.13). 37

3.15 Matriz de restrições. . . . . . . . . . . . . . . . . . . . . . . . . . 38

3.16 Solução encontrada pelo Solver PLI para o exemplo. . . . . . . 39

3.17 Fluxo completo de solução. . . . . . . . . . . . . . . . . . . . . . . 39

4.1 Diagrama de Seqüência - Sinergia entre Gerador de Caminhos e Solver. . . . . . . . . . . . . . . . . . . . 42

4.2 Exemplo Circuito C3. . . . . . . . . . . . . . . . . 45

4.3 Exemplo de Rota Spot $(\mathrm{C} 0) \ldots \ldots$. . . . . . . . . . . . 46

4.4 Custo C0 x Custo C1 (Adaptado de STRINGHER, 2004). . . . . 47

4.5 Árvore de Nós posteriores (determinados pelo tamanho da bolha). $\quad 50$

4.6 Raios de Investimento. . . . . . . . . . . . . . . . . . . . . . . 51

4.7 Custos referência de operação. . . . . . . . . . . . . . . . . . 52

4.8 Exemplo de Ciclo e Gráfico de Raio de Investimento no decorrer do percurso. . . . . . . . . . . . . . . . . . 53

4.9 Gráfico de Raio de Investimento em relação a distância percorrida. 54

4.10 Gráfico simplificado de Raio de Investimento Misto. . . . . . . . . 55

4.11 Algoritmo 2 - Algoritmo para Geração Paralela de Caminhos Guiado pela Raio de Investimento. . . . . . . . . . . . . . . . . 56

4.12 Algoritmo 3 - Algoritmo de Propagação da Busca nos Nós. . . . . 57

4.13 Paralelização do Loop de Propagação de Busca (Algoritmo 3). . 58

4.14 Heurística de Priorização de Ciclos. . . . . . . . . . . . . . . . . . 58

4.15 Demanda Máxima. . . . . . . . . . . . . . . . . . . 59

4.16 Heurística de Priorização de Ciclos. . . . . . . . . . . . . . . . . 61 
5.1 Tela do Gerador de Instâncias. . . . . . . . . . . . . . . . . . . 68

5.2 Instâncias de Teste. . . . . . . . . . . . . . . . . . . . . . . . 69

5.3 Distribuição Uniforme de 500 Nós. . . . . . . . . . . . . . . . 70

5.4 Variáveis do Modelo. . . . . . . . . . . . . . . . . . . . . 71

5.5 Linhas de Análise. . . . . . . . . . . . . . . . . . . . . . 72

5.6 Monitoramento de Memória durante a Execução. . . . . . . . . . 73

5.7 Gráfico de Tempo do Gerador (ms) de Raio Misto para o Grupo 1.76

5.8 Gráfico de Tempo do Gerador (ms) de Raio Fixo para o Grupo 1.76

5.9 Gráfico de Tempo do Gerador (ms) de Raio Variável de 10\% para o Grupo 1. . . . . . . . . . . . . . . . . . . . . 77

5.10 Gráfico de Tempo do Gerador (ms) de Raio Variável de 5\% para o Grupo 1. . . . . . . . . . . . . . . . . . . . 77

5.11 Gráfico de Tempo do Gerador (ms) de Raio Variável de 64\% para o Grupo 1. . . . . . . . . . . . . . . . . . . . 77

5.12 Gráfico Resumo dos Tempos (ms) dos Métodos do Gerador para o Grupo 1. . . . . . . . . . . . . . . . . . . . 78

5.13 Gráfico do Tempo de Gerador (ms) em Função da Cardinalidade (K) Máxima.

5.14 Gráfico de Tempo do Gerador um Função de Particionamentos Paralelos. . . . . . . . . . . . . . . . . . . . 79

A.1 Rede Logística da Empresa A. . . . . . . . . . . . . . . . . 96

A.2 Comparativo de Custos (Empresa A) . . . . . . . . . . . . . 96

A.3 Comparativo de Custos (Empresa B) . . . . . . . . . . . . . . . . 97

A.4 Comparativo de Custos (Empresa B). . . . . . . . . . . . . . 97

A.5 Operação Colaborativa entre A e B. . . . . . . . . . . . . . . . . 97

B.1 Representação dos pontos no Google Maps. . . . . . . . . . . . . . 100

B.2 Representação dos Pontos no Software . . . . . . . . . . . . . . 100

B.3 Distribuição dos Custos encontrados pela Solução. . . . . . . . . . . 101

B.4 Desbalanceamento dos vetores de cargas no Brasil. . . . . . . . . . 102 


\section{Lista de Tabelas}

2.1 Custo de transporte segmentado segundo Alvarenga e Novaes (2000). 5

2.2 Exemplo de planilha de custo (Lima, M.P. $\left.{ }^{[6]}\right) \ldots \ldots$

2.3 Níveis de Dicisão em sistemas de Transporte. . . . . . . . . . . . . 10

3.1 Resultado Combinatório da Quantidade de Caminhos. . . . . . . . 34

4.1 Comparação entre Abordagens. . . . . . . . . . . . . . . . . 64

5.1 Custos Referência para as Amostras. . . . . . . . . . . . . . 70

5.2 Quantidade de Caminhos Calculada para o Gerador Combinatório. 73

5.3 Quantidade de Caminhos Gerados com Gerador de Raio de Investimento Misto com no máximo um reposicionamento. . . . . . . . 74

5.4 Quantidade de Caminhos Gerados com Gerador de Raio de Investimento Misto com no máximo dois reposicionamentos. . . . . . . 74

5.5 Quantidade de Caminhos Gerados com Gerador de Raio de Investimento Variável de um reposicionamento e 10\% do custo core. . . 74

5.6 Quantidade de Caminhos Gerados com Gerador de Raio de Investimento Variável de dois reposicionamentos e 10\% do custo core. . 74

5.7 Quantidade de Caminhos Gerados com Gerador de Raio de Investimento Variável de um reposicionamento e 5\% do custo core. . . 75

5.8 Quantidade de Caminhos Gerados com Gerador de Raio de Investimento Variável de dois reposicionamentos e 5\% do custo core. . 75

5.9 Análise da Qualidade dos Caminhos Gerados para a Instância com 10 Arcos . . . . . . . . . . . . . . . . . 80

5.10 Análise da Qualidade dos Caminhos Gerados para a Instância com 20 Arcos. . . . . . . . . . . . . . . . . . 81

5.11 Análise da Qualidade dos Caminhos Gerados para a Instância com 30 Arcos. . . . . . . . . . . . . . . . . . . 81 
5.12 Análise da Qualidade dos Caminhos Gerados para a Instância com 40 Arcos.

5.13 Análise da Qualidade dos Caminhos Gerados para a Instância com 50 Arcos.

5.14 Resumo das Diferenças das Soluções Obtidas pelos Solvers. . . . . 83

5.15 Tempo de Execução do Solver (HSPC) para a Instância de 100 arcos. 84

5.16 Tempo de Execução do Solver (HSPC) para a Instância de 200 arcos. 85

5.17 Tempo de Execução do Solver (HSPC) para a Instância de 500 arcos. 85

5.18 Tempo de Execução do Solver (HSPC) para a Instância de 1000 arcos. . . . . . . . . . . . . . . . 85

5.19 Tempo de Execução do Solver (HSPC) para a Instância de 3000 arcos. . . . . . . . . . . . . . . 86

5.20 Tempo de Execução do Solver (HSPC) para a Instância de 5000 arcos. . . . . . . . . . . . . . . 86

5.21 Diferença entre a Solução do HSPC e PLI para o mesmo conjunto de Caminhos Gerados. . . . . . . . . . . . . . 87

A.1 Benefícios do Transporte Colaborativo (Figueiredo e Eiras ${ }^{[7]}$ ). . . 95

B.1 Desbalanceamento dos Vetores de Cargas no Brasil (Fonte: FIPE/IDET para Jan/2010). . . . . . . . . . . . . . . . . . . . . 99

B.2 Custos Associados a Rede Modelada. . . . . . . . . . . . . . . . . 101

A.1 PIB dos estados da Região Norte em $2010\left(\mathrm{R} \$ 10^{6}\right)$. . . . . . . . 103

A.2 Tabela FIPE/IDET Cargas Movimentadas (ton) - Janeiro2010 entre Regiões. . . . . . . . . . . . . . . . . . . . . . . . . . . . . 104

A.3 Tabela FIPE/IDET Cargas Movimentadas (ton) - Janeiro2010 Destino: Região Norte. . . . . . . . . . . . . . . . . . . . . . . . . 104

A.4 Tabela FIPE/IDET Cargas Movimentadas (ton) - Janeiro2010 Destino: Região Centro-Oeste. . . . . . . . . . . . . . . 105

A.5 Tabela FIPE/IDET Cargas Movimentadas (ton) - Janeiro2010 Destino: Região Sudeste. . . . . . . . . . . . . . . . . . . 106

A.6 Tabela FIPE/IDET Cargas Movimentadas (ton) - Janeiro2010 Destino: Região Sul. . . . . . . . . . . . . . . . . . . . . . . 107 


\section{Lista de Abreviaturas}

PCR Problema de Cobertura de Rotas

PCRCR Problema de Cobertura de Rotas com Cardinalidade Restrita

PCV Problema do Caixeiro Viajante

PCC Problema do Carteiro Chinês

PCC2 Problema de Cobertura por Ciclos

TL Truck Load - Carga lotação

LTL Less than Truck Load - Carga Fracionada

PLI Programação Linear Inteira

B\&B Branch-and-Bound

HSPC Heurística Solver por Priorização de Caminhos

HGCGRI Heurística de Geração de Caminhos Guiada por Raio de Investimento 


\section{Introdução}

Em mercados tradicionais de carga lotação (modalidade de transporte de cargas que possui somente uma coleta e uma entrega para a carga transportada), o embarcador (responsável por contratar o transportador) envia requisições a vários transportadores e negocia um preço com eles. Essas requisições consistem em demandas isoladas a serem atendidas, onde cada demanda corresponde a um carregamento da origem até o destino com um veículo totalmente carregado. Como normalmente não existe sinergia entre os embarcadores no planejamento dessas demandas, os reposicionamentos (deslocamentos vazios) dos veículos são necessários, aumentando o custo improdutivo, o preço do frete e assim o custo total com transporte. O problema objeto de estudo deste trabalho visa encontrar as sinergias entre demandas de embarcadores, com o intuito de reduzir os deslocamentos improdutivos (reposicionamentos) e assim reduzir os custos de transporte.

Os embarcadores são os contratantes do frete, por exemplo, fabricantes, distribuidores, varejistas ou empresas especializadas em fazer esse tipo de contratação. Transportadores são empresas de transporte, como transportadores rodoviários, ferroviários, companhias aéreas e fornecedores de transporte marítimo. Existem dois tipos principais de operações de transporte para o modal rodoviário: as operações por carga lotação, onde o caminhão é geralmente dedicado a um único carregamento que se desloca da origem até o destino (somente uma operação de carga e somente uma operação de descarga), em contraste com as operações por cargas fracionadas e transportadores de encomendas, que consolidam muitos carregamentos menores em um único caminhão ${ }^{[8]}$.

Vários autores juntam teoria de jogos colaborativos e problemas clássicos de roteamento. Engeval, Goothe-Lundgren e Varbrand ${ }^{[9]}$ consideram um jogo de roteamento colaborativo de veículos quando são permitidas diferentes capacidades aos veículos. Encontrar rotas eficientes, caminhos contínuos e rede de colaboração de cargas lotação foram estudados por Ergun em ${ }^{[10]}$, Stringher em ${ }^{[11]}$ e Moore, Warmke e Gorban em ${ }^{[12]}$. Os três últimos autores (de ${ }^{[12]}$ ) desenvolveram uma 
ferramenta de simulação e otimização, que identifica duas demandas que podem ser atendidas em sequência e um conjunto de transportadores que podem atender ambas as demandas. Esta ferramenta é utilizada pelo departamento de compras centralizado da Reynolds Metal Company. A centralização das contratações e procura por contínuas oportunidades resultou em $\$ 7$ milhões de economia em custos de transporte.

Quanto à caracterização do problema estudado aqui em relação aos problemas clássicos, ele pode classificado como um caso especial do Problema do Carteiro Chinês, cujo objetivo é cobrir um conjunto de rotas com o mínimo custo, e onde as demandas das rotas não são unitárias.

Definido por Ergun ${ }^{[10]}$, e detalhado no Capítulo 3, o Problema de Cobertura de Rotas (PCR), em língua inglesa Lane Covering Problem (LCP) é a definição que mais se aproxima do problema aqui estudado. Dado um conjunto de demandas, o objetivo é encontrar um conjunto de rotas que atende todas as demandas de tal forma que a custo total das rotas seja minimizado.

\subsection{Objetivo da Dissertação}

O objetivo desta pesquisa é desenvolver uma heurística para achar uma solução para o problema abordado neste trabalho, que está intimamente ligado à colaboração logística em redes de carga lotação (cargas operadas em rotas diretas de uma origem e um destino sem realizar paradas intermediárias). Como este tipo de problema cresce exponencialmente em custo computacional, este trabalho se propõe a resolver casos de grande escala através de heurísticas especializadas e considerando sua escalabilidade computacional (utilizando programação paralela). Visando aproximar-se ao máximo dos problemas reais, será levado em consideração custos fixos e variáveis, demandas não unitárias e possibilidade de cobertura de rotas através de frota dedicada e contratação temporária de terceiros.

\subsection{Delineamento do Trabalho}

Esta dissertação está dividida em cinco capítulos:

1. Introdução: Apresentação do problema, trabalhos relacionados, objetivo da dissertação e delineamento do trabalho. 
2. Conceitos Preliminares: apresenta os conceitos base para o desenvolvimento do trabalho.

3. O Problema de Cobertura de Rotas - PCR: Descreve o problema, estrutura da solução, conceitos relacionados e compara conceitualmente trabalhos.

4. Proposta: Descreve o funcionamento das heurísticas Gerador de Caminhos e Solver por Priorização, suas premissas e conceitos.

5. Resultados: Aplicação da Propostas em amostras geradas e análise dos resultados.

6. Conclusões: discussão sobre os resultados até o momento, cronograma de conclusão da dissertação e conclusões.

Conforme ilustrado na Fig. (1.1), no Capítulo 3 partiu-se da definição do problema, em seguida a modelagem do problema e abordagens de solução existentes para resolver o PCR, baseadas em Gerador de Caminhos e Solvers. No Capítulo 4, apresenta-se a modelagem e as heurísticas propostas (Gerador e Solver) para resolver o PCR. O passo seguinte, no Capítulo 5, foi executar os testes e analisar os resultados, onde os casos testes foram criados pelo Gerador de Instância. E por fim, no Capítulo 6, as considerações finais e conclusão.

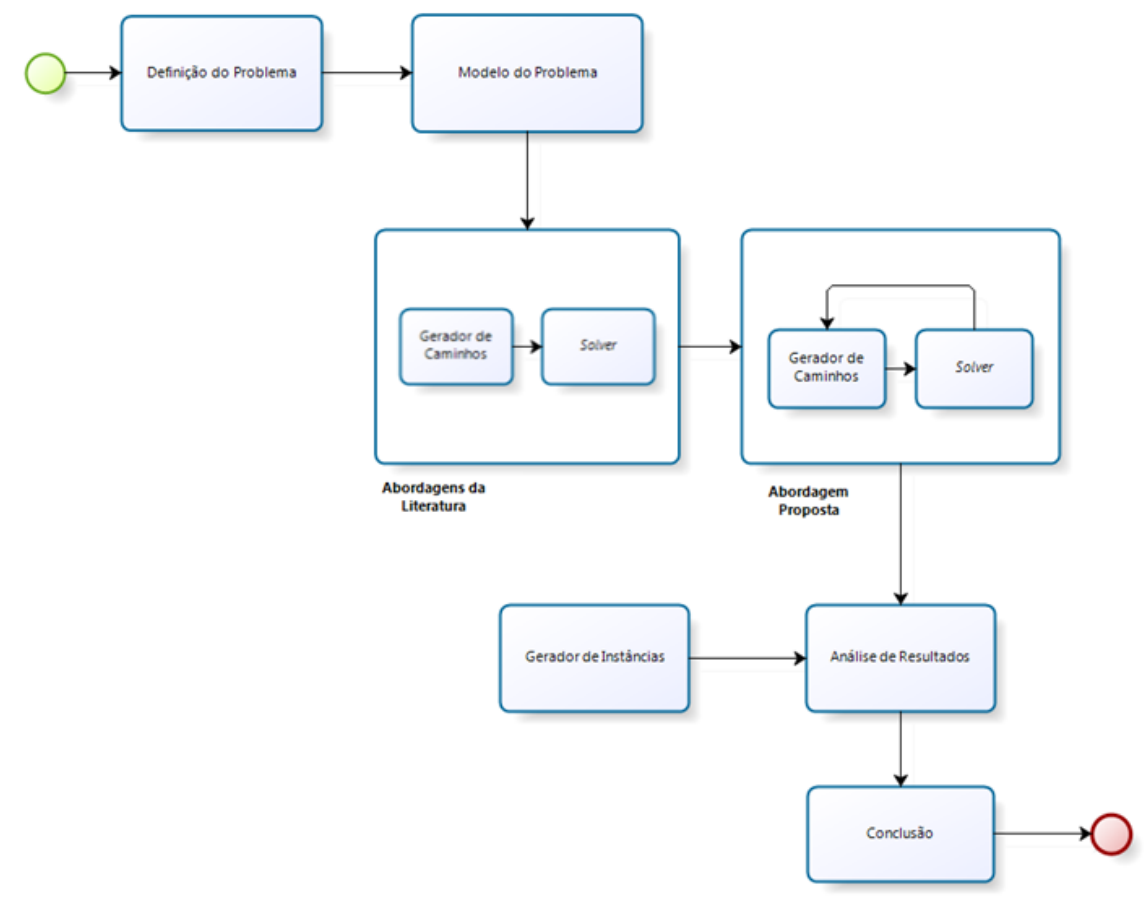

Figura 1.1: Fluxograma Metodologia.

Seguindo a metodologia, após o próximo capítulo com conceitos preliminares, será definido o problema e suas principais vertentes. 


\section{Conceitos Preliminares}

Este capítulo apresenta os conceitos base para o desenvolvimento do trabalho, assim como a taxonomia dos problemas correlatos e as ferramentas para solucionálos. Serão apresentados a modelagem de custos, os problemas de roteamento e a programação linear inteira.

\subsection{Modelagem de Custos de Transporte}

Os custos de transporte são elementos fundamentais para a política de preços, avaliação de desempenho da cadeia de suprimentos e a eficiência no uso dos recursos de uma organização. O presente trabalho presta-se a otimizar os custos totais de uma rede de transporte que possui demandas a serem atendidas. Portanto, é de suma importância saber como os custos de transporte são estruturados.

\subsubsection{Fatores que influenciam o custo e o preço do trans- porte}

Basicamente, os custos de transporte são funções de:

1. Operação / serviços a serem realizados;

2. Tipos e características do transporte.

Do ponto de vista de operação e serviços, os seguintes fatores influenciam os custos:

1. Coleta, transferência, distribuição e entrega.

2. Origem e destino: distância, condições da estrada, custo do combustível, etc.

3. Tipo de carga: Fracionada (LTL - less than truck load) ou Veículo completo (TL - truck load). 


\subsubsection{Componentes do Custo}

De acordo com Alvarenga e Novaes ${ }^{[13]}$, vide Tab. (2.1), os custos de transportes, assim como outros itens de custo, podem ser divididos em custos fixos, custos variáveis e custos indiretos, que consideram:

1. Custo Fixo: Considera as parcelas do custo de capital, impostos e taxas, seguro equipamento, remuneração do motorista, remuneração do pessoal operacional, etc.

2. Custo Variável: Considera combustível, manutenção, pneus, lubrificante (cárter e câmbio) e lavagem.

3. Custo Indireto: Serviços contábeis, setor pessoal e serviços administrativos.

Para efeito de cálculo, muitas empresas incluem o custo indireto dentro do custo fixo através de um rateio percentual pelos veículos da frota. Embora contabilmente não seja correto fazer essa consideração, para simplificar os cálculos essa prática será adotada nesta dissertação.

Tabela 2.1: Custo de transporte segmentado segundo Alvarenga e Novaes (2000).

\begin{tabular}{|c|l|l|}
\hline \multirow{2}{*}{ Direto } & Fixo & $\begin{array}{l}\text { Depreciação do veículo } \\
\text { Remuneração do capital } \\
\text { Salário e gratificação do motorista } \\
\text { Seguro } \\
\text { Licenciamento }\end{array}$ \\
\cline { 2 - 3 } & & $\begin{array}{l}\text { Combustível } \\
\text { Lubrificação } \\
\text { Vanutenção } \\
\text { Pneus }\end{array}$ \\
\hline \multirow{2}{*}{ Indireto } & $\begin{array}{l}\text { Serviços contábeis } \\
\text { Setor de pessoal } \\
\text { Serviços administrativos de modo geral }\end{array}$ \\
\hline
\end{tabular}

Agora, o cálculo de cada uma dessas parcelas será detalhado. Os coeficientes CF (Coeficiente de Custo Fixo - R $\$ / \mathrm{h}$ ) e CV (Coeficiente de Custo Variável $\mathrm{R} \$ / \mathrm{km}$ ) são definições para determinar o custo de uma rota. 


\section{Coeficiente de Custo Fixo (CF)}

Para calcular CF, os seguintes componentes do custo fixo mensal são utilizados:

1. Depreciação do veículo (mensal)

$$
C_{\text {dep }}=\frac{\text { Vaquisicao }-V_{\text {residual }}}{n^{\circ} \text { demeses }}
$$

$C_{d e p}$ : Custo de depreciação mensal $(\mathrm{R} \$)$

Vaquisição : Valor da aquisição do veículo $(\mathrm{R} \$)$

Vresidual : Valor residual do veículo $(\mathrm{R} \$)$

$\mathrm{n}^{\mathrm{o}}$ de meses: quantidade de meses levados em conta na análise.

2. Remuneração de capital (mensal)

$$
C_{\text {r.cap }}=\operatorname{Vaquisicao}\left(\sqrt[12]{1+\operatorname{taxa}_{\text {anual }}}-1\right)
$$

Cr.cap: Custo que o veículo tem pelo capital investido $(\mathrm{R} \$)$

taxa $a_{\text {anual }}$ : Taxa anual de retorno de capital

3. Salário da tripulação $(\mathrm{R} \$)$

4. IPVA e Seguro obrigatório

$$
C_{\text {seg/IPVA }}=\frac{\text { Valoranual }}{12}
$$

Dados todos os componentes do custo fixo mensal, definimos o coeficiente $(\mathrm{R} \$ / \mathrm{h})$ como:

$$
C_{F}=\frac{\sum_{i} C_{F}^{i}}{T_{u t i l}}=\frac{C_{d e p}+C_{r, c a p}+C_{s e g / I P V A}}{T_{u t i l}}
$$

Onde são os componentes do custo dados em $(\mathrm{R} \$)$ e , dado em (horas), é o tempo total útil que um veículo trabalha em um mês. Está relacionado à quantidade de turnos, quantidade de motoristas, carga horária diária e fatores regulatórios.

\section{Coeficiente de Custo Variável (CV)}

Esta componente do custo está relacionada aos custos por $\mathrm{km}$ rodado e possui uma relação direta com o coeficiente, que possui a mesma unidade de medida. 
1. Combustível

2. Óleo de cárter

3. Óleo de câmbio e diferencial

4. Lavagem e lubrificação

5. Pneus e câmaras

$C_{V}$ é dado pela soma dos componentes de custo variável, dados em $\mathrm{R} \$ / \mathrm{km}$ rodado.

$$
C_{v}=\sum_{i} C_{v}^{i}
$$

\section{Custo total da rota $(\mathrm{CP})$}

Para o cálculo do custo define-se uma equação geral que é função da distância total percorrida e do tempo total necessário para atender a demanda.

$$
C_{P}=T_{\text {total }} \cdot C_{F}+\text { Distancia } \cdot C_{v}
$$

- $C_{P}$ : Custo total para percorrer a rota uma vez.

- $T_{\text {total }}$ : Tempo total de uma rota (carga, descarga, viagem e procura por carga).

- $C_{F}$ : Custo fixo em $\mathrm{R} \$ / \mathrm{h}$.

- $C_{V}$ : Custo variável em $\mathrm{R} \$ / \mathrm{km}$.

- Distancia: Distância percorrida na rota em km.

De forma resumida, neste trabalho assume-se os custos como dispostos na Tab. (2.2), retirada de [NTC] ${ }^{[6]}$. 
Tabela 2.2: Exemplo de planilha de custo (Lima, M.P. ${ }^{[6]}$ ) .

\begin{tabular}{|c|c|c|}
\hline \multicolumn{3}{|l|}{ Dados de Entrada } \\
\hline \multicolumn{3}{|l|}{ Custos da empresa } \\
\hline Salário do motorista & RS/ mês & 750,0 \\
\hline Horas de trabalho/ mês & h.h./mês & 17 \\
\hline Encargos e benefícios do motorista & RS/ mês & 562,5 \\
\hline Taxa de oportunidade & $\%$ a.a. & \\
\hline Custos administrativo & RS/ mês & 500,0 \\
\hline \multicolumn{3}{|l|}{ Dados do veiculo } \\
\hline Consumo de combustivel & $\mathrm{Km} /$ litro & 2,5 \\
\hline Intervalo entre troca de óleo & $\mathrm{Km}$ & 1000 \\
\hline Litros de óleo por troca & litro & \\
\hline Número de pneus & & \\
\hline $\begin{array}{l}\text { Intervalo entre troca de pneu/ recapagem } \\
\text { Número de recapagens }\end{array}$ & $\mathrm{Km}$ & 8 \\
\hline Custos de manutenção & $\mathrm{R} \$ / \mathrm{Km}$ & 0,1 \\
\hline Intervalo entre lubrificações & $\mathrm{Km}$ & 200 \\
\hline \multicolumn{3}{|l|}{ Dados de mercado } \\
\hline Valor de aquisição do veículo & RS & 165000 \\
\hline Vida útil do veículo & meses & 12 \\
\hline Valor residual do veículo & RS & 6500 \\
\hline Preço do óleo & $\mathrm{RS} /$ litro & 2 \\
\hline Preço do combustivel & RS/ litro & 0,6 \\
\hline Preço do pneu & RS & 62 \\
\hline Preço da recapagem & & 18 \\
\hline |PVAS Seguro Obrigatório & RS/ ano & \\
\hline
\end{tabular}

\begin{tabular}{|c|c|c|}
\hline \multicolumn{3}{|c|}{ Dados de Saída } \\
\hline \multicolumn{3}{|l|}{ Itens de custo fixo } \\
\hline Depreciação & RS/ mês & 833,33 \\
\hline Remuneração de capital & RS/ mês & $1.565,65$ \\
\hline Mão de obra & RS/ mês & $1.312,50$ \\
\hline IPVASequro Obrigatório & RS/ mês & 100,00 \\
\hline CF & RS/ mês & $3.811,48$ \\
\hline Custos administrativo & RS/ mês & 500.00 \\
\hline CF c/ custos administrativos & RS/ mês & $4.311,48$ \\
\hline \multicolumn{3}{|l|}{ Itens de custo variável } \\
\hline Combustivel & $\mathrm{R} \$ / \mathrm{Km}$ & 0,26 \\
\hline Óleo & $\mathrm{R} \$ / \mathrm{Km}$ & 0,01 \\
\hline Pneu & $\mathrm{R} \$ / \mathrm{Km}$ & 0,07 \\
\hline Manutenção & $\mathrm{R} \$ / \mathrm{Km}$ & 0,13 \\
\hline Custo variável & $\mathrm{R} \$ / \mathrm{Km}$ & 0,47 \\
\hline Custos fixos (R\$/ hora) & $\begin{array}{l}\text { RS/ hora } \\
\text { RS/ Km }\end{array}$ & 24,50 \\
\hline Custos variáveis (R\$/ Km) & $\mathbf{R S} / \mathrm{Km}$ & 0,47 \\
\hline
\end{tabular}

\subsection{Problemas de Roteamento}

Um sistema de roteamento pode ser considerado como um conjunto organizado de meios que objetivam o atendimento de demandas localizadas nos arcos ou nos vértices de redes de transportes.

De acordo com Goldbarg e Luna ${ }^{[3]}$, a idéia básica do problema de roteamento é fácil de definir: o que se deseja é, com o uso de veículos, visitar uma série de clientes ao menor custo possível, atendendo a todas as demais imposições do problema. Nesta seção os problemas serão classificados de acordo com suas características e também pela vertente de origem nos problemas clássicos de roteamento.

\subsubsection{Caracterização dos Problemas de Roteamento}

Um sistema de transporte de cargas, em especial no que tange à roteirização, pode ser visualizado como um sistema que objetiva o atendimento de demandas localizadas nos arcos ou vértices de um grafo que representa uma rede de transportes.

Partindo de uma abordagem de cima para baixo, adaptada de ${ }^{[3]}$, é possível 
estruturar os problemas de decisão em transportes como:

\section{Decisões Estratégicas;}

2. Decisões Táticas;

3. Decisões Operacionais.

Em um nível mais alto de um sistema de transporte de cargas, tem-se as decisões estratégicas, que normalmente impactam todo o sistema e tem efeito duradouro. Vale ressaltar, que de acordo com a estratégia adotada, a solução otimizada do sistema pode chegar a resultados distintos. Por exemplo, se a estratégia de uma empresa de transportes é atender ao mercado de curta distância, não será relevante preocupar-se com o frete de retorno, pois isto implica um tempo de espera e em alguns casos o capital desperdiçado não compensaria a espera. Do ponto de vista tático, as decisões são basicamente de alocar e gerenciar recursos para que o sistema opere alinhado com as estratégias estabelecidas. Preocupações como nível de estoque, regime de trabalho, localização de garagens e nível de serviço são pertinentes a este nível de decisões. Por fim, do ponto de vista operacional, as decisões estão voltadas para os problemas do dia-a-dia, como por exemplo: controle de manutenção da frota, agendamento e despacho de cargas.

A Tab. (2.3) apresenta um resumo geral das decisões em sistemas logísticos de acordo com o nível de decisão. 
Tabela 2.3: Níveis de Dicisão em sistemas de Transporte.

\begin{tabular}{|c|c|}
\hline Nível de Decisão & Sistema de transportes \\
\hline Estratégico & $\begin{array}{ll}\text { - } & \text { Mercado de atuação } \\
\text { - } & \text { Localização de fábricas e depósitos } \\
\text { - } & \text { Dimensões de qualidade e nível de serviço } \\
\text { - } & \text { Restrições legais }\end{array}$ \\
\hline Tático & $\begin{array}{l}\text { - } \quad \text { Definição de circuitos } \\
\text { - } \quad \text { Número de veículos } \\
\text { - } \quad \text { Contratação de mão-de-obra e serviços de } \\
\text { terceiros } \\
\text { - } \quad \text { Nível de estoque } \\
\text { - } \quad \text { Regime de trabalho } \\
\text { - } \quad \text { Localização de garagens }\end{array}$ \\
\hline Operacional & $\begin{array}{l}\text { - Políticas de atendimento da demanda dos } \\
\text { clientes } \\
\text { - } \quad \text { Política de controle de estoques } \\
\text { - Acompanhamento dos processos de } \\
\text { transporte }\end{array}$ \\
\hline
\end{tabular}

\subsubsection{Critérios gerais de decisões e restrições}

Para modelar um problema de transporte de cargas precisa-se pensar nas características da operação e restrições. Essas características são importantes, pois, para cada conjunto de restrições adotadas, a modelagem do problema é direcionada a um tipo específico de modelo matemático. Tais variáveis ou restrições estão listadas abaixo, adaptadas de ${ }^{[3]}$ :

- Janela de Tempo para servir um nó ou arco

- Tempo especificado e prefixado

- Flexível

- Número de arcos ou nós para atender por viagem 
- Mais de um: carga fracionada

- Tamanho da frota

- Um veículo atende todas as demandas

- Mais de um veículo para atender as demandas

- Tipo de frota disponível

- Homogênea (somente um tipo de veículo)

- Heterogênea (diferentes tipos de veículos)

- Natureza da demanda e parâmetros

- Determinística

- Estocástica

- Localização da demanda

- Nos Arcos

- Nos Nós

- Misto

- Grafo de substrato

- Direcionado

- Não direcionado

- Misto

- Restrições na capacidade dos veículos

- Todos sujeitos às mesmas restrições

- Restrições diferentes

- Tempo de roteamento

- O mesmo tempo para todos

- Tempos diversos

- Sem restrições de tempo 
- Variáveis (associados à rota)

- Fixos

- Restrições de Operação

- De entrega

- De recolhimento

- Ambas

- Objetivo

- Minimizar custos fixos

- Minimizar custos de operação na rota

- Minimizar o número de veículos

- Restrições na capacidade dos arcos

- Impostas a todos os arcos

- Impostas a um subconjunto de arcos

- Sem restrições

- Tipos de rotas

- Rotas spot (sem retorno)

- Circuitos fechados

De acordo com as restrições ou características acima, é definido um problema e parte-se para uma estratégia de solução. A literatura de problemas de roteamento é muito rica, fazendo considerações, generalizações ou restrições para chegar ao problema estudado. A seguir serão apresentados alguns problemas clássicos, com foco na vertente base do problema aqui estudado.

\subsubsection{Problemas Clássicos de Roteamento}

Os pontos de parada dos veículos, bem como a sequência das paradas nos respectivos pontos estabelecem as rotas para os veículos.

De uma forma geral, os problemas de roteamento podem ser divididos em dois grupos, de acordo com a localização das demandas a serem atendidas: Problemas 
de Cobertura de Nós (com as demandas nos Nós) e Problemas de Cobertura de Arcos (com as demandas nos Arcos).

Os dois problemas clássicos que tiveram grandes contribuições aos dois grupos de problemas citados são: o Problema do Caixeiro Viajante - PCV (do inglês Travelling Salesman Problem - TSP) e o Problema do Carteiro Chinês - PCC (do inglês Chinese Postman Problem - CPP), cujas demandas estão localizadas respectivamente nos Nós e Arcos, conforme ilustrado na Fig. (2.1) .

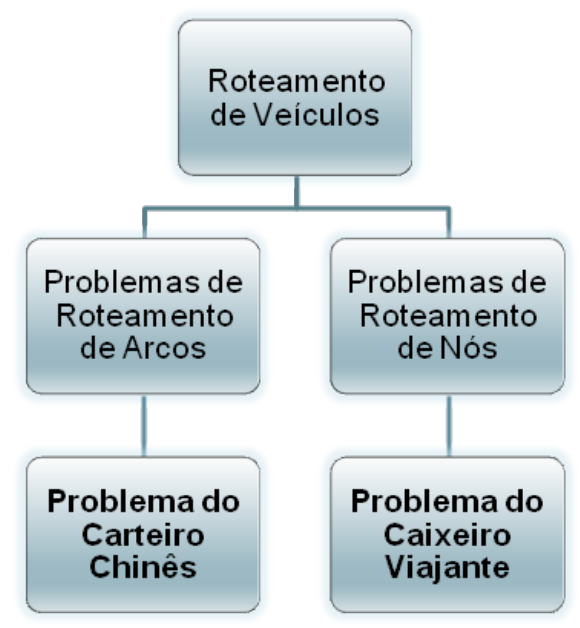

Figura 2.1: Problemas de Roteamento de Veículos.

\subsubsection{Problema do Caixeiro Viajante}

O Problema do Caixeiro Viajante - PCV talvez seja o problema de roteamento mais conhecido pela comunidade acadêmica. Introduzido por Dantzig e Hamser em 1959, o PCV é base para muitos problemas de roteamento e com grande aplicação prática, de acordo com Yeun ${ }^{[14]}$. No PCV procura-se uma rota que visite todos os vértices de um grafo, cada vértice exatamente uma vez, cuja distância total percorrida seja mínima, conforme ilustrado Fig. (2.2). 


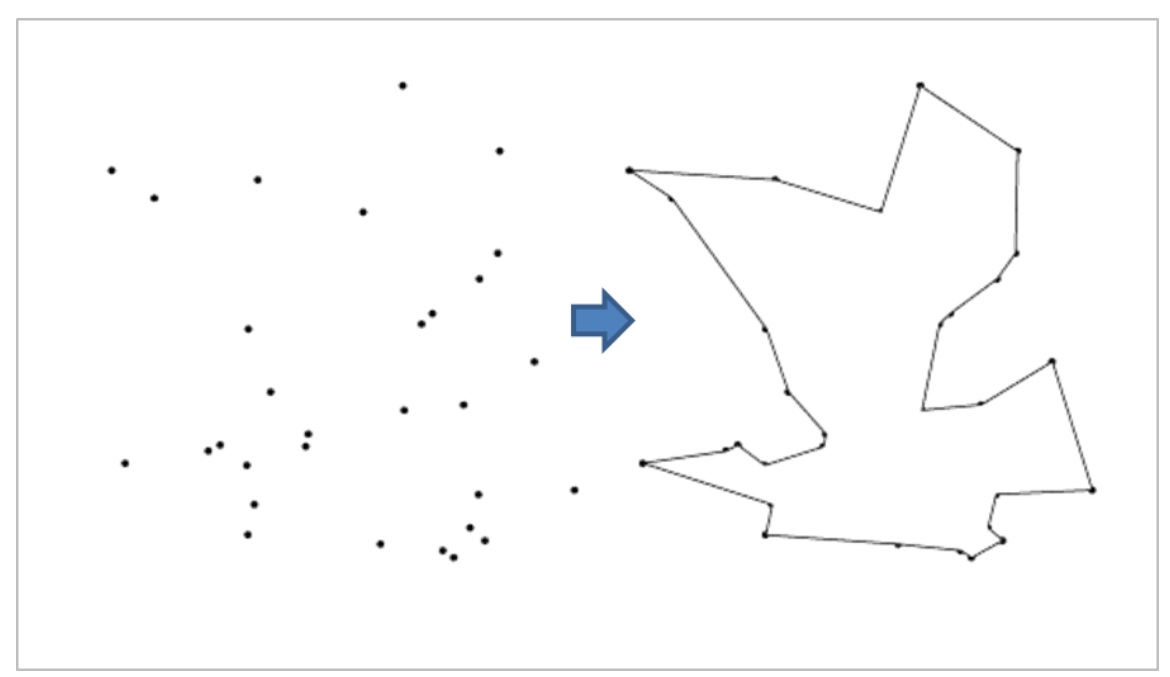

Figura 2.2: Cobertura de Nós através da solução do PCV (adaptado de Wolfram.com).

A solução do PCV implica em encontrar o ciclo de Hamilton com custo mínimo. O ciclo Hamiltoniano é caracterizado por uma rota que passa por todos os nós de um grafo sem nunca repetir um nó, ilustrado na Fig. (2.3) . Este ciclo é denominado de Hamilton em homenagem Willian Rowan Hamilton, que em 1857 propôs um jogo de tabuleiro denominado Around the World, cujo objetivo é encontrar o ciclo aqui citado.
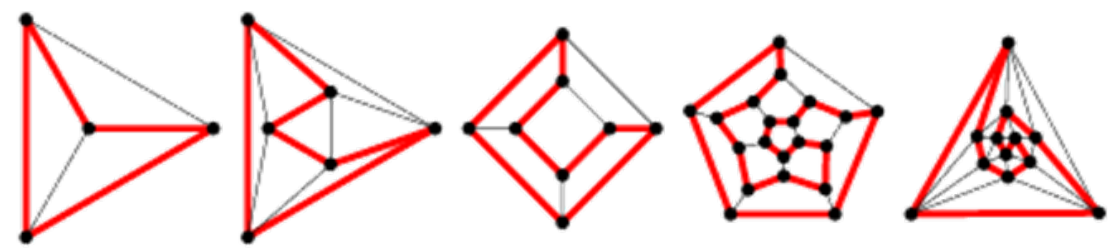

Figura 2.3: Ciclos Hamiltonianos (WEISSTEIN ${ }^{[1]}$ ).

\subsubsection{Problema do Carteiro Chinês (PCC)}

Antes de falar do Problema do Carteiro Chinês, será apresentado um problema que foi um dos precursores da teoria de grafos e tem forte relação com o PCC. Conhecido popularmente como "Problema das Sete Pontes", o problema das pontes de Königsberg (Prússia, atual Kaliningrado Rússia), ilustrado na Fig. (2.4) , foi proposto no século XVIII e consiste em realizar um percurso fechado passando pelas sete pontes sem repetir nenhuma (percurso chamado mais adiante de ciclo euleriano). O matemático suíço Leonard Euler provou em ${ }^{[15]}$ que era impossível encontrar uma solução, pois, ao transformar o mapa em um grafo, onde as ilhas e o continente são os vértices e as pontes arestas, conforme ilustrado na Fig. (2.4), notou que os vértices possuíam grau (número de arestas que incidem no vértice) ímpar. 
TEOREMA: De acordo com Euler ${ }^{[15]}$, um grafo $\mathrm{G}=(\mathrm{N}, \mathrm{E})$ contém um circuito euleriano se, e somente se, o grafo não tem nenhum nó de grau ímpar.

Adaptado de Sherafat ${ }^{[16]}$, o Caminho e Ciclo Eulerianos são definidos como:

1. Caminho Euleriano: caminho que inclui, sem repetir, todas as arestas de um grafo.

2. Ciclo Euleriano: caminho euleriano fechado.

Considerado um marco inicial para a teoria de grafos, o Problema das Sete Pontes é um dos primeiros Problemas de Roteamento em Arcos e possui forte relação com o Problema do Carteiro Chinês, proposto pela primeira vez na revista Chinese Mathematics por Mei-Ko Kwan em 1962.
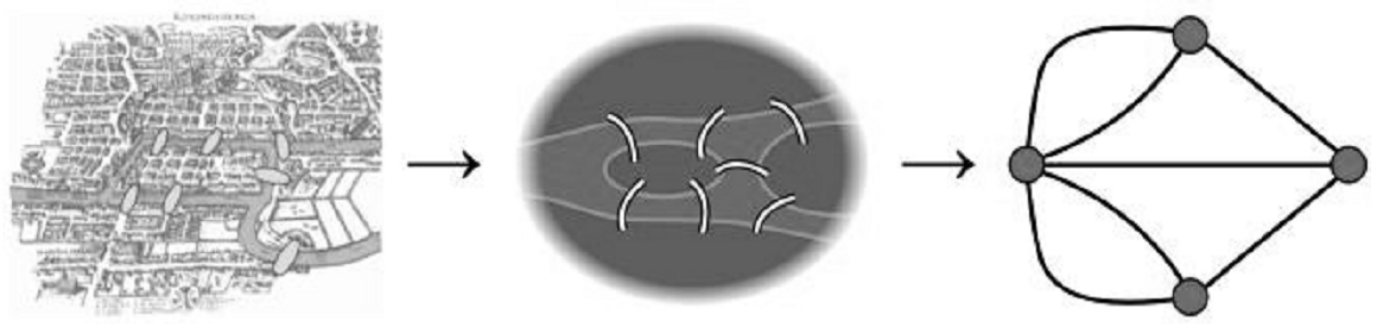

Figura 2.4: Transformação das sete pontes de Königsberg em um grafo por Euler (Gomes et al, 2009) ${ }^{[2]}$.

O PCC, segundo Belfiore ${ }^{[17]}$, consiste em determinar um único roteiro com menor custo possível que permita ao carteiro chinês (veículo) visitar todas as ruas (arcos ou aresta do grafo) pelo menos uma vez. Nesta definição do problema não há restrições de capacidade de veículos e a demanda é determinística.

Características do PCC:

1. cada rota (ou caminho) inicia e termina no vértice inicial (depósito).

2. as demandas unitárias de todos os arcos são atendidas.

3. o custo total de transporte é mínimo.

De acordo com Goldbarg e Luna ${ }^{[3]}$, o passeio do carteiro (ou tour) distinguese do ciclo euleriano por nele ser permitida a repetição de arestas. No entanto, o ciclo euleriano, quando existente, é a solução PCC. 
A principal diferença entre o Problema das Sete Pontes e o PCC está em que este último permite ao carteiro passar mais de uma vez por um arco e que ele deve retornar, ao fim do percurso, no ponto de partida.

Segundo os autores de ${ }^{[3]}$, o PCC divide-se em quatro categorias:

(a) PCC para grafos não orientados;

(b) PCC para grafos orientados;

(c) PCC para grafos mistos;

(d) PCC Capacitado.

Para os itens (a) e (b) existe solução em tempo polinomial, já para os itens (c) e (d) a solução não pode ser encontrada em tempo polinomial.

\subsection{Programação Linear Inteira}

Um problema de Programação Inteira (PI), de acordo com Hillier e Lieberman ${ }^{[18]}$, é um caso particular de problema de otimização no qual as variáveis só podem assumir valores inteiros (ou discretos); um problema de Programação Inteira Mista (PIM ou MIP, sigla em inglês de Mixed Integer Programming) é outro caso particular no qual apenas uma parte das variáveis está restrita a valores inteiros. O PLI é um caso particular do PIM, cujo domínio das variáveis é inteiro e a modelagem matemática do problema é linear em relação às variáveis.

Partindo da definição acima, dos problemas de otimização inteira, o problema a ser tratado neste trabalho é um problema de variáveis inteiras e de modelagem linear, portanto é classificado como um problema de PLI.

Os problemas de variáveis inteiras possuem algumas diferenças em relação aos problemas cujas variáveis estão no domínio real, mesmo considerando apenas os problemas com função objetivo e restrições lineares (PL - Programação Linear).

1. PL - Existem condições necessárias e suficientes de otimalidade teoricamente provadas que podem ser testadas eficientemente se uma solução viável é uma solução ótima ou não.

2. PI e PIM - Não existem condições de otimalidade conhecidas para testar se uma dada solução viável é ótima a não ser pela comparação explícita 
ou implícita desta solução com cada uma das soluções viáveis do problema. Este é o motivo pelo qual os problemas inteiros de otimização são resolvidos por intermédio de métodos enumerativos, que buscam a solução ótima no conjunto das soluções viáveis.

Uma classificação geral para os métodos de solução de PIs, pode ser, adaptado de ${ }^{[3]}$ :

- Técnicas de Relaxação

- Técnicas convencionais de otimização (Simplex ou Kamarkar) com aproximação para inteiros depois de encontrar a solução ótima.

- Técnicas de Enumeração

- Separação e avaliação progressiva ou Branch-and-Bound (B\&B) Enumeração implícita

- Técnicas de Cortes

- Cortes inteiros (primais e duais)

- Cortes combinatórios

- Cortes de interseção

- Técnicas Híbridas

- Branch-and-Cut

- Teoria de Grupo

- Técnicas Heurísticas

- Simulated Annealing

- Tabu Search

- GRASP (Greedy randomized adaptive search procedure)

A seguir será descrito sucintamente o funcionamento dos algoritmos $B \mathscr{E} B$ e Branch-and-Cut. 


\subsubsection{Algoritmo Branch-and-Bound}

Conforme Goldbarg e Luna ${ }^{[3]}$, o método (BE⿱EB ) baseia-se em desenvolver uma enumeração inteligente dos pontos candidatos à solução ótima inteira de um problema. O termo branch refere-se ao fato de que o método efetua partições no espaço das soluções. O termo bound ressalta que a prova da otimalidade da solução utiliza-se de limites calculados ao longo da enumeração. A idéia geral é a de se dividir o conjunto de soluções viáveis em subconjuntos sem interseções entre si, calculando-se os limites superior e inferior para cada subconjunto, e então eliminando certos subconjuntos de acordo com regras pré estabelecidas, como ilustrado na Fig. (2.5).

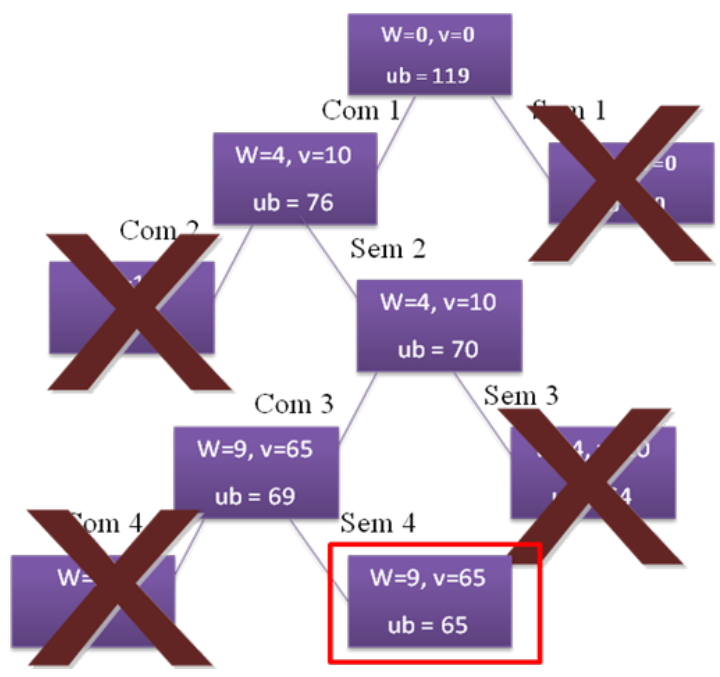

Figura 2.5: Exemplo ilustrativo do algoritmo $B \mathscr{E} B$ (adaptado de ${ }^{[3]}$ ).

\subsubsection{Algoritmo Branch-and-Cut}

É o método de otimização combinatória para resolver PLI que utiliza técnica híbrida de otimização para encontrar a solução ótima. Sendo assim o híbrido entre BEBB, Cutting Plane e Simplex (ou Kamarkar).

O funcionamento deste método, de acordo com Gurobi ${ }^{[4]}$, é dado pelos seguintes passos:

1. Encontra-se a solução ótima do problema sem se preocupar com as restrições de valores inteiros através do algoritmo simplex ou Karmarkar (Fig. (2.6)). 


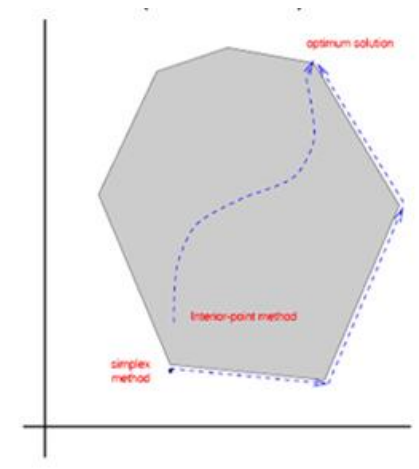

Figura 2.6: Simplex e Kamarkar (retirado de ${ }^{[4]}$ ).

2. Quando a solução ótima do passo anterior é obtida, e essa solução pode não respeitar as restrições de domínio inteiro, o algoritmo de Cutting Plane é utilizado para encontrar a restrição linear (plano de corte) mais próxima que satisfaz todos os possíveis pontos inteiros que formam uma solução viável como ilustrado na Fig. (2.7) .

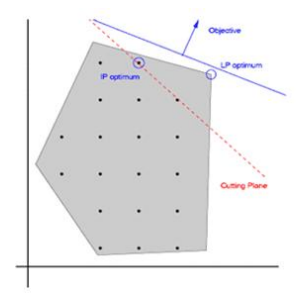

Figura 2.7: Abordagem Cutting Plane (retirado de ${ }^{[4]}$ ).

3. Neste momento, entra a técnica do $B \mathscr{E} B$ que vai trabalhar dividindo em dois subgrupos, como na Fig. (2.8) :

(a) Primeiro com a restrição maior ou igual ao inteiro mais próximo.

(b) Segundo com a restrição menor ou igual inteiro mais próximo.

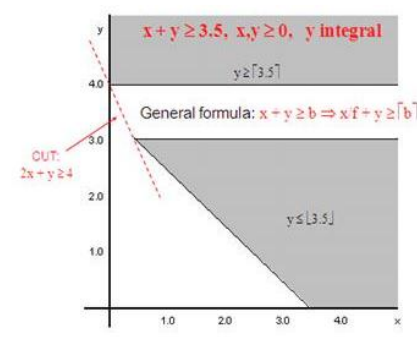

Figura 2.8: Grupos de domínios para o B\&B (retirado de ${ }^{[4]}$ ).

4. Durante o processo do $B \mathscr{E} B$, podem surgir novos planos de corte e o processo descrito se repete. 


\subsubsection{Matriz Totalmente Unimodular (TUM) e Algorit- mos de Relaxação}

Existe ainda outra maneira de solucionar o PLI, usando métodos convencionais de resolução de problemas não inteiros, como o Simplex ou Kamarkar. No entanto não funciona sempre, pois depende da matriz de restrições respeitar um conjunto de regras para ser uma Matriz Totalmente Unimodular (Totally Unimodular Matrix - TUM), definida a seguir de acordo com Papadimitriou e Steiglitz [19].

Definição: Uma matriz é TUM se cada submatriz quadrada tiver determinante igual a $0,+1$ ou -1 .

Exemplo de matriz TUM:

$$
A=\left[\begin{array}{cccccc}
-1 & -1 & 0 & 0 & 0 & +1 \\
+1 & 0 & -1 & -1 & 0 & 0 \\
0 & +1 & +1 & 0 & -1 & 0 \\
0 & 0 & 0 & +1 & +1 & -1
\end{array}\right]
$$

Teorema: Se uma matriz A é TUM e b é inteiro onde A.x=b, então x é inteiro (vetor composto por elementos inteiros).

Em conseqüência do teorema anterior, concluímos que a solução encontrada pelo método convencional, que busca o vértice do polítopo, é de solução inteira. Portanto para esses casos, pode-se usar os métodos de relaxação para solucionar um PLI.

Existem métodos para avaliar e transformar matrizes que não são TUM em matrizes TUM, mas não foram estudados neste trabalho. 


\section{O Problema de Cobertura de Rotas}

Como mencionado no Capítulo 1, o problema objeto de estudo deste trabalho é muito próximo do Problema de Cobertura de Rotas (PCR), e por isso será dedicado este capítulo ao estudo do PCR.

Estudado originalmente por Ergun e Savelsberch ${ }^{[20]}$, o PCR pode ser considerado uma das variações do PCC, pois o objetivo principal desse problema é cobrir as demandas localizadas nos arcos através de circuitos. O PCC difere-se do PCR por se tratar de apenas um ciclo (tour) para as demandas unitárias dos arcos, conforme ilustrado na Fig. (3.1). Partindo como base o PCC, o PCR pode ser interpretado como um PCC com vários carteiros (vide Fig. (3.2)).

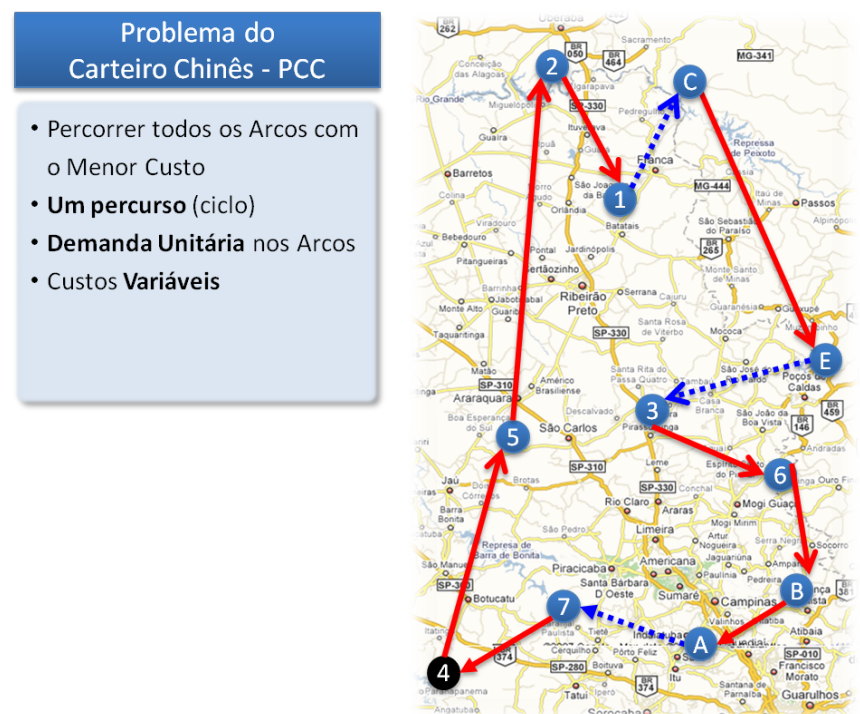

Figura 3.1: Problema do Carteiro Chinês. 


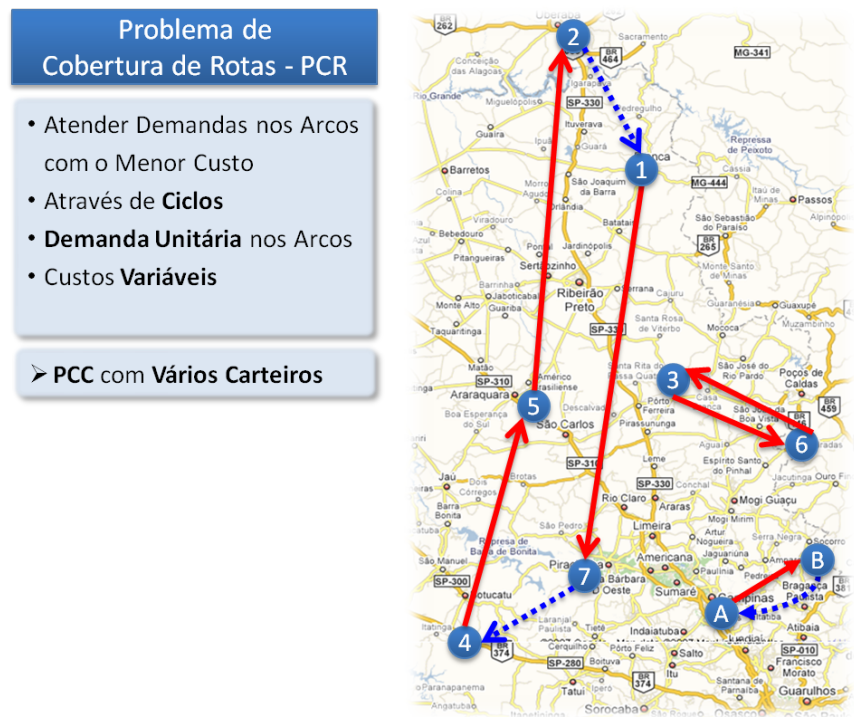

Figura 3.2: Problema de Cobertura de Rotas.

O problema objeto de estudo deste trabalho, na forma como estudado por Stringher ${ }^{[11]}$, traz alguns pontos que expandem o PCR original, como por exemplo a possibilidade de contratação pontual de terceiros (sem o embarcador se preocupar com a carga retorno), acrescenta a análise de custos fixos e também permite demandas não-unitárias, conforme Fig. (3.3). Com tais mudanças, o PCR expandido (assim tratado neste trabalho) se aproxima mais dos problemas reais. Neste Capítulo o PCR expandido será tratado de forma mais conceitual e no Capítulo 4 será aprodundado com a forma de modelagem e solução propostos neste trabalho.
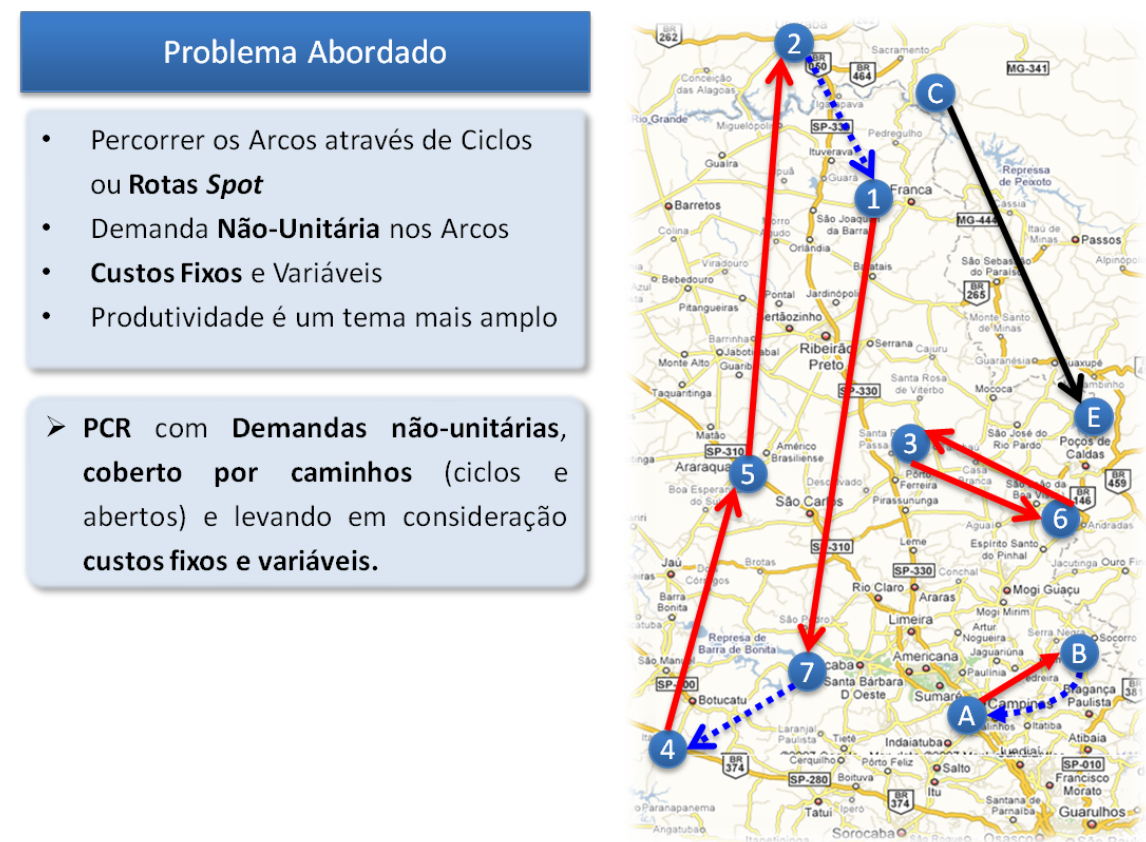

Figura 3.3: Problema Abordado neste trabalho. 
Tratando o problema de forma mais genérica, de acordo com Agarwal [21], será considerado não somente um embarcador, mas um grupo de embarcadores com diversas demandas a serem atendidas e que através da colaboração das previsões de demandas e sinergia de operação objetivam minimizar o custo total de transporte.

Antes de prosseguir com a descrição do problema, suas premissas são explicitadas a seguir:

1. Cada embarcador deve aceitar participar da colaboração, ou seja, todas as suas demandas serão atendidas.

2. Não há restrições de janelas de tempo (processo de carga e descarga flexíveis), certificações de transportadores, tempo de espera em filas superiores ao planejado, etc.

3. Não há restrições do tipo de veículos / ativos (carreta, caminhão, avião, etc) utilizados para fazer o transporte e atender as demandas. Somente é necessário que a frota seja homogênea e as demandas sejam compatíveis com o veículo.

Adaptado de Agarwal ${ }^{[21]}$, o PCR é definido pelo grafo direcionado (ou dígrafo) Euclidiano $G=(V, A)$, onde $\mathrm{V}$ é um conjunto de vértices e $A$ é um conjuntos de arcos, e $L \subset A$ é o conjunto de $\operatorname{arcos} a_{i j}$ que possuem demandas de transporte rij associadas. Definindo como $c_{i j}$ o custo para cobrir uma demanda do arco $a_{i j}$ e definindo $h_{i j}$ como o custo de um arco de reposicionamento do nó $i$ para o nó $j$, o PCR é o problema que busca minimizar o custo de se cobrir as demandas do conjunto de $\operatorname{arcos}$ de $L$.

$$
(P): f_{L}(r)=\min \sum_{i, j \in L} c_{i j} x_{i j} \sum_{i, j \in A} h_{i j} z_{i j}
$$

Sujeito a

$$
\begin{gathered}
\sum_{j \in V} x_{i j}-\sum_{j \in V} x_{j i}+\sum_{j \in V} z_{i j}-\sum_{j \in V} z_{j i}=0, \forall i \in V \\
x_{i j} \geqslant r_{i j}, \forall(i, j) \in L \\
z_{i j} \geqslant 0, \forall(i, j) \in A \\
x_{i j}, z_{i j} \in \mathbb{Z}
\end{gathered}
$$


Em $(\mathrm{P}), x_{i j}$ representa o número de vezes que a rota $(i, j) \in L$ é coberta com uma carga completa e $z_{i, j}$ representa o número de vezes que é feito o reposicionamento (sem atender uma demanda, ou seja, vazio) através do arco $(i, j) \in A$. A restrição Eq. (3.2) obriga que o ciclo seja fechado, ou seja, o caminho inicia e termina em um mesmo vértice. A restrição Eq. (3.3) garante que as demandas do $\operatorname{arco}(i, j) \in A$ sejam atendidas. A restrição Eq. (3.4) garante que as variáveis de reposicionamento sejam positivas. Por fim, a restrição Eq. (3.5) garante que arcos com demanda ou de reposicionamento sejam percorridos um número inteiro de vezes. Ergun, Kuyzu e Savelsberch ${ }^{[22]}$ demonstraram que o PCR sem restrições pode ser resolvido em tempo polinomial e também concluíram que as variações do PCR com restrições de cardinalidade, que é o foco deste trabalho, ou comprimento máximo não podem ser resolvidas em tempo polinomial.

O Problema de Cobertura por Ciclos (PCC2), em língua inglesa Cycle Covering Problem (CCP), citado em ${ }^{[10]}$, procura cobrir um grafo direcionado, no menor custo possível, com ciclos (neste trabalho chamados de circuitos) de no mínimo três arcos diferentes. Para esta versão com restrição do PCC, de acordo com Thomassen ${ }^{[23]}$, concluiu ser um problema NP-difícil para grafos gerais e equivalente ao PCC para grafos planares, de acordo com ${ }^{[24]} \mathrm{e}^{[25]}$. Como visto em ${ }^{[20]}$, o PCC2 é uma abordagem de solução para o PCR, onde são gerados circuitos para cobrir os arcos com demandas. Baseado nessa abordagem por ciclos, serão definidos mais adiante, para a solução adotada neste trabalho, o Gerador de Caminhos e a Heurística de Solução baseada em circuitos.

Focando na solução baseada em circuitos (ou ciclos), a seguir será definida a modelagem matemática do PCR baseado em ciclos com cardinalidade restrita, adaptado de ${ }^{[22]}$ para rotas com demanda não unitária, o PCR baseada em ciclos com cardinalidade restrita. Dado um conjunto $C_{k}=\left\{C_{1}, C_{2}, \ldots, C_{n}\right\}$, que representa todos os ciclos direcionados em $\mathrm{G}$ com cardinalidade menor ou igual a $\mathrm{K}$ cobrindo pelo menos uma rota (arco com demanda).

$$
f_{L}(r)=\min \sum_{C \in C_{k}} c_{C} x_{C}
$$

Sujeito a:

$$
\sum_{C \in C_{K}} l_{C}^{i j} x_{C} \geq r_{i j}, \forall(i, j) \in L
$$

Assume-se que cada ciclo $C \in C_{K}$ seja tal que $C \bigcap L \neq \emptyset$. O coeficiente 
$c_{C}$ é o custo do ciclo $C, l_{C}^{i j} \in(0,1)$ assume o valor 1 se o arco com demanda $l^{i j} \in L$ participa do ciclo, e 0 se não participa do ciclo. É importante ressaltar que o custo $c_{C}$ é calculado não somente com o custo dos arcos com demanda, mas também com o custo dos arcos de reposição.

Dadas as características gerais do problema, é possível citar algumas das principais variações do PCR conforme ilustrado na Fig. (3.4). Ergun, Kuyzu e Savelsberch (em ${ }^{[22]}$ ), Ferri (em ${ }^{[26]}$ ) e Stringher (em ${ }^{[11]}$ ) estudaram o PCR com Cardinalidade Restrita - PCRCR, em que o número de arcos (com ou sem carga) pertencentes ao ciclo é limitado. Em ${ }^{[10]}$ foi proposto o PCR com Restrição de Distância Máxima - PCRRDM e também estudou-se o PCR com Janela de Tempo - PCRJT. Ozener e Ergun ${ }^{[27]}$ estudaram o PCR com Múltiplos Transportadores - PCRMT, onde a principal diferença está no custo de operação de uma rota, que é variável de acordo com o transportador.

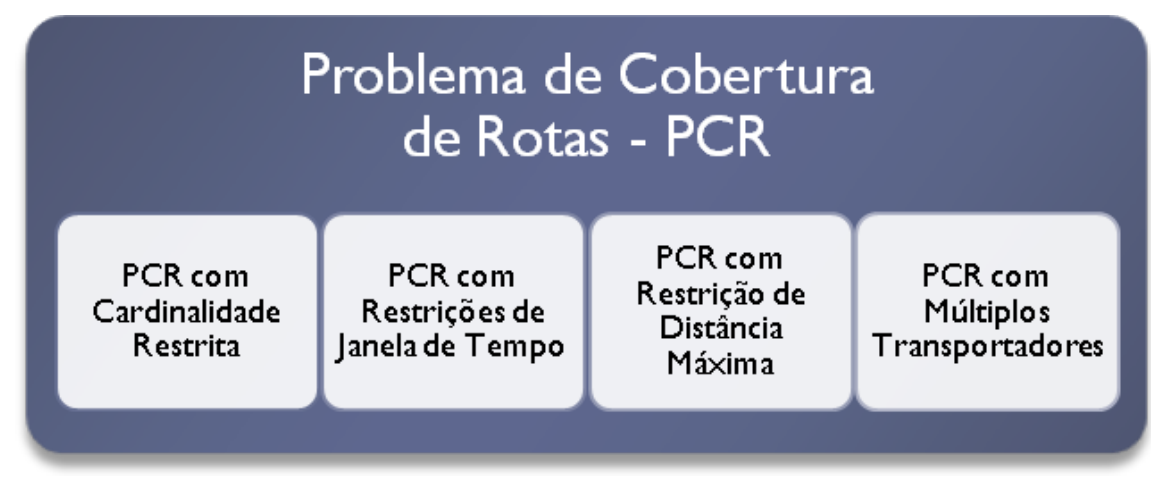

Figura 3.4: Problema de Cobertura de Rotas e suas principais vertentes.

As abordagens de ${ }^{[22]}$ e ${ }^{[26]}$ levam em consideração apenas circuitos fechados, mas com o intuito de comparar entre operação com frota dedicada ou frota temporária, Stringher ${ }^{[11]}$ introduziu em seu estudo as rotas spot, rotas cobertas por um caminho aberto de cardinalidade 1, ou seja, coberta por um único arco, explicadas em detalhe adiante.

A seguir serão definidos os circuitos logísticos (ciclos) e as rotas spot com suas respectivas características e propósitos.

\subsection{Cobertura por Ciclos (Circuitos Logísticos)}

Circuitos logísticos são caminhos pré-definidos que estabelecem ao veículo um ponto de partida e o mesmo ponto de chegada, como ilustrado na Fig. (3.6). A utilização de circuitos estáticos é uma estratégia para melhorar o desempenho do sistema de transporte de cargas para uma rede logística com frota dedicada. 
O uso de circuitos gera uma economia de rede, permitindo ao veículo rodar o máximo possível carregado, aproveitando melhor o ativo desde que ele não fique aguardando por cargas de retorno.

Através dos circuitos logísticos é possível chegar à máxima utilização dos ativos de transporte com a continuidade das rotas, isso traz benefícios operacionais como previsibilidade e otimização de processos. Em ${ }^{[28]}$ estudou-se a logística colaborativa do ponto de vista operacional e através das rotas contínuas (Continuous Move Routes - CMR) citou benefícios para os embarcadores e transportadores. Embarcadores podem, através de colaboração com outros embarcadores, criar rotas continuas com o mínimo de reposicionamentos (deslocamentos sem cargas), reduzindo assim os custos de operação da rota e ganhando poder de negociação com transportadores. Pelo lado dos transportadores, partindo da previsibilidade das demandas e das rotas a serem atendidas torna-se mais fácil realizar as manutenções programadas, planejar a escala e rodizio de motoristas e atingir a máxima utilização dos ativos (cavalo motor, carreta, garagens, etc.), minimizando os custos de transporte, reduzindo a rotatividade de motoristas e provendo um melhor nível de serviço. Em suma, existe um grande potencial de ganhos quando associase circuitos logísticos e logística colaborativa.

Em ${ }^{[5]}$, de acordo com a Fig. (3.5), a Nistevo Logistics conseguiu através de logística colaborativa e rotas contínuas chegar a uma economia de aproximadamente $19 \%$ em custos de transporte e melhorias nos indicadores de rotatividade de funcionários. Esses resultados mostram que a logística colaborativa possui grande potencial de redução de custos, melhorando a competitividade das empresas envolvidas.

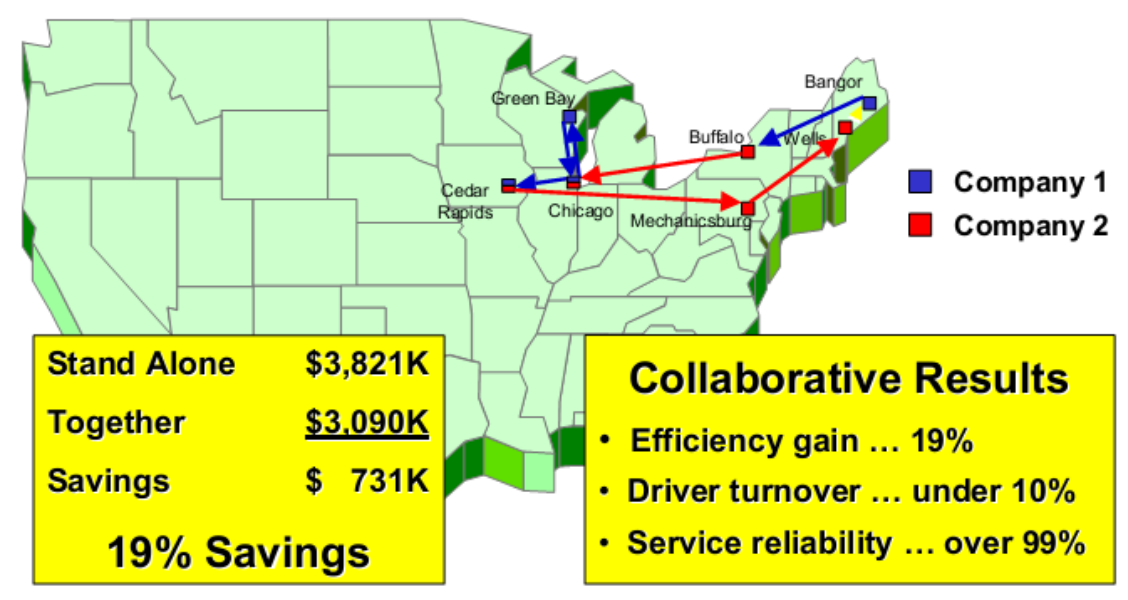

Figura 3.5: Exemplo de Logística Colaborativa promovendo economia com Circuitos Logísticos (retirado de Savelsbergh, Ergun e Kuyzu ${ }^{[5]}$ ). 
Para os casos em que não há carga de retorno nem a possibilidade de pegar outra carga com destino mais próximo da origem para fechar o circuito, cabe ao planejador escolher entre utilizar um circuito fechado com o veículo voltando vazio ou contratar pontualmente um transportador (contratação spot). Essa decisão depende de fatores como a distância do retorno vazio, tempo de espera para conseguir uma nova carga, entre outros fatores. A estratégia de contratação spot será detalhada mais adiante.

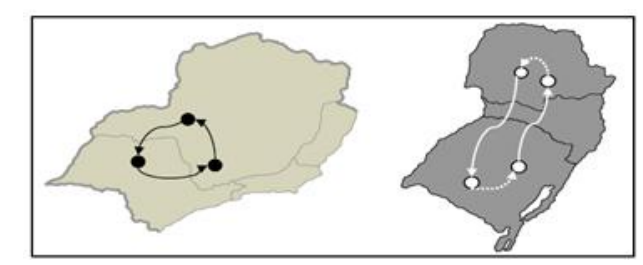

Figura 3.6: Exemplos de Circuitos Fechados. (Fonte: Ilustração CEL/Coppead)

Seguindo a notação adotada em ${ }^{[11]}$, os circuitos possuem uma classificação de acordo com o número de demandas que são atendidas pelo caminho, conforme ilustrado na Fig. (3.7) , por exemplo: circuito C1 atende uma demanda pelo circuito; circuito C2 atende duas demandas pelo caminho; etc. Lembrando que essa classificação não remete a cardinalidade do ciclo, que é igual a quantidade total de arcos no caminho, independente se os arcos possuem demanda ou não.

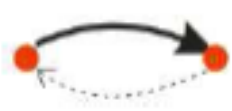

(a)

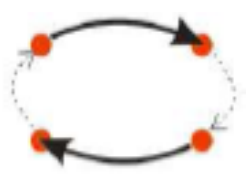

(b)

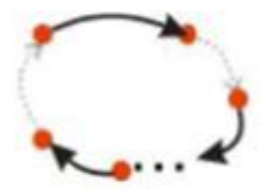

(c)

Figura 3.7: Classificação das rotas (conjunto de arcos com demandas conectados, também chamados circuitos).

(a) C1 corresponde de uma demanda com retorno vazio. (b) C2 corresponde ao atendimento de duas demandas intercaladas por zero ou mais deslocamentos vazios para fechar o circuito. (c) Cn corresponde ao atendimento de $\mathrm{n}$ demandas intercaladas por zero ou mais deslocamentos sem carga.

\subsection{Cobertura por Rotas Spot (Terceirização de Frota)}

As rotas spot representam a parcela das rotas de uma rede cuja frota de atendimento não é dedicada, ou seja, é contratada pontualmente para atender uma 
demanda sem se preocupar com a continuidade do contrato ou reposicionamentos necessários ao veículo para atender uma próxima demanda. Do ponto de vista de modelagem matemática as rotas spot são muito semelhantes aos circuitos de uma rota com retorno vazio $(\mathrm{C} 1)$, pois também cobrem uma rota, mas diferem no custo, pois não consideram o custo de reposicionamento do veículo e consideram um adicional de custo fixo por rota, relacionado ao custo associado ao tempo de espera parado por uma nova carga. A Fig. (3.8) ilustra esse tempo de espera dos caminhoneiros por uma carga de retorno, ou mesmo uma outra próxima carga para minimizar a ociosidade do veículo. O cálculo do custo de rotas será detalhado mais adiante no item 4.2.1. Neste trabalho, assim como em ${ }^{[11]}$, esse grupo de caminhos será classificado como C0.

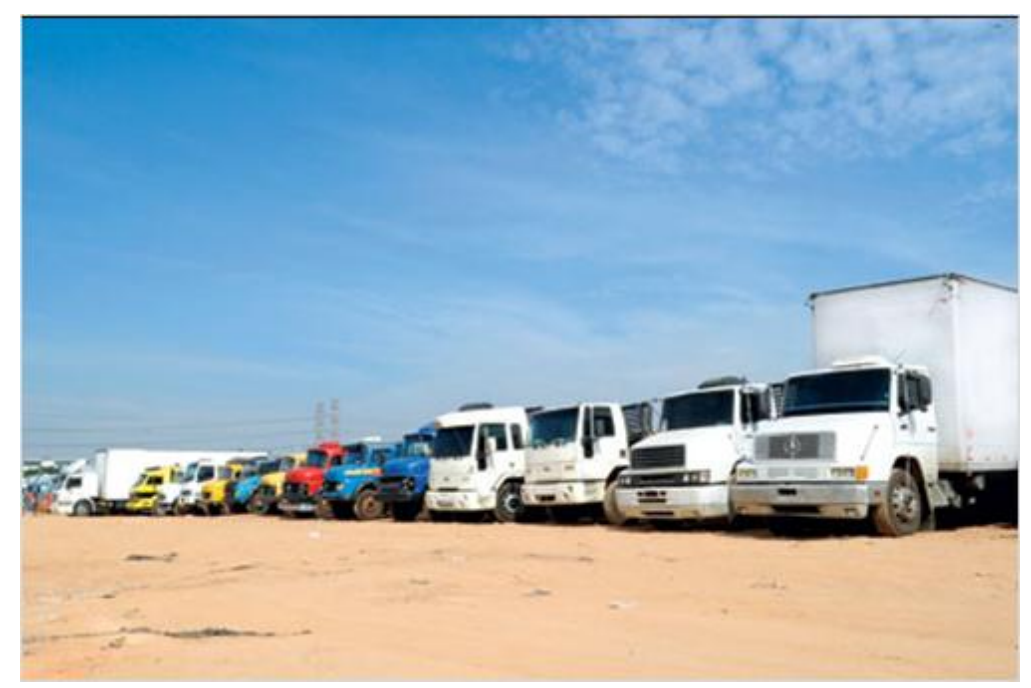

Figura 3.8: Caminhoneiros aguardando para acessar o Terminal de Cargas da Fernão Dias (Foto retirada do site: revistaocarreteiro.com.br, em 02 de Janeiro de 2013).

Ao repassar o risco de carregamento futuro ao transportador e contabilizar esse risco como um acréscimo de valor no frete (relacionado ao tempo médio de espera por uma nova carga), as rotas spot funcionam como uma variável de decisão entre utilizar frota dedicada ou contratar pontualmente transportadores para atender as demandas. Dessa forma, as rotas cuja produtividade é alta, ou seja, os circuitos logísticos explicados no item 3.1 são designados a uma operação com frota dedicada (frota própria ou contratos de longo prazo com transportadores) e as rotas cuja produtividade é baixa, com reposicionamentos de custo muito alto, são repassadas a terceiros na modalidade de rotas spot. O raciocínio matemático de decisão entre operação por frota dedicada ou rotas spot pode ser simplificado na comparação entre os custos de C0 e C1, explicado na seção 4.2.2. 


\subsection{Modelagens e Abordagens de Solução para o PCRCR}

Partindo da definição geral do PCR para o PCR com Cardinalidade Restrita que foi demonstrado em ${ }^{[20]}$ ser NP-Difícil, será definida primeiramente uma estrutura padrão para comparar as abordagens encontradas. Esta estrutura é a mesma utilizada neste trabalho para resolver o problema e foi baseada no trabalho de Stringher ${ }^{[11]}$. Basicamente a estrutura se divide em, Modelo do Problema em Grafo, Gerador de Caminhos e Solver, Fig. (3.9) .

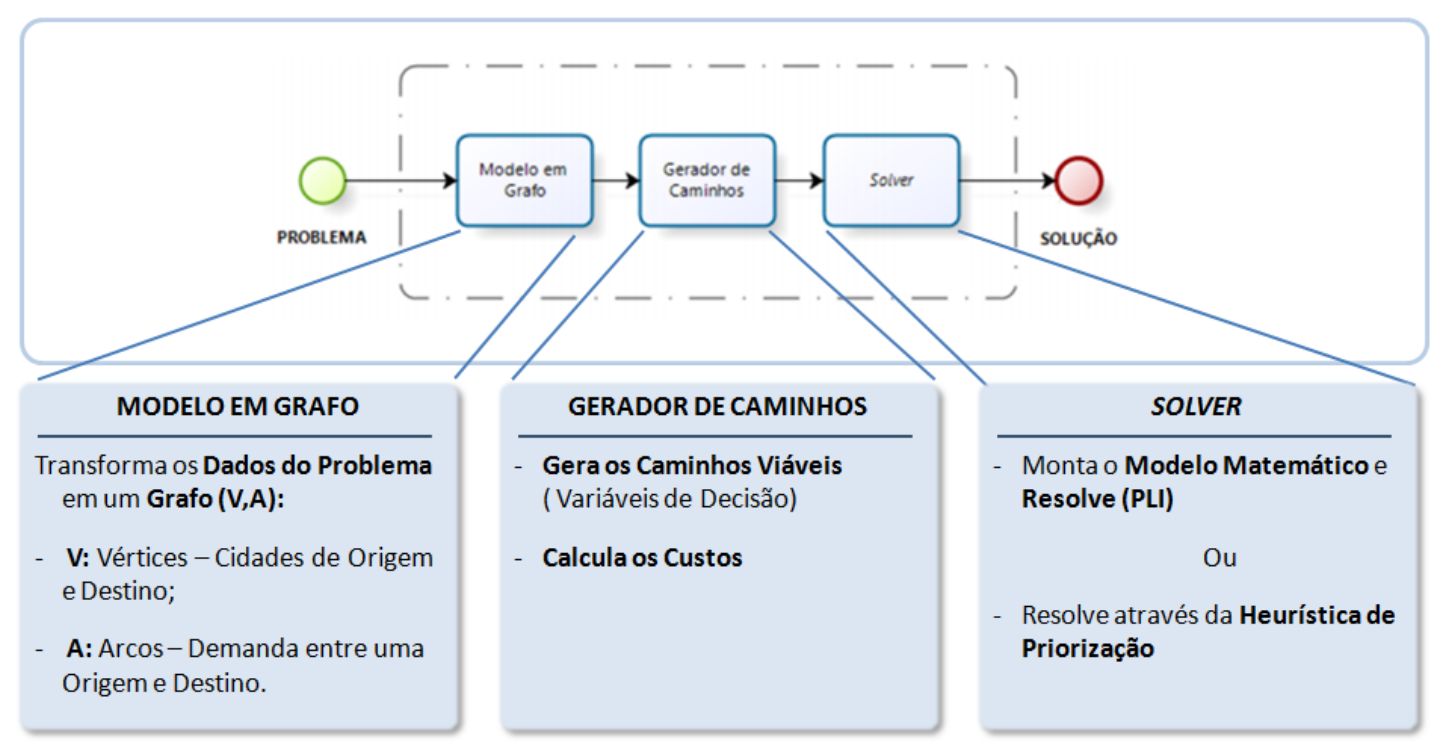

Figura 3.9: Estrutura geral das abordagens do PCRCR.

O Modelo do Problema em Grafo é basicamente a representação do problema em arcos e nós de um grafo, que será utilizado pelo gerador e pelo solver para encontrar a solução. Cada demanda entre uma origem e um destino no problema é modelada como um arco direcionado entre dois nós no modelo em grafo, esse tipo de arco recebe uma atribuição de quantidade de demandas maior que zero.

Dado que as abordagens estudadas neste trabalho são baseadas em ciclos ou caminhos e a solução do problema consiste em selecionar os ciclos ou caminhos de um conjunto de candidatos para a solução final, partimos para os outros dois componentes: Gerador de Caminhos e Solver(traduzido para português do Brasil: solucionador). O Gerador de Caminhos é responsável por compor arcos com demandas e arcos de reposicionamentos (sem demandas) formando caminhos candidatos à solução, enquanto o Solver é responsável por selecionar e atribuir demandas aos caminhos que vão cobrir os arcos com demandas do problema minimizando o custo total. 
Ergun, Kuyzu e Savelsberch ${ }^{[22]}$ e Ferri ${ }^{[26]}$ tratam em suas pesquisas o PCRCR com demandas unitárias, cobertura somente por ciclos fechados e modelo de custos baseado somente em custos variáveis. Para esse problema, em ${ }^{[22]}$ os autores propõem uma solução de Geração de Caminhos Guiada por Junção de Ciclos e uma heurística de solução baseada em priorização de caminhos com maior comprimento. Em ${ }^{[26]}$ trata-se a solução do problema de forma semelhante, porém durante a criação dos ciclos alguns são excluídos de acordo com um critério de qualidade mínima, reduzindo assim o total de caminhos candidatos.

Em ${ }^{[11]},{ }^{[29]}$ e neste trabalho, é tratado o PCRCR com demandas não unitárias, cobertura por ciclos fechados ou rotas spot e modelo de custos baseado tanto em custos fixos quanto custos variáveis. Uma característica importante destes trabalhos é a possibilidade do atendimento através de rotas spots, possibilitando a decisão da composição da frota de atendimento entre frota dedicada e frota contratada pontualmente. Em ${ }^{[11]} \mathrm{e}^{[29]}$ utilizaram-se a geração combinatória de ciclos e o solver PLI para encontrar a solução final.

\subsection{Gerador de Caminhos}

Conforme indicado anteriormente, o gerador de caminhos é o responsável por gerar os caminhos viáveis utilizados pelo solver na seleção da solução final. Grande parte da desempenho e qualidade da solução do problema estão ligados ao conjunto de caminhos gerados, quando o trade-off entre economia satisfatória e desempenho está entre gerar todos os caminhos ou gerar apenas os melhores candidatos.

O ideal seria gerar todos os caminhos possíveis para minimizar a possibilidade de escolher caminhos menos econômicos, mas como é possível notar na seção seguinte, problemas com poucas dezenas de demandas distintas inviabilizam o problema completo de ser resolvido. Para isso, adotam-se algumas heurísticas, simplificações e restrições como cardinalidade máxima ou distância máxima.

Baseado na maneira como são gerados os caminhos, os geradores de caminhos são classificados como:

1. Gerador Combinatório de Caminhos: neste tipo de gerador, utiliza-se a combinação de arcos com demandas para gerar os caminhos, não se preocupando com o potencial de economia do caminho gerado, mas somente com a cardinalidade máxima do mesmo. Stringher ${ }^{[11]}$ utiliza essa abordagem, 
fazendo somente a simplificação de remoção dos ciclos com subciclos.

2. Gerador Guiado de Caminhos: neste tipo de gerador, evita-se gerar todos os caminhos possíveis, pois quanto mais caminhos gerados, mais tempo é gasto gerando caminhos e mais variáveis de decisão precisam ser analisadas pelo solver. Para reduzir a quantidade de caminhos gerados, este tipo de gerador utiliza-se de guias para gerar os caminhos. Neste trabalho são abordados dois tipos: gerador guiado pela junção de ciclos baseado no "fator qualidade", proposto em ${ }^{[22]} \mathrm{e}^{[26]}$; e o gerador guiado por raio de investimento, proposto por este trabalho, que é baseado na distância máxima (raio de investimento) para buscar uma nova carga.

\subsubsection{Geração Combinatória de Caminhos}

Esta abordagem de geração de caminhos foi proposta por Stringher ${ }^{[11]}$ em sua modelagem para que servisse de base para o Solver de Programação Linear Inteira (PLI) utilizado em seu trabalho. Como característica geral dessa abordagem pode-se ressaltar que, para problemas em grande escala, o número de caminhos (e consequentemente o número de variáveis de decisão) cresce muito (crescimento fatorial), elevando muito o custo computacional de se processar o problema. Extrapolando o algoritmo de ${ }^{[11]}$ para gerar circuitos com cardinalidade maior que 3, tem-se:

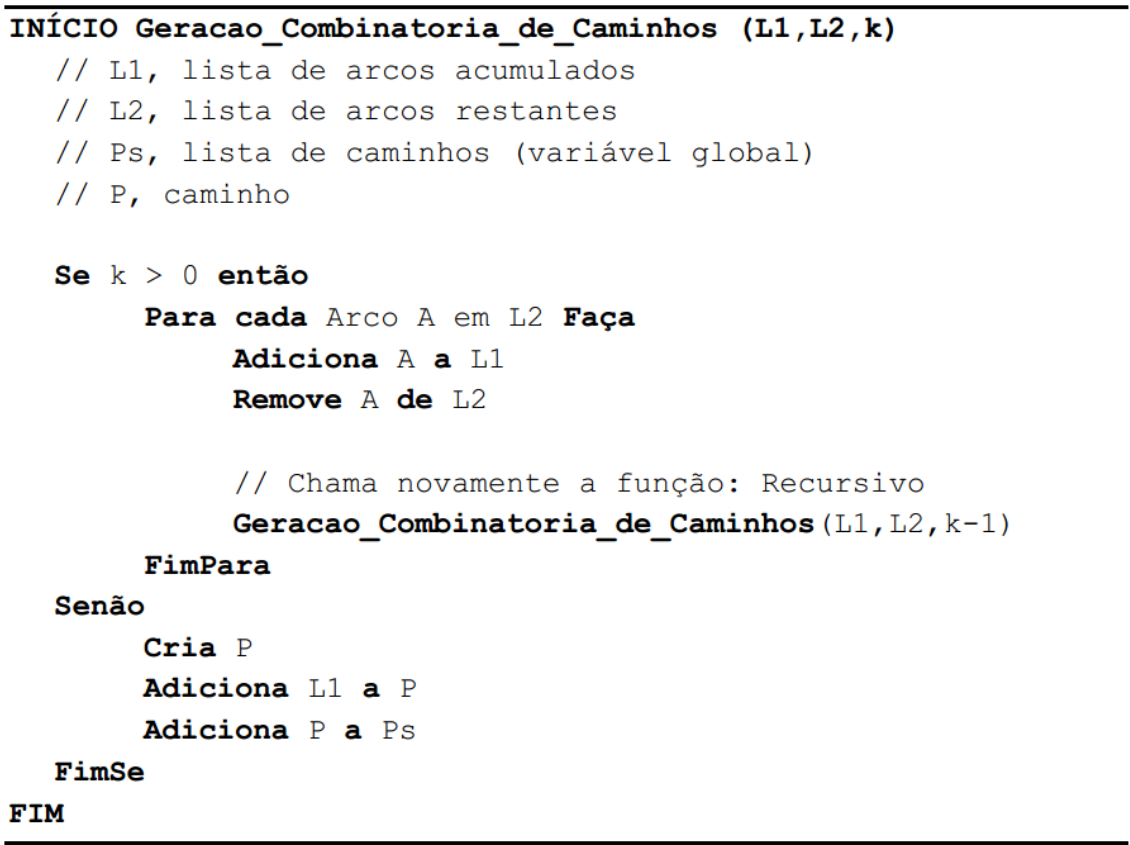

Figura 3.10: Algoritmo para Geração de Caminhos - Extrapolado de (STRINGHER, 2004). 
Para encontrar o total de circuitos gerados pelo gerador de caminhos combinatório, parte-se de dois pontos:

1. Para montar um circuito, basta pensar nos arcos com demandas numa determinada ordem (importa a ordem e a permutação é circular) e nos arcos sem demandas unindo os nós para fechar um circuito.

Exemplo: Três arcos com demandas: $\mathrm{A} 1(N 1 \rightarrow N 2)$, A2( $N 3 \rightarrow N 4)$ e A3( N5 $\rightarrow$ N6). Configurando um circuito C3, ilustrado na Fig. (3.11) (lado esquerdo).

Para uma configuração com 3 arcos com demanda existem PC3 (Permutação circular de 3) casos, ou seja, 2 casos.

Permutação circular: $P C_{n}=(n-1)$ !
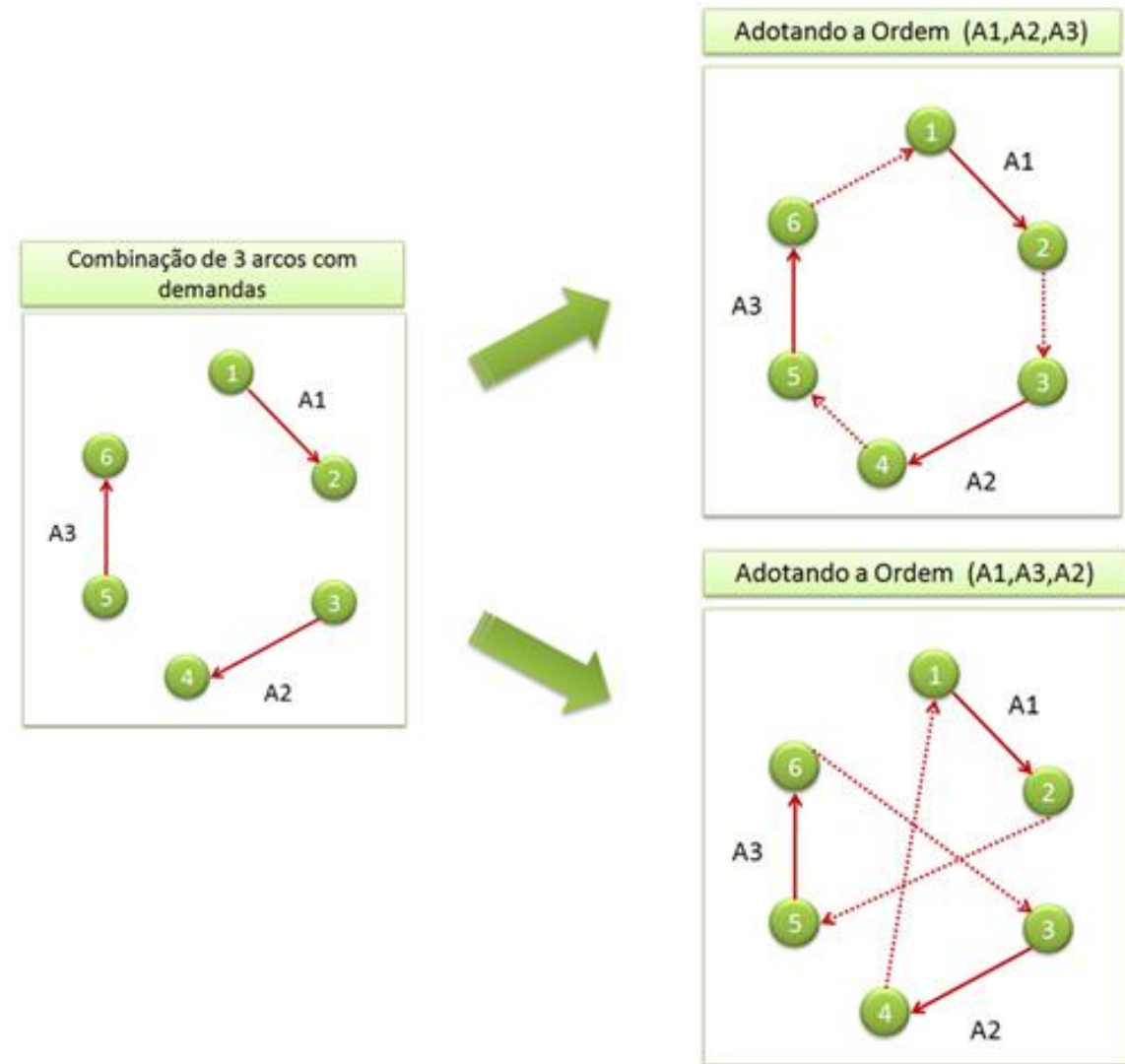

Figura 3.11: Exemplo: Permutações possíveis para formar um circuito C3.

Generalizando, para cada grupo encontrado com n arcos com demandas, existem PCn (permutação circular de n) circuitos possíveis.

Otimização do número de circuitos: Percebendo que estes circuitos encontrados atendem o mesmo grupo de arcos, o algoritmo implementado faz a 
primeira otimização, selecionando entre eles apenas o mais econômico para pertencer ao grupo de circuitos candidatos para a otimização do problema.

2. Feita a consideração dos circuitos encontrados para um grupo de arcos com demandas, é preciso encontrar quais são os grupos de arcos a serem repassados ao crivo anterior. Nesse caso, é possível pensar em grupos de 1 arco com demanda (C1), 2 arcos com demanda (C2), até k arcos com demandas $(\mathrm{Ck})$.

Pensando na representação dos circuitos como uma seqüência de arcos com demanda, tem-se:

$$
(A 1, A 2, A 3, \ldots, A k-1, A k)
$$

Adotando S para arcos selecionados para o circuito e N para arcos não selecionados para o circuito, tem-se por exemplo:

$$
(S, S, N, N, \ldots, S, N)
$$

Para circuitos $\mathrm{C} 2$, dois arcos selecionados são representados por $\mathrm{S}$ e os demais com N. Exemplo: $(N, S, N, \ldots, S, N)$, onde os arcos $A 2$ e $A k-1$ foram selecionados para pertencer ao circuito.

Utilizando essa forma de representação, circuitos C1 possuem apenas uma letra $\mathrm{S}$, circuitos $\mathrm{C} 2$ apenas duas letras $\mathrm{S}$ e circuitos $\mathrm{Ck}$ possuem k letras $\mathrm{S}$, sendo as demas letras $\mathrm{N}$.

Estruturado dessa forma, é possível chegar ao número de grupos de arcos C1, C2, C3 até Ck utilizando uma simples análise combinatória, permutando com repetição as letras $\mathrm{S}$ e as letras $\mathrm{N}$ da seqüência.

- Para circuitos $\mathrm{C} 1$ : \# Circuitos $\mathrm{C} 1$ = Permutação de $\mathrm{k}$ com repetição de 1 (S) e k-1 (N) $P k^{1, k-1}$

- Para circuitos C2: \# Circuitos C2 = Permutação de k com repetição de 2 (S) e k-2 (N) $P k^{2, k-2}$

- Generalizando:

- Para circuitos Cr: \# Circuitos $\mathrm{Cr}=$ Permutação de k com repetição de $\mathrm{r}$ (S) e k-r (N) $P k^{r, k-r}$

Portanto, o números de circuitos gerados até Cr é a soma das permutações, dada pela equação: 


$$
\text { \#Circuitos }(r)=\sum_{i=0}^{r} P k^{i, k-i}
$$

Como exemplo, a Tab. (3.1) mostra o comportamento da quantidade de circuitos encontrados. No exemplo foram utilizados até 100 arcos com demanda e circuitos até $\mathrm{C} 5$.

Tabela 3.1: Resultado Combinatório da Quantidade de Caminhos.

\begin{tabular}{|c|c|c|c|c|c|c|c|c|}
\hline \multirow{2}{*}{\multicolumn{2}{|c|}{ \# Circuitos }} & \multicolumn{6}{|c|}{ Tpo de Ginto (Gr) } & \multirow{2}{*}{ Total } \\
\hline & & CO & C1 & C2 & C3 & C4 & C5 & \\
\hline \multirow{18}{*}{ 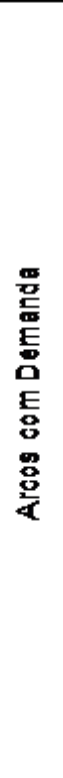 } & 1 & 1 & 1 & - & - & - & - & 2 \\
\hline & 2 & 2 & 2 & 1 & - & - & - & 5 \\
\hline & 3 & 3 & 3 & 3 & 1 & - & - & 10 \\
\hline & 4 & 4 & 4 & 6 & 4 & 1 & - & 19 \\
\hline & 5 & 牙 & 5 & 10 & 10 & 5 & 1 & 36 \\
\hline & 6 & 6 & 6 & 15 & 20 & 15 & 6 & 68 \\
\hline & 7 & 7 & 7 & 21 & $3 \mathbf{3}$ & 3 & 21 & 126 \\
\hline & 8 & 8 & 8 & 28 & 56 & 7 & 56 & 226 \\
\hline & 9 & 9 & 9 & 3 & 84 & 128 & 18 : & 390 \\
\hline & 10 & 10 & 10 & 45 & 120 & 210 & 8क्य & 647 \\
\hline & 20 & 20) & 20 & 190 & 1,140 & 4,845 & 15,504 & 21,719 \\
\hline & 30 & 30 & 30 & 453 & 4,060 & 27,405 & 142,506 & 174,466 \\
\hline & 50 & 50 & 50 & 1,228 & 19,600 & Z30,300 & $2,118,760$ & $2,369,985$ \\
\hline & 60 & 60 & 60 & $1,7 \mathrm{~m}$ & 34,200 & 487,695 & $5,461,512$ & $5,985,257$ \\
\hline & 70 & $\pi$ & $\pi$ & 2,415 & 54,740 & 916,806 & $12,103,014$ & $13,077,204$ \\
\hline & 80 & 80 & 80 & 3,160 & 82,160 & $1,5 B 1,5 \mathrm{BD}$ & $24,040,016$ & $25,707,076$ \\
\hline & 90 & 90 & 90 & 4,004 & 117,480 & 2द厉, 190 & $43,949,268$ & $46,626,123$ \\
\hline & 100 & 100 & 100 & 4,900 & 161,700 & 3,921,22: & $76,287,500$ & $79,375,595$ \\
\hline
\end{tabular}

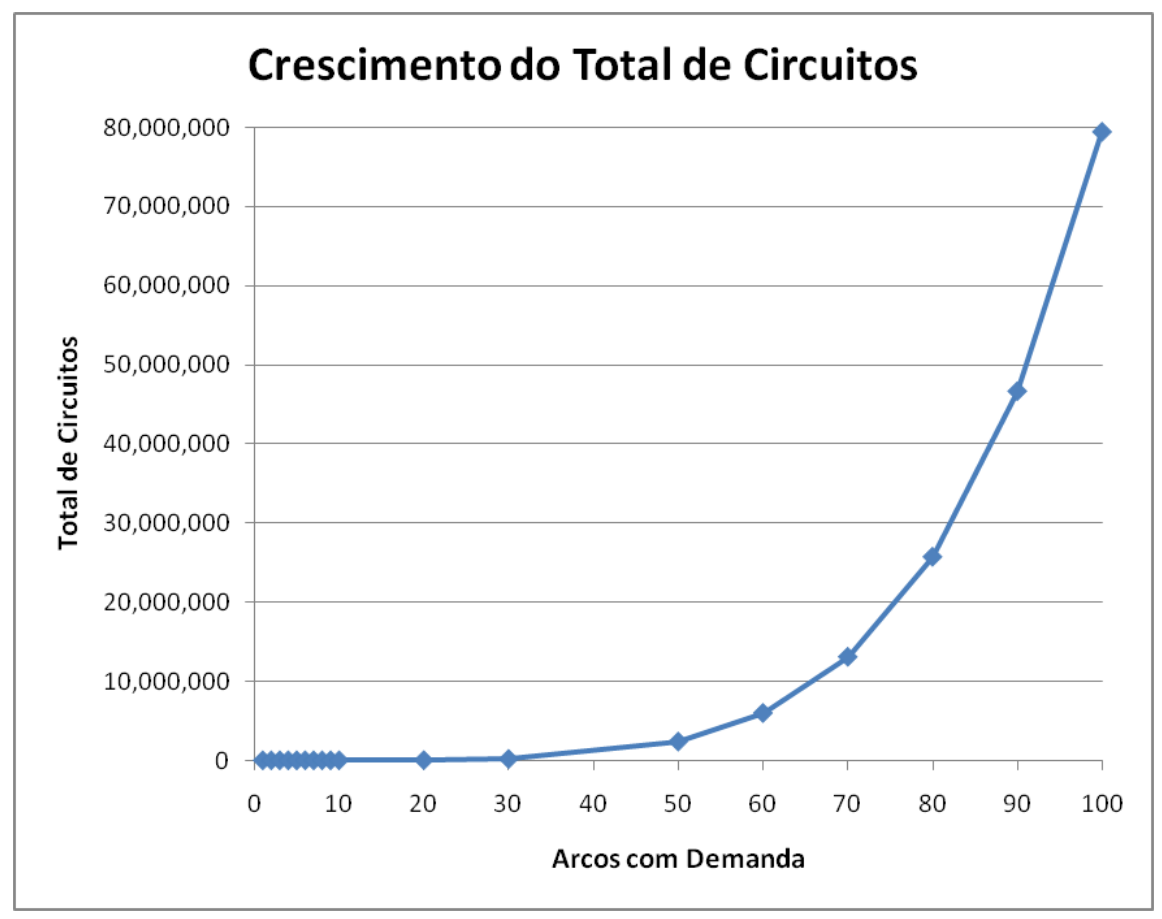

Figura 3.12: Crescimento do Número de Circuitos. 
Um ponto a ser levantado é o quão complexa, do ponto de vista computacional, fica a solução do problema de otimização com o aumento das demandas e da ordem dos circuitos, como mostra a Fig. (3.12) . Por exemplo, para uma rede com 100 demandas e levando em conta até circuitos C5 (última linha da Tab. (3.1)), o problema matemático terá uma função objetivo de quase 80 milhões de variáveis de decisão e 100 restrições.

Redução do número de circuitos: Além da redução do total de circuitos que chegou a Eq. (3.8), foi considerado a redução de circuitos com subcircuitos, que se pensar de forma ampla, são circuitos de ordem menor sendo reinseridos na lista de circuitos. Devido ao fato desses circuitos surgirem em maior ou menor número em função da distribuição física da rede e das demandas, não foi possível estabelecer uma fórmula assertiva para calcular o total de circuitos realmente gerados, mas de qualquer forma será retificada a equação Eq. (3.8) para a inequação Eq. (3.9).

$$
\text { \#Circuitos }(r) \leq \sum_{i=0}^{r} P k^{i, k-i}
$$

\subsubsection{Geração de Caminhos Guiada pela Junção de Ciclos}

As abordagens guiadas para gerar os caminhos procuram eliminar o excesso de caminhos gerados na abordagem combinatória, deixando apenas os melhores candidatos à solução. Consequentemente reduzindo o esforço computacional nesta etapa. Esses geradores serão tratados em dois tópicos, guiado por junção de ciclos e guiado por raio de investimento.

De acordo com ${ }^{[20]}$, os algoritmos para gerar os ciclos apresentam as seguintes características:

1. Gera todos os ciclos de um arco (com demanda) que atendam uma rota específica, apagando-a do conjunto de rotas até que esteja vazio.

2. Gera ciclos acrescentando mais uma rota aos ciclos do item 1, compondo no início (busca anterior) ou no fim (busca posterior) do caminho.

3. Gerar ciclos agrupando ciclos e formando ciclos maiores, respeitando a restrição de cardinalidade máxima.

Ferri ${ }^{[26]}$ utiliza essa mesma abordagem, no entanto define um fator "p", chamado de qualidade do caminho, que é a razão entre o custo total do ciclo 
sem considerar os reposicionamentos sobre o custo total do ciclo considerando os reposicionamentos. A partir desse parâmetro, se p é maior que um valor definido o ciclo é descartado, antes de chegar ao solver. Dessa forma, o algoritmo de ${ }^{[26]}$ trabalha com um número menor de ciclos, portanto mais rápido para encontrar a solução e, de acordo com os resultados, com diferenças muito pequenas na solução encontrada

\subsection{Solver}

Baseado na abordagem da cobertura por ciclos, cada ciclo se torna uma variável de decisão, que somadas às restrições do problema e à função objetivo, configuram um problema matemático de pesquisa operacional de programação linear inteira. Esse problema pode ser resolvido de diversas maneiras, seja por métodos determinísticos ou por heurísticas. O componente responsável por resolver esse problema será chamado neste trabalho por Solver.

O problema abordado neste trabalho é um típico problema de Programação Linear Inteira (PLI), que possui algumas maneiras de ser resolvido, que serão apresentadas no próximo tópico. Outra maneira de resolver o presente problema, é olhar para suas características e elaborar uma heurística que se aproxime do PLI, mas que tenha um desempenho computacional melhor, é o caso da proposta deste trabalho e outras propostas como em ${ }^{[26]}$ e em ${ }^{[22]}$. A seguir será descrita a abordagem de solução do problema matemático de PLI, que foi a solução adotada $\mathrm{em}^{[11]}$ e em ${ }^{[29]}$.

\subsubsection{Programação Linear Inteira - PLI}

Nesta abordagem é necessário gerar todos os caminhos possíveis antes de executar o solver, que pode ser qualquer solver comercial que resolva problema de Programação Linear Inteira.

Seguindo a modelagem matemática por ciclos, adaptada de ${ }^{[22]}$, cada caminho ou ciclo se torna uma variável de decisão, cujo somatório do produto do custo do caminho pelas demandas atendidas compõem a função objetivo a ser minimizada, como apresentado Eq. (3.7). Em seguida são adicionadas ao modelo matemático as restrições de atendimentos as demandas dos arcos, Eq. (3.7).

Para simplificar a explicação de como é montado o PLI (função objetivo e matriz de restrições), será utilizado um problema fictício como exemplo, descrito 
em passos a seguir:

\section{Problema Proposto (Modelo do Problema em Grafo)}

Considere uma rede com três cidades e quatro demandas entre elas. Isso nos dá num modelo em grafo com 3 nós e 4 arcos com demandas, conforme ilustrado na Fig. (3.13) . Supondo que as demandas mensais nos arcos sejam: $\mathrm{A} \rightarrow \mathrm{B}$ (30 cargas), $\mathrm{B} \rightarrow \mathrm{C}(70$ cargas $), \mathrm{C} \rightarrow \mathrm{B}$ (30 cargas) e $\mathrm{C} \rightarrow \mathrm{A}(30$ cargas).

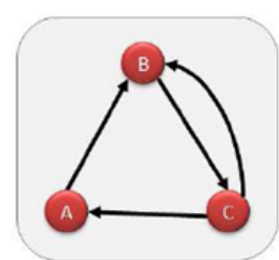

Figura 3.13: A rede representada na figura inclui quatro demandas entre três cidades $(\mathrm{A}, \mathrm{B}$ e $\mathrm{C}) . \mathrm{A}=\mathrm{A} \rightarrow \mathrm{B}, \mathrm{B} \rightarrow \mathrm{C}, \mathrm{C} \rightarrow \mathrm{B}, \mathrm{C} \rightarrow \mathrm{A}$.

\section{Caminhos Possíveis (Gerador de Caminhos)}

Dada a configuração da rede (arcos com demandas), o Gerador de Caminhos gera todos os caminhos possíveis que vão fazer parte do conjunto de variáveis de decisão do problema matemático a ser resolvido.

Os circuitos \# i, para $4<i<12$, mostrados na Fig. (3.14) levam em consideração movimentos vazios. Circuitos \# 12 e \# 13 são equilibrados.

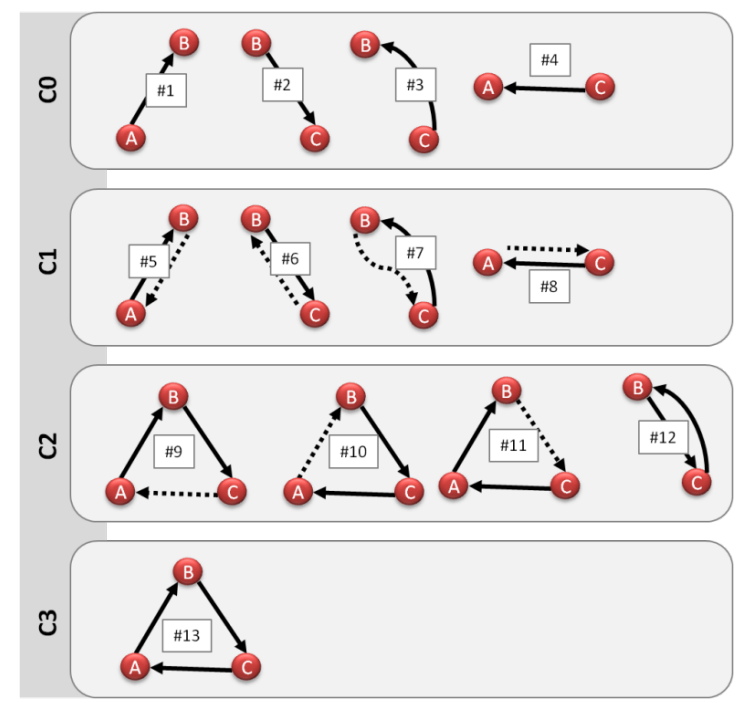

Figura 3.14: Circuitos gerados a partir da configuração da rede dada na Fig. (3.13). 
Para a configuração dada, foram gerados os circuitos representados na Fig. (3.14) e também a matriz de restrições M, representada na Fig. (3.15). Nesta matriz, cada linha representa um arco com demanda e cada coluna representa um circuito. Os valores da matriz podem ser 0 ou 1, onde 1 na coluna indica que o correspondente arco com demanda faz parte do circuito da coluna. Movimentos vazios não são representados na matriz. As linhas representam respectivamente as seguintes demandas: $\mathrm{A} \rightarrow \mathrm{B}, \mathrm{B} \rightarrow \mathrm{C}, \mathrm{C} \rightarrow \mathrm{A}$, $\mathrm{C} \rightarrow \mathrm{B}$.

Cada arco precisa ter suas demandas atendidas $\left(r_{i j}\right)$, e isso é garantido pela Eq. (3.7), onde o coeficiente $c_{C}$ é o custo do ciclo $C, l_{C}^{i j} \in(0,1)$ assume o valor 1 se o arco com demanda $l^{i j} \in L$ participa do ciclo, e 0 se não participa do ciclo. A partir desse conjunto de inequações, os coeficientes $l^{i j}$ formam a matriz de restrições da Fig. (3.15).

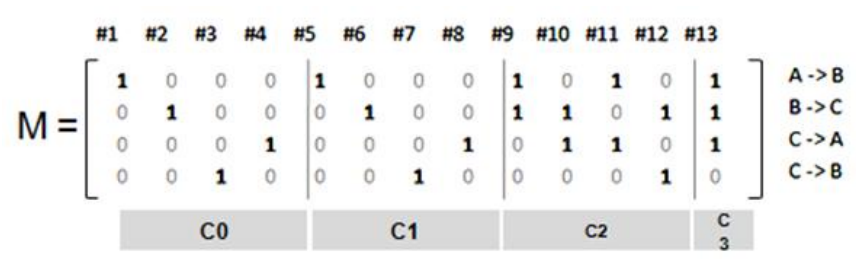

Figura 3.15: Matriz de restrições.

Os circuitos C0 na Fig. (3.14), de 1 a 4, são contratações spot e não consideram o retorno, por isso não são representados como circuitos fechados.

Obtida a matriz de restrições $\mathrm{M}$, os custos associados a cada caminho (variável de decisão) e o vetor d de demandas nos arcos, obtém-se o modelo matemático Eq. (3.10) a ser resolvido pelo PLI:

$$
\left\{\begin{array}{l}
f \quad=\sum C_{P}^{i} \cdot x_{i} \\
M \cdot x \geq d
\end{array}\right.
$$

\section{Resultado (Solver)}

Dadas as características da rede proposta e suas respectivas demandas, o solver PLI ao resolver a Eq. (3.10) encontraria a solução representada em círculos na Fig. (3.16) pelos caminhos \#6, \#12 e \#13, com 10 cargas, 30 cargas e 30 cargas atendidas respectivamente. 


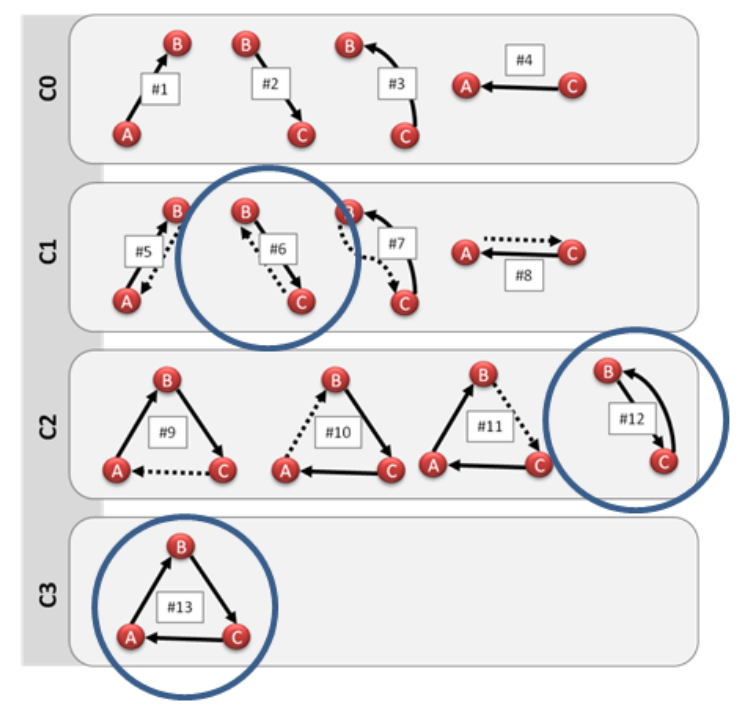

Figura 3.16: Solução encontrada pelo Solver PLI para o exemplo.

Essa sequência de passos resume o fluxo da Fig. (3.9): Modelo em Grafo, Gerador de Caminhos e Solver. Em resumo (vide Fig. (3.17)), no exemplo dado transforma-se cidades de origem e destino em nós, estradas em arcos e obtém-se o Modelo em Grafo, em seguida gera-se os Caminhos e finalmente o solver escolhe e atribui as demandas aos caminhos.

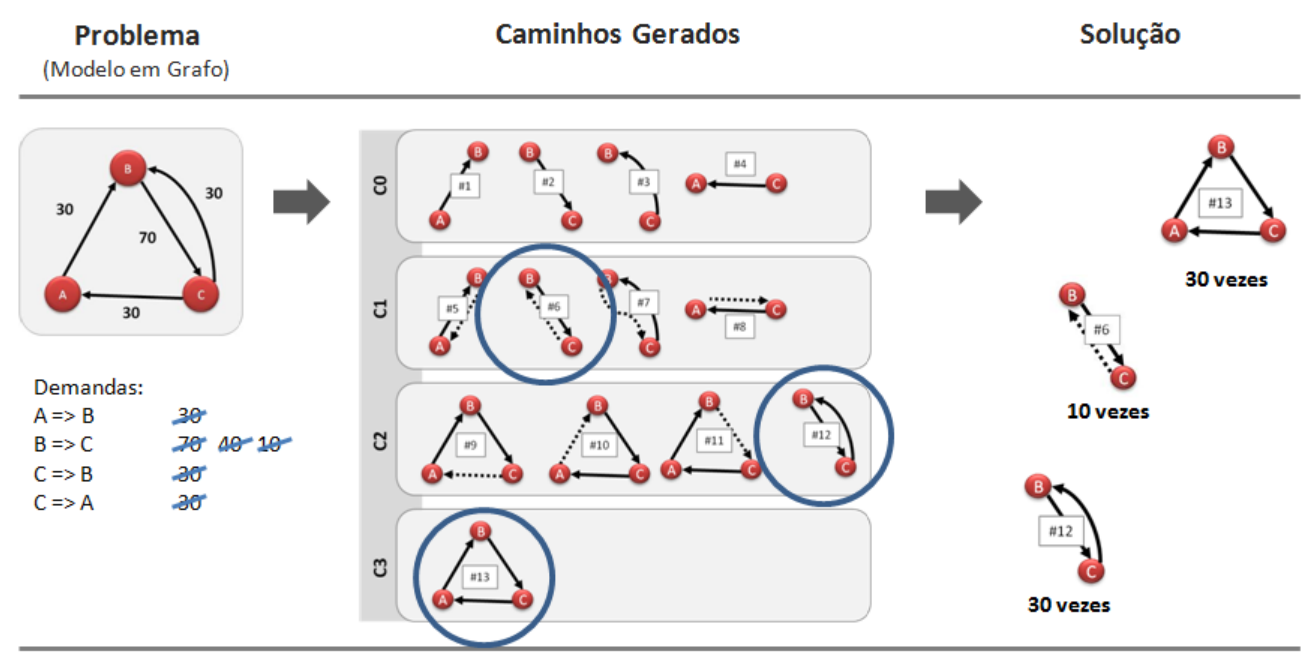

Gerador de Caminhos

\section{Solver}

Figura 3.17: Fluxo completo de solução.

\subsubsection{Heurísticas}

As heurísticas de Ferri ${ }^{[26]}$ e Ergun ${ }^{[22]}$ são baseadas no parâmetro de qualidade "p" e na priorização dos caminhos com maior comprimento. A principal diferença entre as heurísticas de ${ }^{[26]}$ e ${ }^{[22]}$ na resolução do problema, é que em ${ }^{[26]}$ faz-se a 
seleção dos caminhos durante a criação dos mesmos, enquanto em ${ }^{[22]}$ primeiro gera-se todos os caminhos possíveis, para depois selecionar. 


\section{Proposta}

A proposta deste trabalho se encaixa no PCRCR e é, portanto, de acordo com ${ }^{[20]}$ um problema NP-Difícil. Expandindo o que foi estudado em ${ }^{[22]} \mathrm{e}^{[26]}$, neste trabalho foi agregado, assim como em ${ }^{[11]} \mathrm{e}^{[29]}$, as rotas spot, a modelagem de custos fixos e variáveis e as demandas não unitárias. Para a solução, foi utilizada uma heurística para gerar os ciclos (Gerador guiado por raio de investimento) e também uma heurística como solver (heurística de priorização de caminhos e antecipação de solução), explicados mais adiante.

Nesta abordagem não se gera primeiro todos os caminhos para depois passar os candidatos ao solver, ao invés disso utiliza-se pontos intermediários bem definidos de repasse para o solver, de acordo com as etapas da heurística.

A estratégia de solução divide-se em três etapas, descritas abaixo e ilustradas na Fig. (4.1):

1. Geração e Priorização de Circuitos Perfeitos: Primeiro são gerados os circuitos sem reposicionamento, utilizando o Gerador de Caminhos Guiado por Raio de Investimento (seção Gerador de Caminhos Guiada por Raio de Investimento) com raio de investimento igual à zero, pois não são permitidos reposicionamentos nesta etapa. Esses circuitos são chamados aqui de "Circuitos Perfeitos", pois seus custos são iguais ao Custo Core (menor custo possível, explicado na seção 4.2.3). Ao fim desta etapa de geração, os circuitos candidatos são repassados ao solver para priorizar (priorização por dimensionamento de frota, explicada na seção 4.4) os que farão parte da solução final.

2. Geração e Priorização de Circuitos com Reposicionamentos: Nesta etapa são gerados os circuitos com reposicionamentos (deslocamento improdutivo), utilizando o Gerador de Caminhos Guiado por Raio de Investimento (seção 4.3). Diferentemente da etapa anterior, os circuitos gerados aqui possuem um custo adicional ao Custo Core (explicado na seção 4.2.3), pois 
são admitidos reposicionamentos. Devido a esse custo adicional que implica diferentes eficiências de um ciclo para outro, a priorização do solver passa a ser uma priorização por eficiência (explicada na seção 4.4), seguida de priorização por dimensionamento de frota. Em um algoritmo iterativo, são atendidas todas as demandas possíveis com os circuitos desta etapa.

3. Geração e Priorização de Caminhos Complementares: Se restarem demandas a serem atendidas após as etapas 1 e 2, elas serão atendidas por caminhos C0 (rotas spot) ou C1 (ciclos com retorno vazio), priorizados no solver pelo custo total através da distância limite explicada na seção 4.2.2.

Com essa estratégia de antecipação de solução, reduz-se a quantidade de demandas a serem atendidas nas etapas posteriores e consequentemente reduz a possibilidades de caminhos gerados, reduzindo assim a quantidade de caminhos gerados, variando de acordo com a configuração da rede.

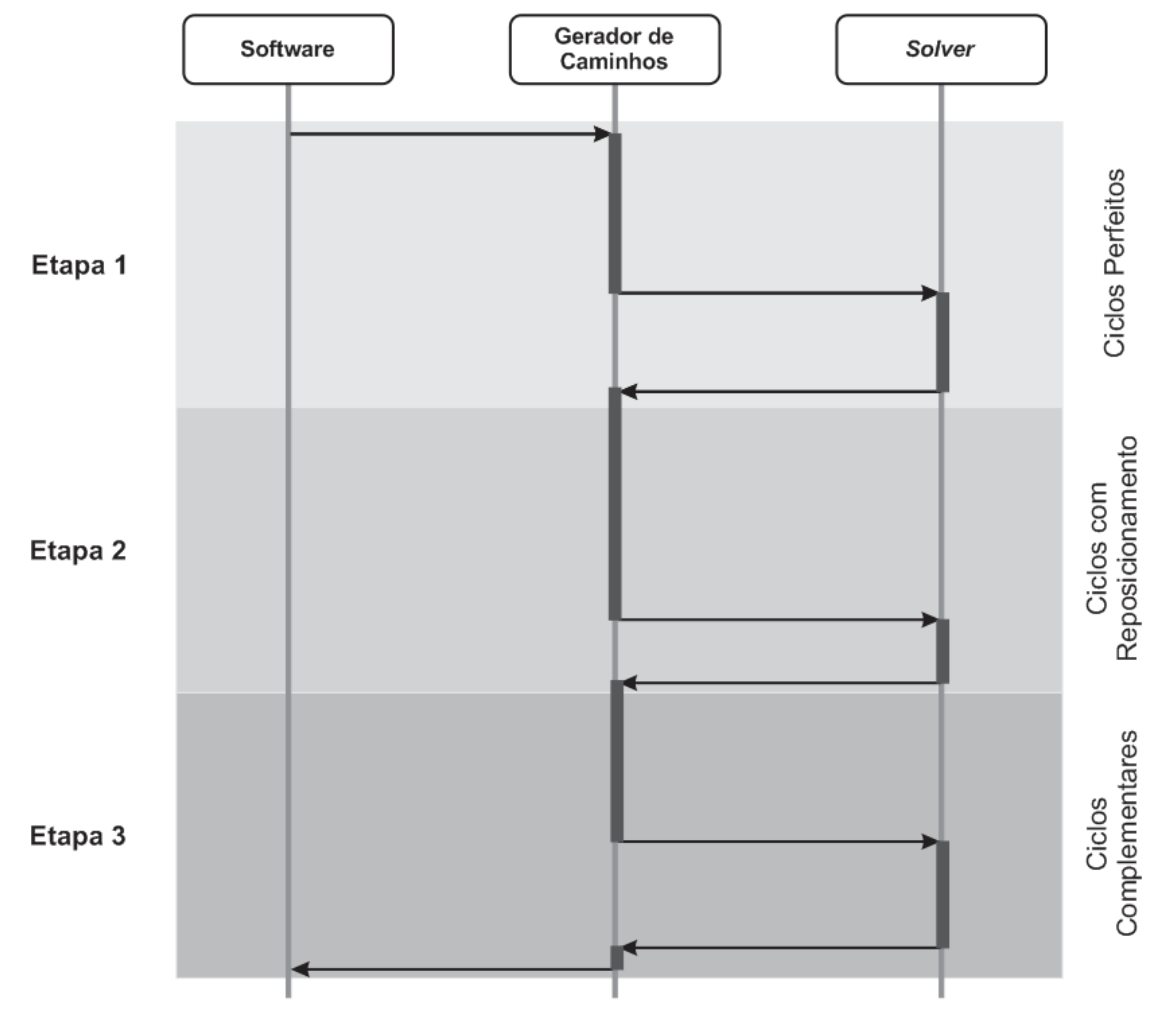

Figura 4.1: Diagrama de Seqüência - Sinergia entre Gerador de Caminhos e Solver.

Com essa sinergia entre solver e gerador de ciclos, associada à paralelização dos algoritmos, é possível reduzir o tempo de processamento de cada fase da heurística, como será visto na seção 5 . 
Antes de entrar nos detalhes do funcionamento das heurísticas, serão estabelecidas as premissas, limitações do modelo e modelagem de custos.

\subsection{Delimitação da modelagem proposta}

De acordo com a lista de critérios de decisão, variáveis e restrições apresentados por ${ }^{[3]}$, o problema de otimização de transporte por circuitos logísticos, proposto por este trabalho, é delimitado como um problema com as seguintes características:

- Possui janelas de tempos (carga, descarga e espera por nova carga) flexíveis.

- Atende à demandas de mais de um arco por vez. Deve ser feito por um ou mais veículos, de acordo com a demanda atribuída ao circuito. Considera frota homogênea.

- As demandas são determinísticas e invariáveis por um determinado intervalo de tempo.

- As demandas estão localizadas nos arcos.

- Cada demanda é uma unidade de carga lotação, que neste estudo é igual a uma carreta totalmente carregada com 27 toneladas.

- O grafo resultante da modelagem é necessariamente um grafo direcionado.

- Devido à frota homogênea, todos os veículos estão sujeitos as mesmas restrições.

- Quanto ao tempo de roteamento, não há restrições diretas, pois se o transporte não consegue atender a demanda no tempo especificado, o problema passa a ser mudança de modal, o que não é contemplado por este trabalho.

- Quanto aos custos, são considerados tantos os custos variáveis quanto os custos fixos.

- De acordo com a operação, o problema se preocupa com o recolhimento e a entrega, traduzidos no tempo de carga e no tempo de descarga.

- O objetivo da otimização é minimizar o custo total da operação da rede logística modelada. 
- As restrições na capacidade dos arcos não serão consideradas, pois cada demanda é atendida por um veículo e a quantidade de veículos que passam por um arco (rodovia) não é objeto de estudo deste trabalho.

\subsection{Modelagem do Custo de Rotas}

Um dos pontos importantes da abordagem proposta neste trabalho é o uso de custos fixos e variáveis para compor os custos de um rota. Isso aproxima a abordagem de problemas reais e torna a solução uma ferramenta de decisão mais precisa.

A seguir será detalhada a forma de cálculo do custo dos caminhos utilizada neste trabalho.

\subsubsection{Cálculo do Custo de Rotas}

Para calcular o custo de uma rota, deve-se considerar tempo de carga, tempo descarga, tempo de busca (tempo para encontrar uma nova carga), tempo de viagem (para isso é necessário a velocidade média) e a distância percorrida.

Define-se os componentes do custo de uma rota:

- $T_{l}$ Tempo de carga (load), dado em horas.

- $T_{u}$ Tempo de descarga (unload), dado em horas.

- $v_{m}$ Velocidade média, dada em $\mathrm{km} / \mathrm{h}$.

- $T_{s}$ Tempo de busca, que é o tempo necessário para encontrar uma nova carga, relativo às contratações spot.

\subsubsection{Custos de Circuitos $\left(C_{k}\right)$}

Para o cálculo do custo de um circuito, baseado na Eq. (2.6), a Eq. (4.1), onde além dos componentes citados anteriormente tem-se o $\Delta$, que é a distância total percorrida, e o $N_{t}$, que é o número de rotas com demandas que o circuito atende no percurso. Neste trabalho, o $N_{t}$ é numericamente igual a cardinalidade do circuito, conforme explicado na seção 3.4.

$$
C_{P}\left(C_{k}\right)=\left[\left(T_{i}+T_{u}\right) N_{t}+\frac{\sum \Delta}{v_{m}}+T_{u}\right] C_{f}+\sum \Delta C_{v}
$$


Exemplo: Para o circuito da Fig. (4.2), com as seguintes características:

- $T_{l}=T_{u}=4 \mathrm{~h}$

- $v_{m}=60 \mathrm{~km} / \mathrm{h}$

- $N_{t}=3$, de acordo com a característica do exemplo (3 arcos com demanda).

- $C_{f}=24,5 \mathrm{R} \$ / \mathrm{h}$

- $C_{v}=0,47 \mathrm{R} \$ / \mathrm{km}$

- $\Delta=800 \mathrm{~km}$

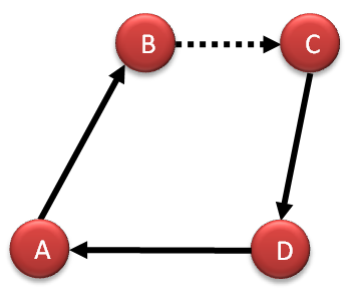

Figura 4.2: Exemplo Circuito C3.

Para o circuito dado, o custo para percorrê-lo uma vez é:

$$
C_{p}\left(C_{3}\right)=1.290,67[\mathrm{R} \$]
$$

\subsubsection{Custos de Rotas Spot $\left(C_{0}\right)$}

O cálculo do custo de uma rota spot é bem parecido com o cálculo para um circuito, a diferença é que neste caso existe um adicional de custo fixo associado ao tempo de busca por uma nova carga, traduzido no parâmetro. Dado que a cardinalidade da rota spot é sempre 1, de acordo com a modelagem proposta neste trabalho, não está expresso na Eq. (4.2) o termo $N_{t}$.

$$
C_{P}\left(C_{0}\right)=\left(T_{l}+\frac{\sum \Delta}{v_{m}}+T_{u}+T_{s}\right) \cdot C_{f}+\Delta \cdot C_{v}
$$

Exemplo: Para o circuito da Fig. (4.3), com as seguintes características:

- $T_{l}=T_{u}=4 \mathrm{~h}$

- $T_{s}=14 \mathrm{~h}$

- $v_{m}=60 \mathrm{~km} / \mathrm{h}$ 
- $C_{f}=24,5 \mathrm{R} \$ / \mathrm{h}$

- $C_{v}=0,47 \mathrm{R} \$ / \mathrm{km}$

- $\Delta=500 \mathrm{~km}$

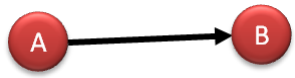

Figura 4.3: Exemplo de Rota Spot (C0).

Para o circuito dado, o custo para percorrê-lo uma vez é:

$C_{p}\left(C_{0}\right)=987,17[\mathrm{R} \$]$

\subsubsection{Comparação entre rota $\mathrm{C} 0$ e circuito $\mathrm{C} 1$}

Nesta seção será feita uma comparação, em termos de custo, entre os circuitos do tipo $\mathrm{C} 1$ com $\mathrm{C} 0$, o que fundamenta um dos fatores determinantes na decisão entre contratação spot ou frota dedicada.

De acordo com a definição da seção 3.4, rotas C0 são contratações spot, onde o retorno não é levado em conta, mas em compensação é levado em conta um fator a mais no tempo total $\left(T_{\text {total }}\right)$, que é o tempo de busca $\left(T_{\text {busca }}\right)$. Já os circuitos $\mathrm{C} 1$, são as viagens que o transportador vai carregado e volta vazio.

De acordo com a modelagem de custos da seção 4.2:

Parâmetros para circuitos C0:

1. $T_{\text {total }}=T_{\text {carga }}+T_{\text {viagem }}+T_{\text {descarga }}+T_{\text {busca }}$

2. Distância $=D$

\section{Parâmetros para circuitos C1:}

1. $T_{\text {total }}=T_{\text {carga }}+2 \cdot T_{\text {viagem }}+T_{\text {descarga }}$

2. Distância $=2 \cdot D$

A partir dos dados acima, os custos de um circuito $\mathrm{C} 0$ e de um circuito $\mathrm{C} 1$ são:

1. Custo $(C 0)=C F \cdot\left(T_{\text {carga }}+T_{\text {viagem }}+T_{\text {descarga }}+T_{\text {busca }}\right)+D \cdot C V$ 
2. Custo $(C 1)=C F \cdot\left(T_{\text {carga }}+2 \cdot T_{\text {viagem }}+T_{\text {descarga }}\right)+2 \cdot D \cdot C V$

Separando os termos que dependem da distância:

1. Custo $(C 0)=C F \cdot\left(T_{\text {carga }}+T_{\text {descarga }}+T_{\text {busca }}\right)+\underbrace{\left(C F \cdot T_{\text {viagem }}+D \cdot C V\right)}_{\mathrm{X}}$

2. Custo $(C 1)=C F \cdot\left(T_{\text {carga }}+T_{\text {descarga }}\right)+2 \underbrace{\left(C F \cdot T_{\text {viagem }}+D \cdot C V\right)}_{\mathrm{X}}$

Portanto:

1. Custo $(C 0)=C F \cdot\left(T_{\text {carga }}+T_{\text {descarga }}+T_{\text {busca }}\right)+\mathbf{X}$

2. Custo $(C 1)=C F \cdot\left(T_{\text {carga }}+T_{\text {descarga }}\right)+2 \mathbf{X}$

O gráfico da Fig. (4.4), nos dá as seguintes conclusões para uma rota com demanda e distância D:

1. $D>D_{\text {limite, }}$ implica que a contratação spot passa a ser mais atrativa que o retorno vazio.

2. $D<D_{\text {limite }}$, implica que vale a pena ter uma frota dedicada com circuito C1 para a rota.

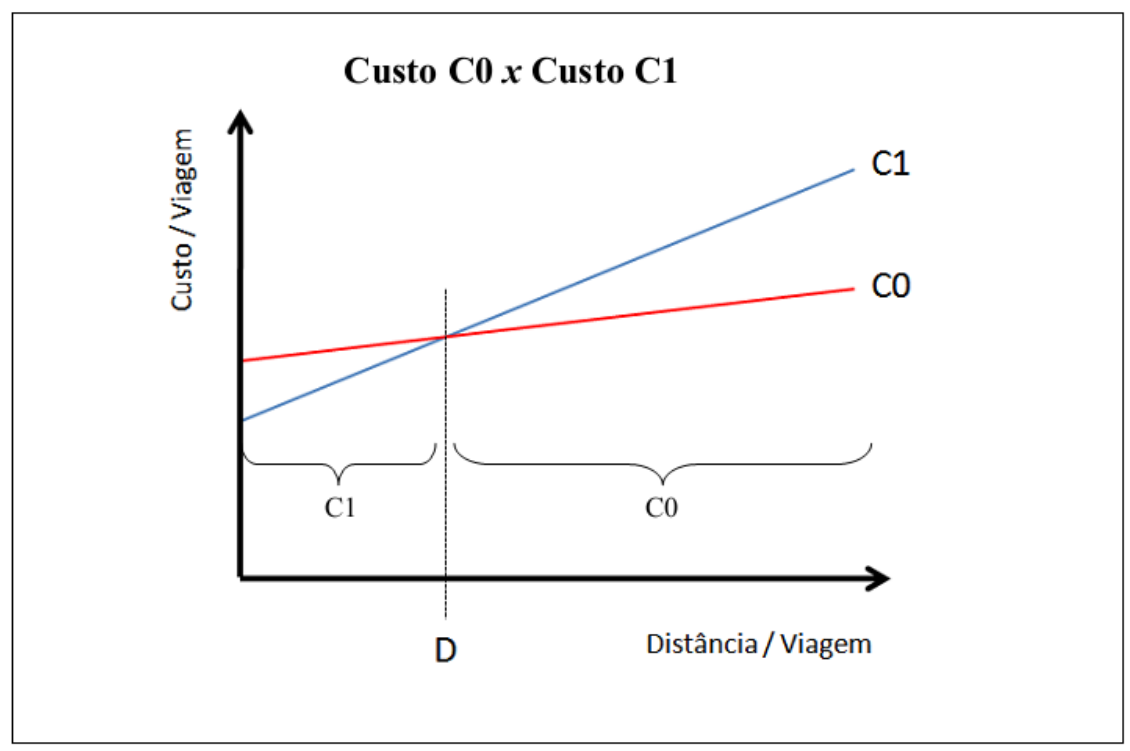

Figura 4.4: Custo C0 x Custo C1 (Adaptado de STRINGHER, 2004). 


\subsubsection{Distância Limite $\left(D_{\text {limite }}\right)$}

A Distância Limite (D) é a distância em que o circuito C1 tem o mesmo custo do circuito $\mathrm{C} 0$ e se a distância for maior que este valor, o circuito C1 passa a ser mais caro (menos competitivo em custo).

- $\operatorname{Custo}(C 1)=$ Custo $(C 0)$

- $C F \cdot\left(T_{\text {carga }}+2 \cdot T_{\text {viagem }}+T_{\text {descarga }}\right)+2 \cdot D \cdot C V=C F \cdot\left(T_{\text {carga }}+T_{\text {viagem }}+\right.$ $\left.T_{\text {descarga }}+T_{\text {busca }}\right)+D \cdot C V$

- $C F \cdot(D / V m)+D \cdot C V=C F \cdot T_{b u s c a}$

$$
D_{\text {limite }}=C F \cdot \frac{T_{\text {busca }}}{\frac{C F}{V_{m}}+C V}
$$

Analisando a Eq. (4.3) e o gráfico da Fig. (4.4), essa distância depende de 4 fatores $\left(\mathrm{CF}, T_{\text {busca }}, T_{\text {viagem }}\right.$ e $\mathrm{CV}$ ) e pode-se concluir que a competitividade do circuito C1 só é representativa se o custo do tempo de busca for maior que o custo da viagem de retorno, ou seja, apenas em casos em que a distância é pequena que vale a pena o veículo voltar vazio.

\subsubsection{Classificação dos custos de operação de uma rede}

Neste trabalho os custos de operação serão classificados em dois tipos: Custo Core e Custo Adicional. Essa divisão de custos nos dá uma visão nítida da máxima economia possível em rede, que é chegar ao Custo Core.

- Custo Core: é a parcela do custo de operação de uma rede que não leva em consideração os custos de reposicionamento nem de espera por uma nova carga, ou seja, leva em consideração apenas os custos de carga, descarga e deslocamento com carga. A equação geral para o custo core é dada por:

$$
C_{\text {core }}=\sum_{(i, j) \in L}\left[\Delta_{i j} \cdot C_{V}+\left(T_{l}+T_{u}+\frac{\Delta_{i j}}{V_{m}}\right) \cdot C_{F}\right] \cdot r_{i j}, \forall(i, j) \in L
$$

Onde $\Delta_{i j}$ é a distância percorrida no arco com demanda $(i, j) \in L, T_{l}$, é o tempo de carga,$T_{u}$ é o tempo de descarga, $r_{i j}$ total de demandas do arco, $\mathrm{Cv}$ e CF coeficientes de custos e $V_{m}$ velocidade média. 
- Custo Adicional: é a parcela do custo de operação de uma rede que representa todos os reposicionamentos, tempo de espera por uma nova carga ou qualquer custos adicionais associados ao não casamento de janelas de tempo. Dado que são custos improdutivos, são o principal foco de uma iniciativa de redução de custos e podem ser alcançados através de colaboração logística. Sua equação geral é dada por:

$$
C_{\text {adicional }}=\sum_{(i, j) \notin L}\left[\Delta r_{i j} \cdot C_{V}+\left(T_{s}+\frac{\Delta r_{i j}}{V_{m}}\right) \cdot C_{F}\right] \cdot n, \forall(i, j) \notin L
$$

Onde $\Delta r_{i j}$ é a distância percorrida no arco de reposicionamento, $T_{s}$ é o tempo de busca por uma nova carga e n é o números de vezes que é necessário esperar por uma nova carga ou reposicionar o veículo.

Em geral, operações dedicadas e restritas a um embarcador carregam consigo um alto custo adicional, de reposicionamento de veículo ou espera por nova carga (contratação spot), pois na maioria das vezes não há um balanceamento de demandas com apenas um embarcador. Em um sistema onde, por natureza, há balanceamento de demandas por transporte e existe pouca ou nenhuma colaboração entre embarcadores, é possível obter uma economia de custos através da colaboração, devido ao casamento de demandas.

\subsection{Gerador de Caminhos Guiada por Raio de Investimento}

Pensando não somente na redução da quantidade de caminhos candidatos à solução, explicado anteriormente, esta abordagem propõe também um método obter escalabilidade computacional através de programação paralela.

A Heurística para Geração de Caminhos Guiada por Raio de Investimento (HGCGRI), proposta neste trabalho, baseia-se na busca por rotas partindo de um Nó (ou vértice) e percorrendo outros Nós até retornar ao Nó inicial e fechar um ciclo, como pode ser visto na Fig. (4.5) . O que define quais nós serão os próximos (árvore de nós posteriores) na formação do caminho base é o raio de investimento, de tamanho explicado adiante. Baseado no custo core ou custo fixo de busca por uma nova carga, a heurística seleciona um conjunto de Nós candidatos a continuar a formação de caminhos, particionando a geração em vários processamentos. A cada novo Nó encontrado inicia-se um novo caminho com os Nós já coletados e 
o novo Nó. Os demais caminhos continuam sendo criados em paralelo e a cada novo Nó, novos caminhos.

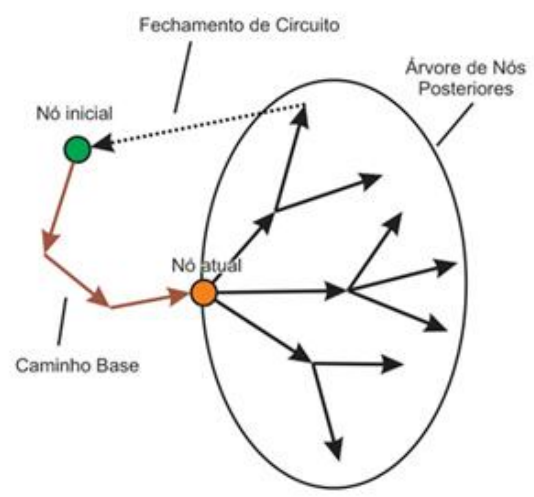

Figura 4.5: Árvore de Nós posteriores (determinados pelo tamanho da bolha).

\subsubsection{Raio de Investimento}

Durante a geração do caminho é necessário escolher quais nós serão os sucessores na formação do caminho base. Cada novo nó dá origem a um novo caminho base e também a uma nova busca. A escolha dos nós sucessores é feita através de uma busca por nós dentro de uma região circular centrada no nó atual e com raio do tamanho do raio de investimento, calculado adiante de acordo com a estratégia de busca (variável, fixo ou misto). O raio de investimento é definido pelo raio de busca e permite a seleção do próximo Nó com carga saindo (através de um reposicionamento limitado pelo raio), percorrendo todo o caminho até chegar ao Nó inicial, como pode ser visto na Fig. (4.6). 


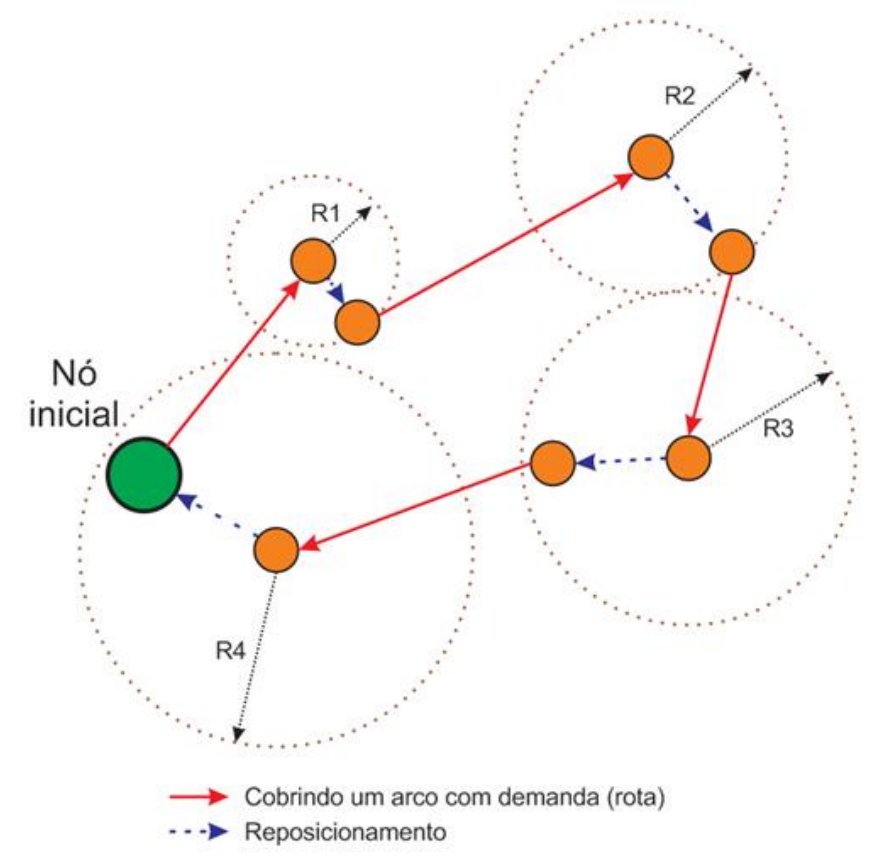

Figura 4.6: Raios de Investimento.

Pensando nos custos referência de operação (Custo Core, Custo C1 e Custo C0), chega-se a conclusão que a solução ótima estaria entre o mínimo entre Custo C0 (operação somente com caminhos C0) e Custo C1 (operação somente com caminhos C1) e acima do Custo Core, como representado na Fig. (4.7). Dessa forma tem-se uma noção dos limites superior e inferior para operar a rede, onde será encontrado o custo otimizado. Seguindo na estratégia de reduzir a quantidade de caminhos e olhando para a composição de custos, estabeleceram-se algumas estratégias de construção de caminhos: Raio Fixo, Raio Variável e Raio Misto. O Raio Fixo olha para o Custo de Operação C0 e utiliza como premissa a composição do Custo C0 (Custo Core e Custo Adicional Fixo) limitando o custo adicional, e isso restringe a quantidade de caminhos gerados. O Raio Variável tenta reduzir a "miopia" do Raio Fixo, olhando para o custo adicional como um percentual máximo do Custo Core e isso permite ser menos restritivo na geração de caminhos maiores, no entanto os menores ficam prejudicados (custo core muito baixo). A estratégia de Raio Misto consegue ser menos restritiva para caminhos menores (herança da estratégia de Raio Fixo) e menos restritiva para caminhos maiores (herança da estratégia de Raio Variável), no entanto por ser menos restritiva nas duas situações acaba gerando mais caminhos e assim permitindo maior complexidade computacional. 


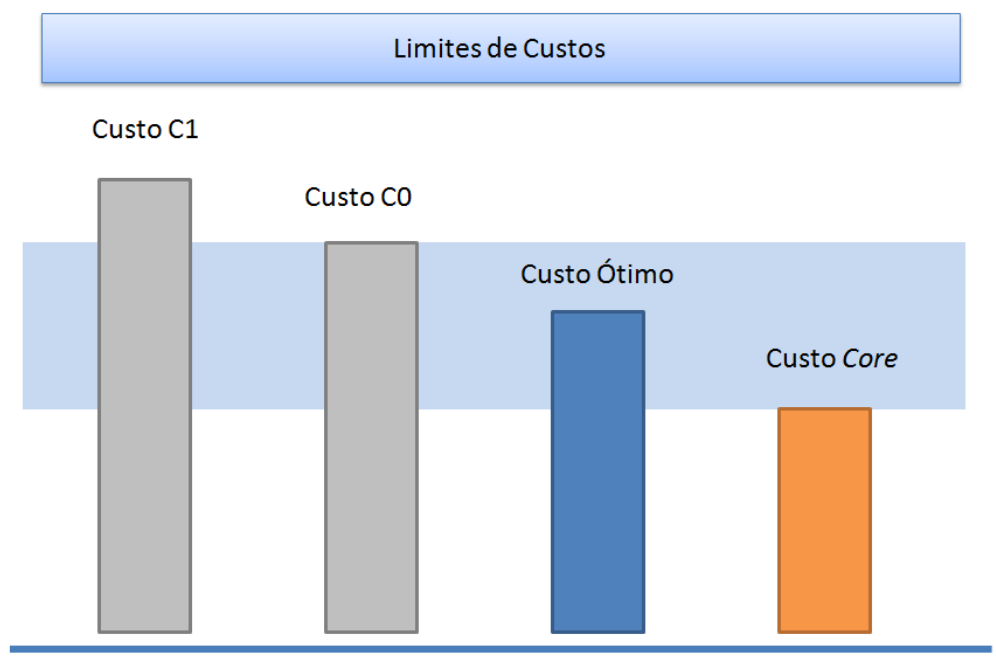

Figura 4.7: Custos referência de operação.

Este raio pode ser calculado de três maneiras, de acordo com a configuração desejada:

\section{Raio de Investimento Variável}

O raio de investimento variável é calculado de acordo com o Custo Core do caminho acumulado até o momento, e é baseado no percentual (p) do Custo Core que se deseja investir, conforme a Eq. (4.6). Durante a construção do ciclo são realizados deslocamentos de reposicionamento e parte do investimento é gasto com isso, por isso a parcela é subtraída do investimento $\left(\right.$ Investimento $\left.=C_{\text {core }} \cdot p\right)$, reduzindo o raio de busca na ponta. É importante ressaltar que o custo core $\left(C_{\text {core }}\right)$ considerado no cálculo é o custo associado ao caminho base, não ao ciclo final.

$$
r_{\text {variavel }}=\frac{C_{\text {core }} \cdot p-C_{\text {adicional }}}{C_{V}+\frac{C_{F}}{V_{m}}}
$$

O raio de investimento cresce proporcionalmente à distância percorrida com o veículo carregado (distância produtiva) e decresce de acordo com a distância percorrida com o veículo descarregado (distância de reposicionamento), conforme exemplo ilustrativo na Fig. (4.8) . Note que os tempos de carga e descarga contribuem para o incremento do raio, pois também contribuem para o custo core. 

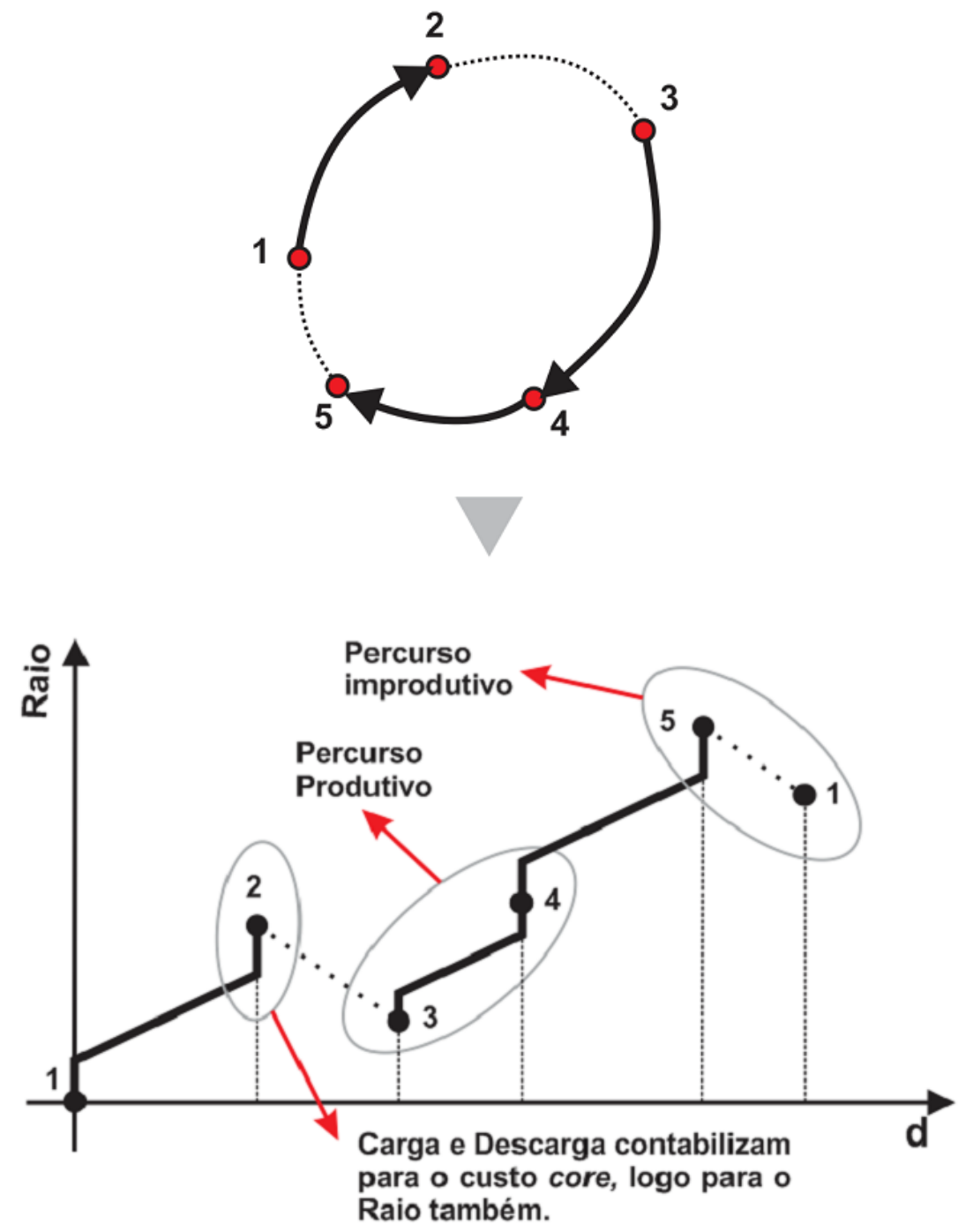

Figura 4.8: Exemplo de Ciclo e Gráfico de Raio de Investimento no decorrer do percurso.

\section{Raio de Investimento Fixo}

O raio de investimento fixo é calculado a partir do tempo de espera por uma nova carga numa contratação spot e está associado à decisão entre frota dedicada ou contratação spot, conforme explicado na seção 3.2. Este raio é calculado de acordo com a Eq. (4.7). Como o tempo médio de espera por uma nova carga $T_{S}$ é uma constante para a modelagem adotada, o raio é uma constante, como pode ser visto no gráfico da Fig. (4.9) .

$$
r_{f i x o}=\frac{C_{F} \cdot T_{S}}{C_{V}+\frac{C_{F}}{V_{m}}}
$$




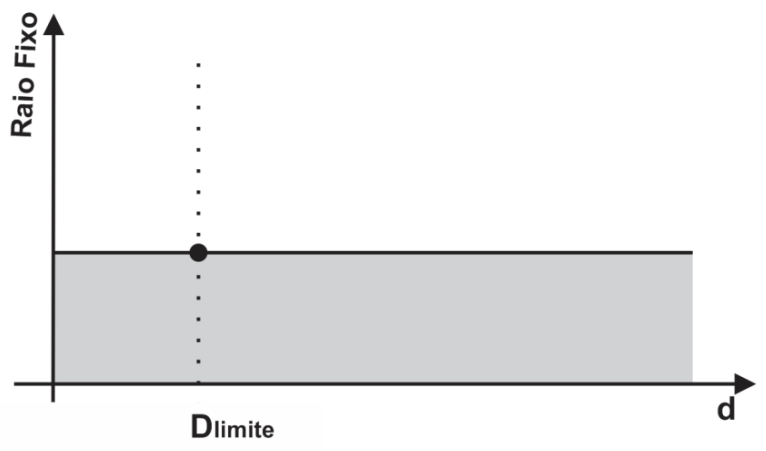

Figura 4.9: Gráfico de Raio de Investimento em relação a distância percorrida.

\section{Raio de Investimento Misto}

Para eliminar possíveis "miopias" da heurística, pode-se utilizar o raio de investimento misto, onde o raio calculado é o máximo entre os dois raios anteriores, conforme a Eq. (4.8).

$$
r_{\text {misto }}=\max \left(r_{\text {variavel }}, r_{\text {fixo }}\right)
$$

Pode ser visto na Fig. (4.10), para caminhos com distância percorrida muito curta o raio variável seria muito restritivo e deixaria de inserir nos caminhos candidatos economicamente viáveis como os ciclos $\mathrm{C} 1$, por exemplo. Por outro lado, os caminhos com distância percorrida muito longa, acima de $D_{\text {lim }}$, seriam penalizados com uma estratégia de raio fixo. 


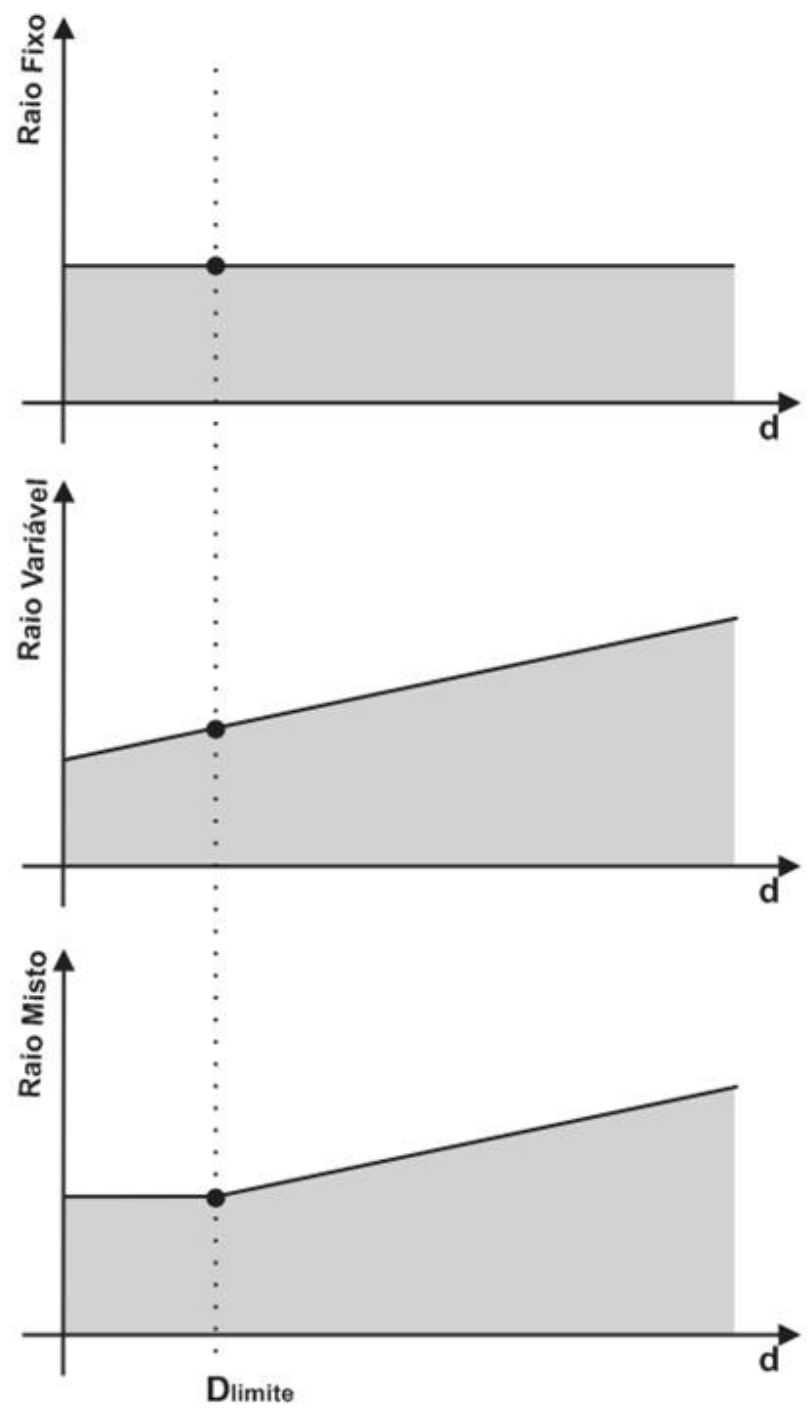

Figura 4.10: Gráfico simplificado de Raio de Investimento Misto.

O raio de investimento misto não serve somente para reduzir as miopias da heurística, serve também para inserir na estratégia de operação da rede a possibilidade de terceirizar parte das demandas através de contratações spot, dado que essa abordagem tem um pouco dos dois mundos. É importante ressaltar que essa abordagem ser menos restritiva que a fixa ou a variável individualmente, ela acaba gerando mais caminhos e consequentemente aumentando o custo computacional da solução.

\subsubsection{Algoritmo Paralelo de Geração de Caminhos}

O algoritmo de geração é baseado em dois algoritmos, um que inicia o processo de busca nos Nós (Fig. (4.11)) e o outro que propaga a busca (Fig. (4.12)), de acordo com o critério do raio de investimento. 


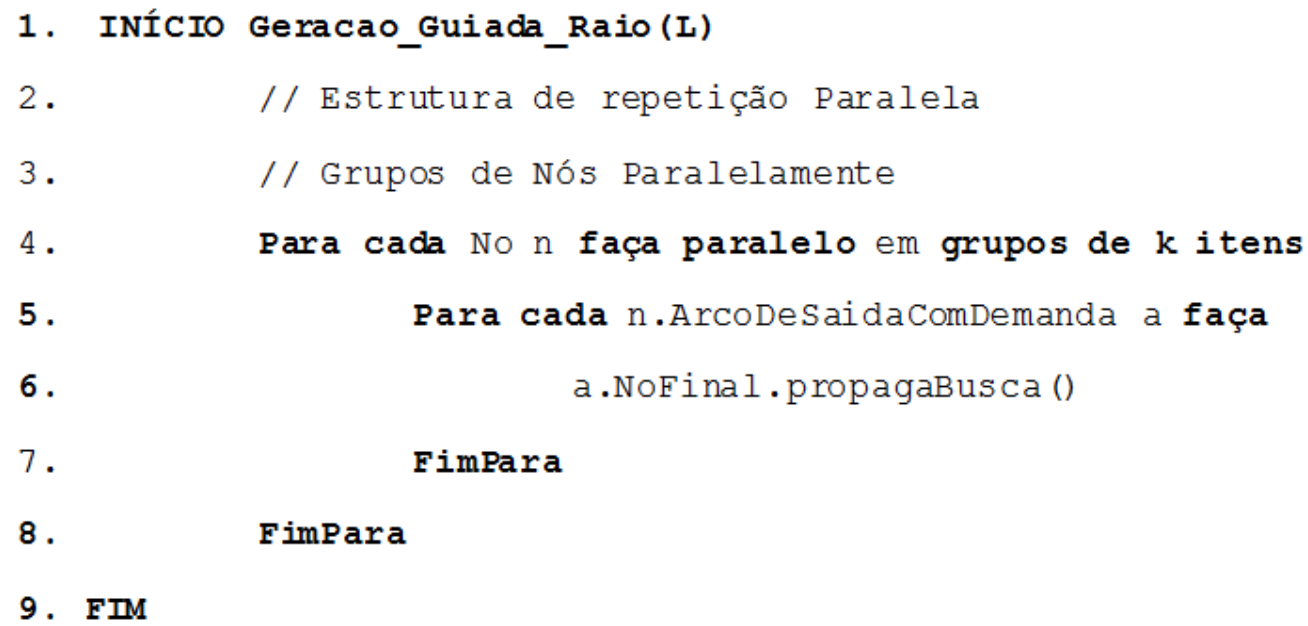

Figura 4.11: Algoritmo 2 - Algoritmo para Geração Paralela de Caminhos Guiado pela Raio de Investimento.

Dado que a informação das demandas e configuração da rede não se altera durante a execução do algoritmo e que cada Nó busca independentemente de outro Nó, o algoritmo de busca pode ser paralelizado por Nó, ou seja, cada Nó se torna um agente independente de busca, podendo estes agentes rodar em threads distintas, processos distintos ou até mesmo computadores distintos, desde que todos os agentes tenham conhecimento prévio das configurações da rede e das demandas associadas.

A estratégia de paralelização adotada neste trabalho paraleliza o processamento por Nó inicial através de múltiplas Threads, de acordo com o limite de cada processador, seguindo o padrão de projeto Loop Parallelism Pattern de ${ }^{[30]}$. 


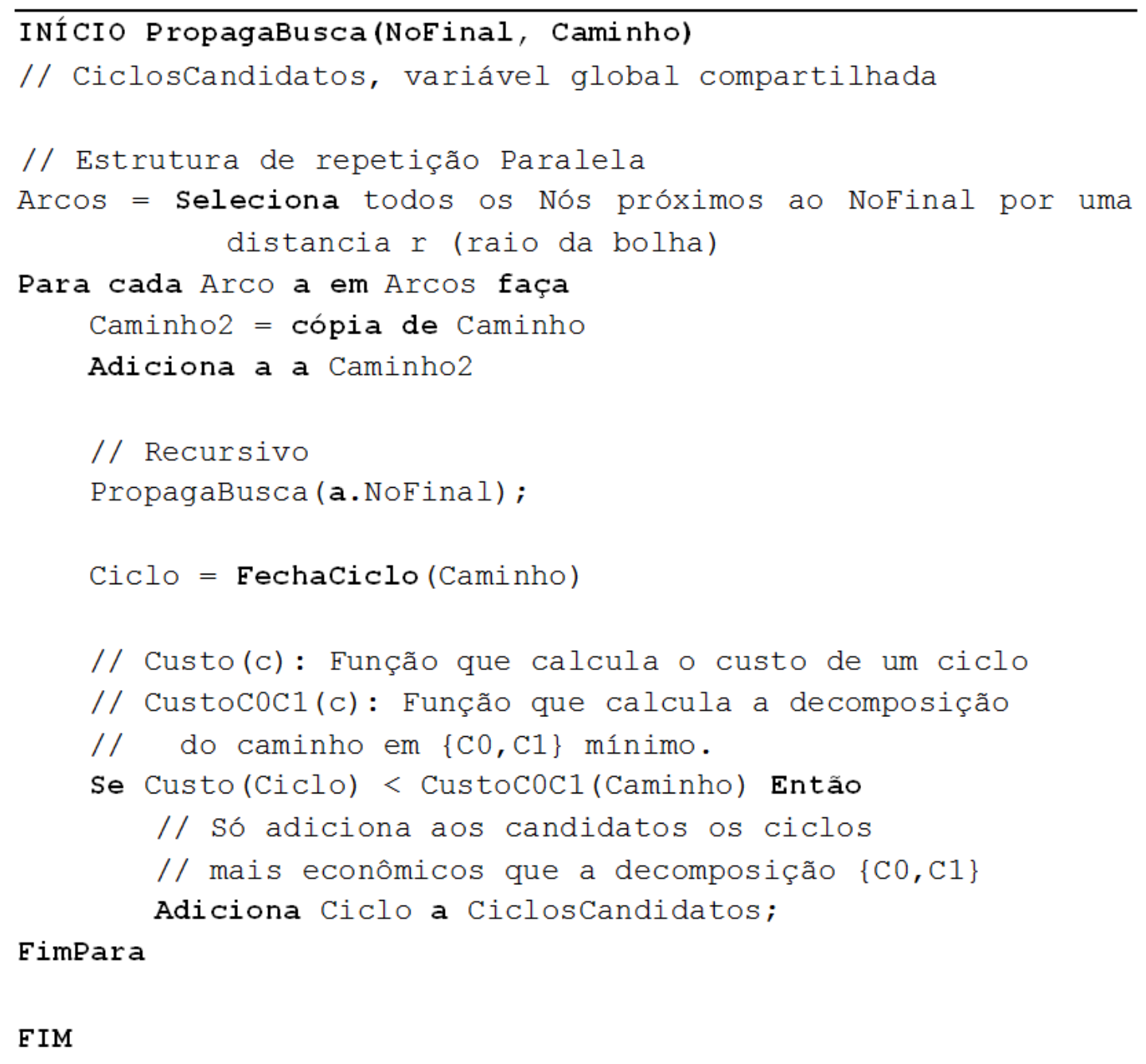

Figura 4.12: Algoritmo 3 - Algoritmo de Propagação da Busca nos Nós.

No Algoritmo 2 (Fig. (4.11)), para cada Nó inicia-se uma propagação pelos arcos sucessores através da execução do Algoritmo 3 (Fig. (4.12)). Essa propagação é paralelizada em $k$ grupos, onde para $k>1$ temos paralelização e para $k=1$ temos a execução serial das propagações, conforme ilustrado na Fig. (4.13) (onde $A_{i}$ é uma propagação).

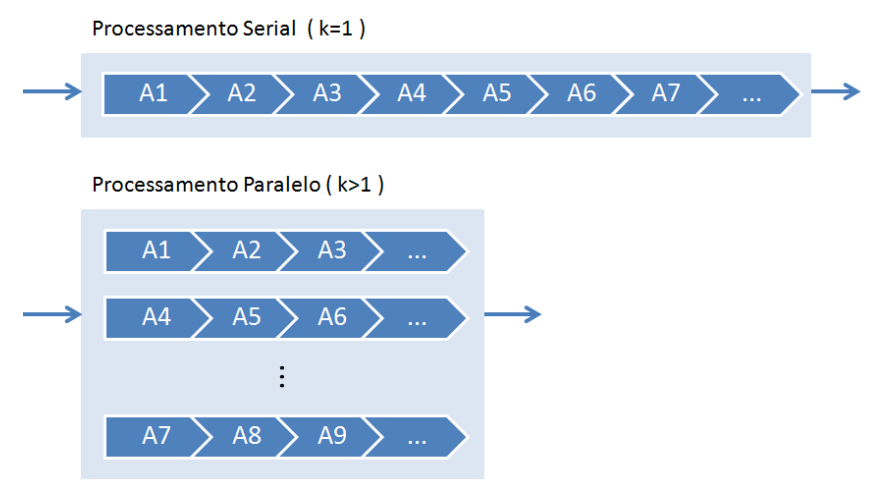

Figura 4.13: Paralelização do Loop de Propagação de Busca (Algoritmo 3). 


\subsection{Solver: Heurística de Priorização de Cami- nhos}

A heurística de solução do problema proposto é uma heurística de priorização assim como as heurísticas propostas em ${ }^{[26]} \mathrm{e}^{[22]}$. No entanto, por se tratar de um problema com demandas não-unitárias, o critério de priorização por tamanho do caminho $\left({ }^{[26]} \mathrm{e}^{[22]}\right)$ não é o critério apropriado, pois é necessário considerar quantas vezes esse caminho precisa se repetir para atender as demandas e também levar em consideração quão econômico é o caminho. Por fim, tanto nas heurísticas para demandas unitárias quanto para as de demandas não unitárias fala-se de um critério de priorização por "energia" (economia, custo ou distância) gasta para atender a demanda de certo arco. O solver proposto, que será chamado doravante de Heurística Solver por Priorização de Caminhos (HSPC), utiliza mais de um critério de priorização, detalhados a seguir.

As heurísticas de priorização podem ser generalizadas em 4 passos, conforme Fig. (4.14).

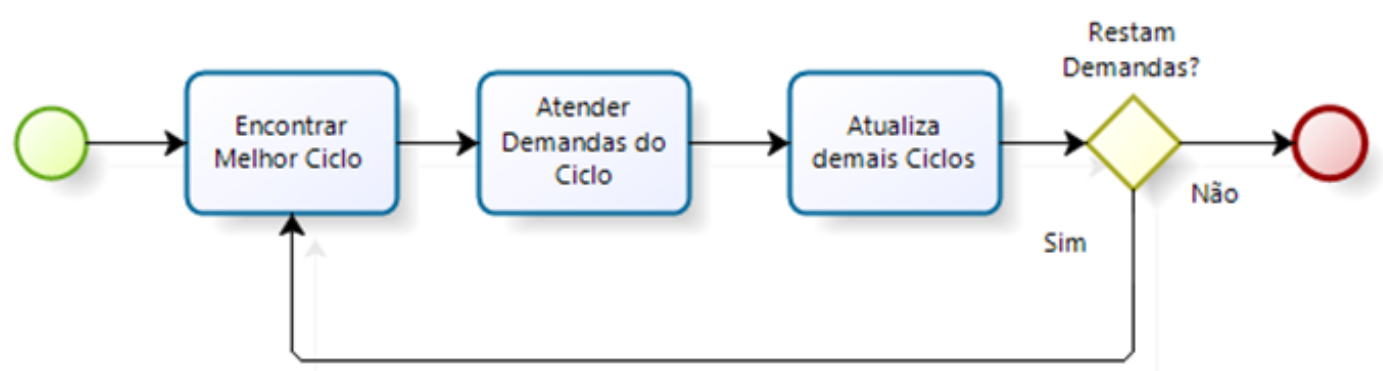

Figura 4.14: Heurística de Priorização de Ciclos.

1. Encontra o melhor ciclo, de acordo com o critério de priorização.

2. Atender a demanda máxima do ciclo encontrado.

Demanda Máxima: menor demanda de arco no caminho. Exemplo ilustrado na Fig. (4.15).

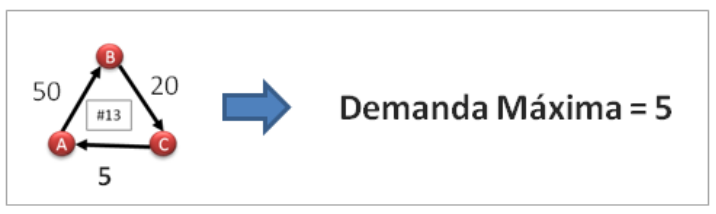

Figura 4.15: Demanda Máxima.

3. Atualizar os demais ciclos e exclui os ciclos cujas demandas de algum arco foram totalmente atendidas. 
4. Repetir o passo 1 até não haver mais demandas a serem atendidas.

Conforme adiantado na introdução da seção 4, existem três estratégias de priorização de caminhos, associadas ao tipo de caminho gerado na etapa:

1. Gerador de Ciclos Perfeitos: Priorização por Dimensionamento de Frota

2. Gerador de Ciclos com Reposicionamento: Priorização por Eficiência do Ciclo

3. Gerador de Ciclos Complementares: Priorização por Melhor Custo

Em suma, todos os critérios de priorização da heurística proposta terão como objetivo principal reduzir o Custo Adicional ao Custo Core (da rede), seja escolhendo entre os Circuitos Perfeitos os maiores em dimensionamento de frota, seja escolhendo os mais eficientes entre os Ciclos Com Reposicionamentos, seja escolhendo os melhores em custo entre C0 e C1 para os Caminhos Complementares.

As três estratégias de priorização serão descritas a seguir.

\subsubsection{Priorização por Dimensionamento de Frota}

A estratégia de Priorização por Dimensionamento de Frota está associada a etapa de Circuitos Perfeitos e visa alocar o maior número possível de veículos aos caminhos mais econômicos (os circuitos perfeitos, onde o $C_{\text {adicional }}=0$ ).

Se tratando de demandas não unitárias e circuitos perfeitos, a priorização por número de veículos é um critério melhor que o critério de priorização pelo tamanho do caminho, proposto em ${ }^{[26]}$, pois, por exemplo, um caminho muito curto, mas com muitas demandas e com um potencial maior de agregar economia à solução final seria despriorizado frente a um caminho longo, com poucas demandas e com baixo potencial de agregar economia a solução final.

Existem várias maneiras de dimensionar a frota para um determinado ciclo, mas para simplificar optou-se por partir do conceito de tempo de ciclo e quantidade de ciclos mensal, descritos a seguir.

\subsubsection{Dimensionamento de Frota}

Para determinar o tamanho ideal da frota para atender um ciclo, adaptado de ${ }^{[11]}$, primeiro determina-se o tempo de ciclo: 


$$
\begin{gathered}
T_{\text {ciclo }}=T_{\text {viagem }}+k \cdot\left(T_{L}+T_{U}\right) \\
T_{\text {viagem }}=\sum \frac{\Delta_{i}}{V_{m}}
\end{gathered}
$$

De Eq. (4.9) e Eq. (4.10):

$$
\begin{gathered}
T_{\text {ciclo }}=\sum \frac{\Delta_{i}}{V_{m}}+k \cdot\left(T_{L}+T_{U}\right) \\
T_{\text {total }}=T_{\text {ciclo }} \cdot D \\
T_{\text {utilmensal }}=T_{\text {utildia }} \cdot D
\end{gathered}
$$

De Eq. (4.12) e Eq. (4.13):

$$
Q=\frac{T_{\text {total }}}{T_{\text {utilmensal }}}
$$

Onde:

- $T_{\text {total }}$ : Tempo total para atender todas as demandas de um ciclo

- $T_{\text {ciclo }}$ : Tempo para atender uma demanda do ciclo

- $T_{\text {viagem }}$ Tempo de viagem (em deslocamento)

- $T_{L}$ :Tempo de carga

- $T_{U}:$ Tempo de descarga

- D: Quantidade de demandas do ciclo (numericamente igual a menor demanda dos arcos com demanda)

- $k$ :Quantidade de cargas

- $V_{m}$ :Velocidade Média do Veículo

- $\Delta_{i}$ :Comprimento do Arco

- $T_{\text {utildia: }}$ Tempo útil diário (ex.: 8 horas)

- $N_{\text {dias }}$ :Número de dias úteis em um mês (ex.: 22 dias) 
- Q:Quantidade de veículos necessários para atender as demandas do ciclo

Calculada a quantidade de veículos para atender o caminho em um mês (Q), basta escolher o maior Q e atender suas demandas (demanda máxima do ciclo). Em seguida atualiza-se as demandas máximas dos demais ciclos, reordena-se e escolhe novamente o maior $\mathrm{Q}$, e assim vai recorrentemente até não sobrar ciclos com demanda máxima, conforme ilustrado na Fig. (4.16) .

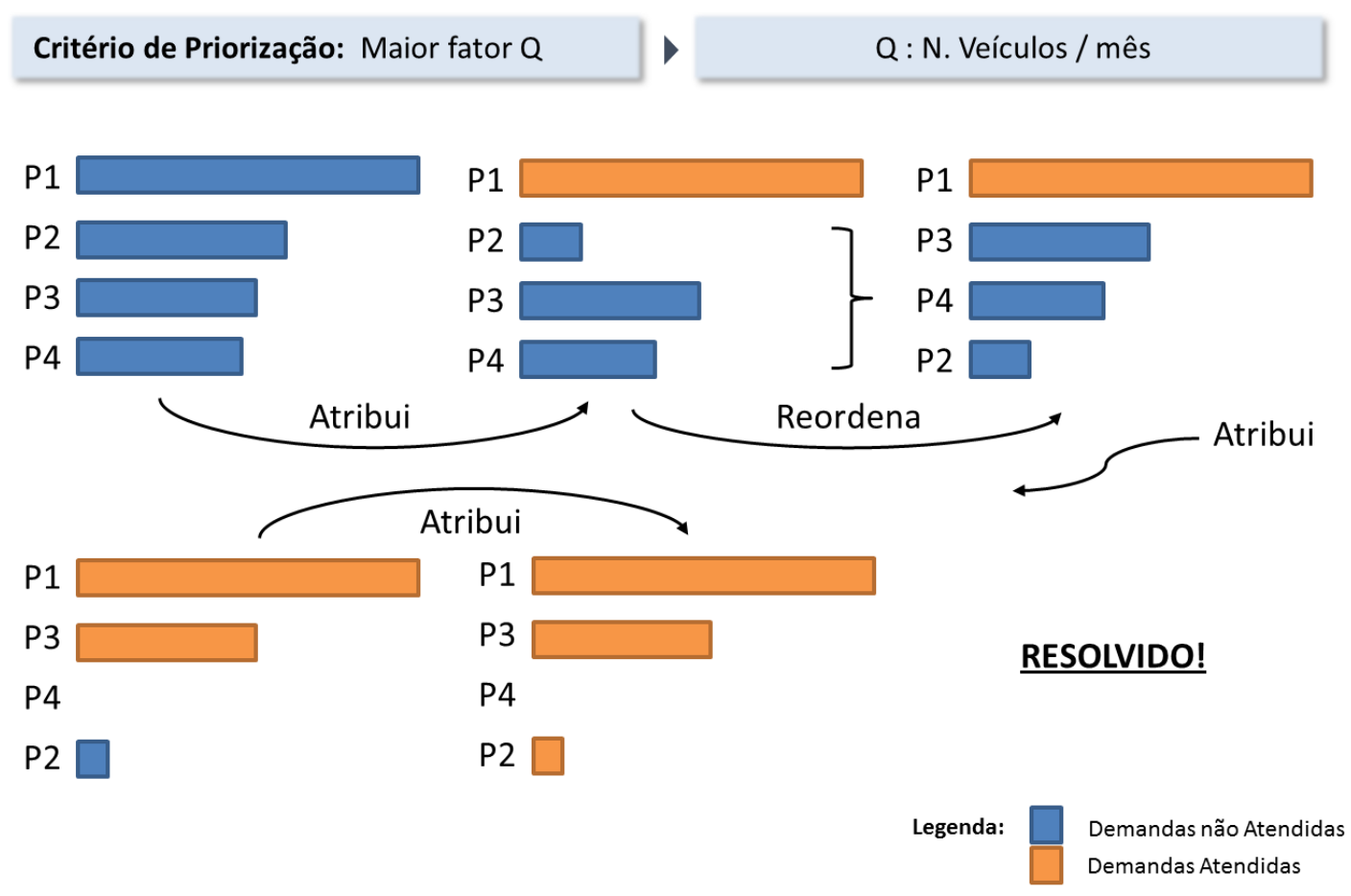

Figura 4.16: Heurística de Priorização de Ciclos.

\subsubsection{Priorização por Eficiência do Ciclo}

Dado que os Circuitos com Reposicionamentos adicionam custos improdutivos (reposicionamentos) ao custo do ciclo (ou seja, $C_{\text {adicional }>0}$ ), introduzimos nesta seção o conceito de eficiência em Eq. (4.15). Dessa forma, mantendo o objetivo principal de reduzir o custo adicional $\left(C_{\text {adicional }}\right)$ da rede, a estratégia adotada nesta etapa é atender primeiro as demandas através dos ciclos mais eficientes, dando origem assim ao critério de priorização desta etapa, a priorização por eficiência do ciclo.

$$
e=\frac{C_{\text {core }}}{C_{\text {total }}}<1
$$

Seguindo o fluxo de priorização da Fig. (4.14), o melhor ciclo é o ciclo de maior eficiência $(e)$ e os demais passos são idênticos. 


\subsubsection{Priorização por Melhor Custo}

Nesta etapa são tratadas demandas individuais que sobraram das etapas anteriores. Serão gerados somente caminhos C0 (rotas spot) e C1 (ciclo com retorno vazio), ou seja, não são geradas combinações de demandas. Dessa forma o priorizador apenas compara o custo de atender a demanda por $\mathrm{C} 0$ ou $\mathrm{C} 1$, priorizando o de menor custo.

Uma forma imediata de comparar custos entre C0 e C1 é comparar a distância (entre origem e destino da demanda) com a distância limite $\left(D_{\text {limite }}\right)$, estudada na seção 4.2.2.

Racional descrito abaixo:

- Se Distância $\geq D_{\text {limite }} \Longrightarrow$ escolhe $\mathrm{C} 0$

- Se Distância $<D_{\text {limite }} \Longrightarrow$ escolhe $\mathrm{C} 1$

\subsection{Comparação entre Abordagens}

É possível dividir os trabalhos em dois grandes grupos de acordo com a modelagem de custos: abordagens somente com custos variáveis, ${ }^{[20]} \mathrm{e}{ }^{[26]}$; abordagens com custos fixos e variáveis, ${ }^{[11]}$ e este trabalho. As abordagens que consideram custos fixos e variáveis são mais próximas dos problemas encontrados nas empresas. 
Tabela 4.1: Comparação entre Abordagens.

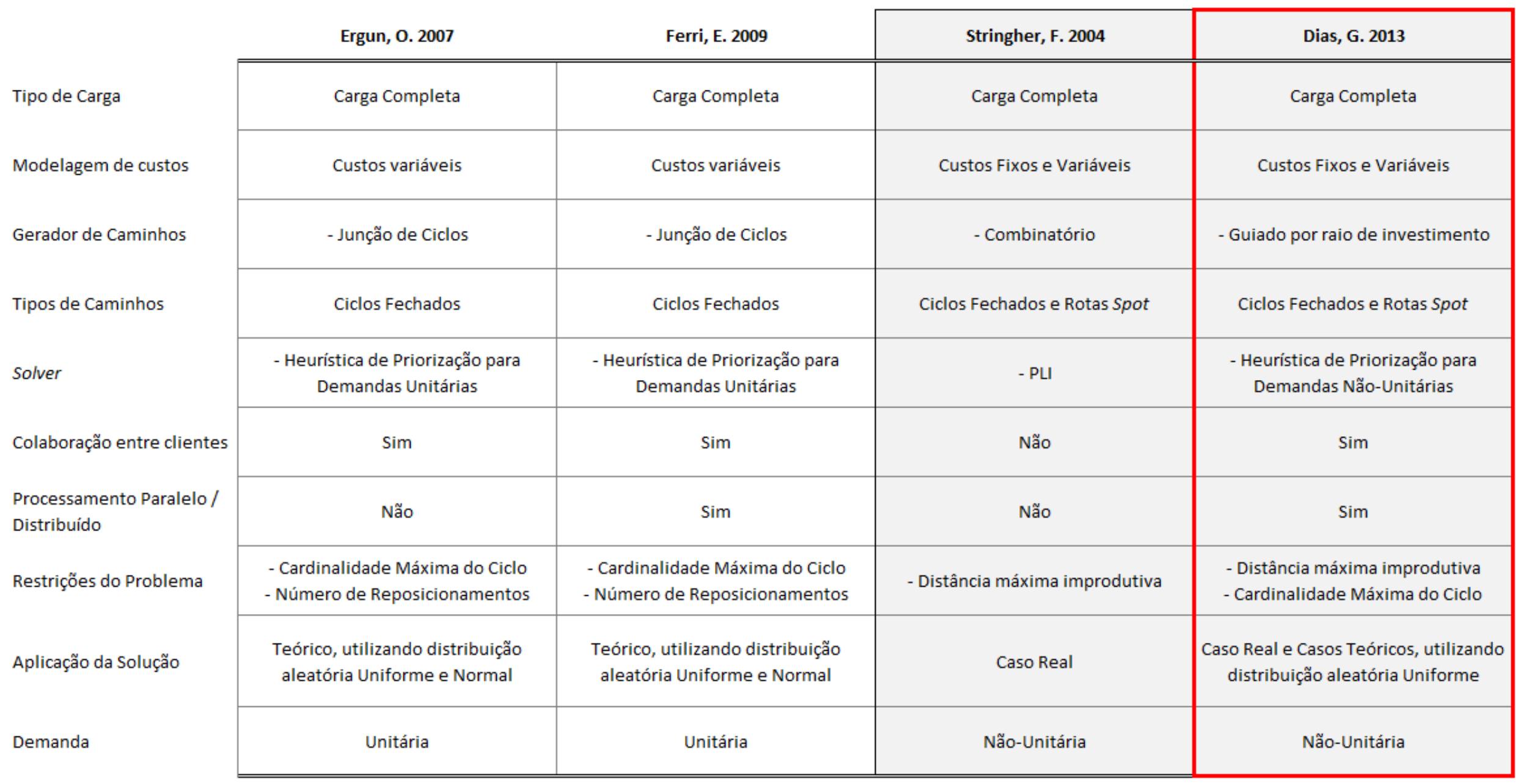


Outra grande diferença entre as abordagens é a forma como são gerados os caminhos (variáveis de decisão), isso impacta diretamente no desempenho do algoritmo. São dois grupos para essa característica: gerador combinatório (em $\left.{ }^{[11]}\right)$, ou heurísticas $\left({ }^{[20]},{ }^{[26]}\right.$ e neste trabalho).

Existem basicamente duas maneiras de achar a solução que minimiza os custos de operação da rede: Solver PLI (Programação Linear Inteira) e Solvers Heurísticos baseados em priorização de ciclos, aos quais este trabalho pertence. Um ponto importante é que as heurísticas não garantem a solução mínima, mas sim uma aproximação, no entanto com um melhor desempenho computacional.

As características das demandas também subdividem os grupos: grupo com demandas unitárias ${ }^{[20,26]}$ e grupo com demandas não unitárias (neste trabalho e $\left.{ }^{[11]}\right)$. Essa característica torna o grupo com demandas não-unitárias mais próximo dos problemas reais, onde através de logística colaborativa ou mesmo sinergia de operação dentro da própria empresa as demandas dos arcos não são idênticas.

Dadas as características gerais, do ponto de vista de modelagem, a proposta se aproxima de ${ }^{[11]}$, por outro lado, do ponto de vista de solução do problema a proposta se aproxima de ${ }^{[20]} \mathrm{e}^{[26]}$.

\subsection{Aplicações Relevantes para a Proposta}

Dados a modelagem de custos, a utilização de rotas spot e a capacidade de resolver problemas de grande escala, a proposta pode ser utilizada como ferramenta de decisão e otimização para problemas da vida real. Pensando nessas aplicações, mas sem perder o foco principal do trabalho, serão dados alguns casos de uso aderentes ao modelo para o melhor entendimento da proposta e também para estimular trabalhos futuros:

- Logística Colaborativa: Planejamento de Demandas e Planejamento Tático em conjunto entre embarcadores para encontrar sinergias e conseguir economias. Para ver detalhes deste caso de uso vide o Apêndice A Aplicação da Proposta ao Transporte Colaborativa.

- Decisão entre Terceirizar ou Dedicar Frota: Olhando somente para a própria rede e seu respectivo custo, muitas vezes a decisão é entre dedicar e manter uma frota para atender ou contratar demanda a demanda o frete.

- Caso de Escala Maior com Dados Reais: Pensando em um caso de 
aplicação real, de grande escala e de grande relevância para a economia, foi elaborado neste trabalho um modelo simplificado das movimentações de cargas no Brasil usando como base as tabelas da FIPE/IDET. Para ver detalhes deste caso de uso vide o Apêndice B - Aplicação da Proposta à Modelo com Dados FIPE/IDET. 


\section{Resultados Experimentais e Discussões}

Este capítulo apresenta os resultados e procedimentos experimentais para análise da heurística desenvolvida.

A heurística do Gerador proposta (HGCGRI), a heurística Solver proposta (HSPC) e demais Geradores e Solvers foram implementados em linguagem C\# e compilador Visual Studio 2010, utilizando a biblioteca Microsoft Solver Foundation para resolver o PLI.

Serão feitas análises de desempenho (tempo de execução) e também análises de qualidade (ligadas às soluções encontradas). Para as análises de qualidade, a referência principal será a solução encontrada pelo Gerador Combinatório com o Solver PLI.

Para processar as instâncias e chegar aos resultados que serão analisados neste capítulo foi utilizado um computador com dois processadores Intel Xeon Hexa Core de $2.4 \mathrm{GHz}$ e 48GB de memória RAM.

\subsection{Gerador de Instâncias}

Assim como em ${ }^{[22]} \mathrm{e}^{[26]}$, neste trabalho foi desenvolvido e utilizado um gerador de instâncias, que serve para criar problemas através de distribuições aleatórias para testar as heurísticas propostas.

Particularmente o gerador de instâncias desse trabalho utilizou distribuição uniforme para obter as coordenadas dos vértices e também distribuição uniforme para definir as demandas dos arcos, o que nos trabalhos de demandas unitárias referenciados não foi utilizado. Os parâmetros de entrada para o gerador são:

- Quantidade de Nós (N).

- Quantidade de $\operatorname{Arcos}(\mathrm{A})$. 
- Distância máxima da origem (D), o que nos gera um quadrado de 2.D por 2D de dimensões.

- Tipo de Coordenadas: Cartesianas ou Geográficas.

A Fig. (5.1) mostra a tela do gerador de instâncias com um exemplo de instância com 500 nós, 500 arcos com demandas e distância de 1000 km. A flecha em azul é a representação de um arco e o polígono em vermelho e cinza é a representação de um ciclo com três arcos com demandas e um arco sem demanda, portanto um ciclo de cardinalidade quatro.

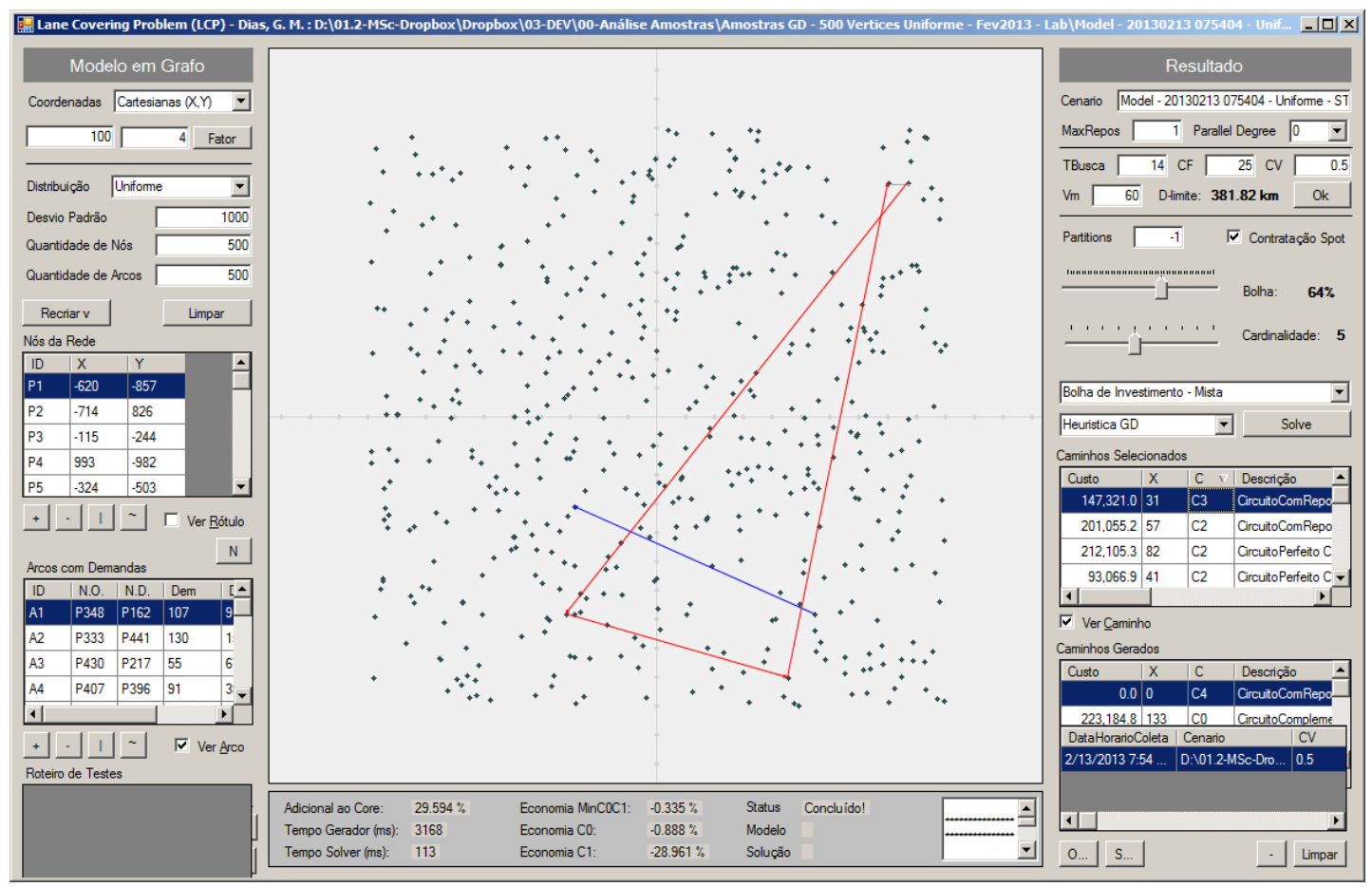

Figura 5.1: Tela do Gerador de Instâncias.

\subsection{Parâmetros de Custo e Operação}

Para calcular os custos de operação das amostras, foram utilizados parâmetros de custos $C_{V}=25 R \$ / \mathrm{km}, C_{F}=0,5 R \$ / \mathrm{h}$ e $V_{m}=60 \mathrm{~km} / \mathrm{h}$. Os tempos de carga, descarga e tempo de espera adotados são, respectivamente: 4h, 4h, e 14h. Disso, utilizando a distância limite, calculada pela Eq. (4.3), é de $381 \mathrm{~km}$.

Partindo da premissa que o maior custo possível para uma operação seja operar com circuitos $\mathrm{C} 1$, é possível calcular um investimento máximo que contempla todos os circuitos $\mathrm{C} 1$ e balizar o parâmetro "p" máximo útil para a busca de raio variável.

Para um arco, o raio variável é dado por: 


$$
\begin{gathered}
r_{\text {variavel }}=\frac{C_{\text {core }} \cdot p}{C_{V}+\frac{C_{F}}{V_{m}}} \\
r_{\text {variavel }}=\frac{\left(D \cdot C_{V}+T_{L} \cdot C_{F}+T_{I J} \cdot C_{F}+\frac{D}{V_{m}}\right) \cdot p}{C_{V}+\frac{C_{F}}{V_{m}}}
\end{gathered}
$$

Dado que o Raio da Investimento Variável deve ser igual a distância de retorno para contemplar $\mathrm{C} 1$ :

$$
r_{\text {variavel }}=D
$$

De Eq. (5.1) e Eq. (5.2), isolando o "p":

$$
p=\frac{\left(C_{V}+\frac{C_{F}}{V_{m}}\right) \cdot D}{D \cdot C_{V}+\left(T_{L}+T_{I J}+\frac{D}{V_{m}}\right) \cdot C_{F}}
$$

Para os parâmetros citados calcula-se $\mathrm{p}=64 \%$, e será utilizado nos testes com Raio de Investimento Misto.

\subsection{Instâncias, Configurações e Linhas de Análise}

Foram geradas aleatóriamente 30 instâncias (5 conjuntos de 6 instâncias), onde foi escolhido aleatóriamente um conjunto com 6 instâncias conforme Fig. (5.2). Esse conjunto escolhido de instâncias foi dividido em dois grupos (Grupo 1 e Grupo 2) devido as características de complexidade computacional observadas no experimento.

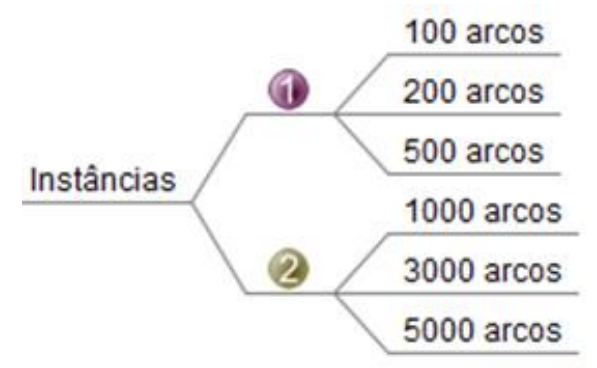

Figura 5.2: Instâncias de Teste.

Antes de executar as heurísticas, levando em consideração os coeficientes de custo, é possível determinar os custos, na Tab. (5.1) , para as amostras escolhidas: Custo Core, Custo C0, Custo C1 e Custo Mínimo entre C0 e C1. Essas 
informações independem do algoritmo Gerador e Solver, portanto podem ser previstas e servem como referência para comparar com as soluções encontradas.

Tabela 5.1: Custos Referência para as Amostras.

\begin{tabular}{|l|r|r|r|r|r|r|}
\hline Instância & 100 & 200 & 500 & 1000 & 3000 & 5000 \\
\hline Custo Core & $12.255 .975,60$ & $24.716 .136,91$ & $59.565 .730,93$ & $122.807 .936,75$ & $371.969 .207,71$ & $633.315 .532,16$ \\
\hline Custo C1 & $22.317 .151,20$ & $45.261 .473,82$ & $108.301 .661,86$ & $224.039 .273,50$ & $678.563 .815,42$ & $1.156 .848 .664,31$ \\
\hline Custo C0 & $16.096 .875,60$ & $32.015 .036,91$ & $78.517 .880,93$ & $160.566 .986,75$ & $486.374 .757,71$ & $825.434 .732,16$ \\
\hline Custo Combinado C1C0 & $16.035 .130,45$ & $31.803 .827,02$ & $77.825 .996,57$ & $159.119 .956,17$ & $482.687 .773,80$ & $818.953 .368,93$ \\
\hline Adicional C1 & $82,1 \%$ & $83,1 \%$ & $81,8 \%$ & $82,4 \%$ & $82,4 \%$ & $82,7 \%$ \\
\hline Adicional C0 & $31,3 \%$ & $29,5 \%$ & $31,8 \%$ & $30,7 \%$ & $30,8 \%$ & $30,3 \%$ \\
\hline Adicional MinCOC1 & $30,8 \%$ & $28,7 \%$ & $30,7 \%$ & $29,6 \%$ & $29,8 \%$ & $29,3 \%$ \\
\hline
\end{tabular}

Analisando os custos de operação das redes das amostras na Tab. (5.1), é possível inferir um potencial de economia para operação dedicada (Custo C1) de em média $80 \%$, e substituindo uma operação totalmente feita por contratações Spot de terceiros (Custo C0) um potencial de economia de 30\%. Todas as instâncias geradas possuíam uma distribuição uniforme de 500 nós em um retângulo de $2000 \mathrm{~km}$ por $2000 \mathrm{~km}$ no plano XY, conforme Fig. (5.3).

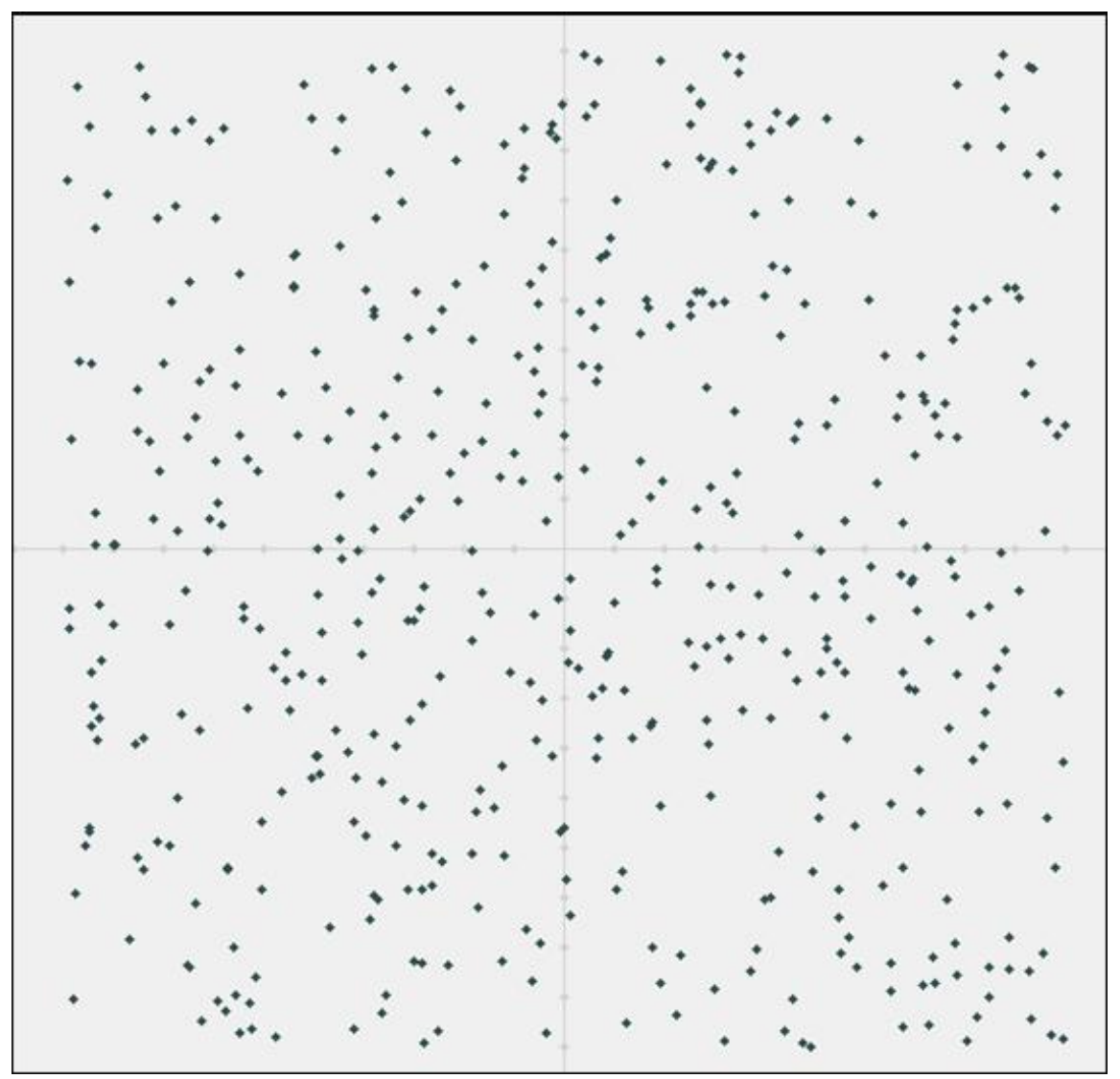

Figura 5.3: Distribuição Uniforme de 500 Nós.

Dadas as características citadas das amostras, foi elaborada uma bateria de testes levando em consideração os parâmetros de configuração do modelo, visando 
analisar o desempenho da solução proposta. Conforme Fig. (5.4) , para análise foram escolhidos e variados os elementos das configuração de modelo: Gerador, Solver, cardinalidade, reposicionamentos e nível de paralelismo. As bolinhas com "1" e "2" na Fig. (5.4) representam respectivamente os Grupos 1 e 2 das amostras que serão testadas com cada configuração.

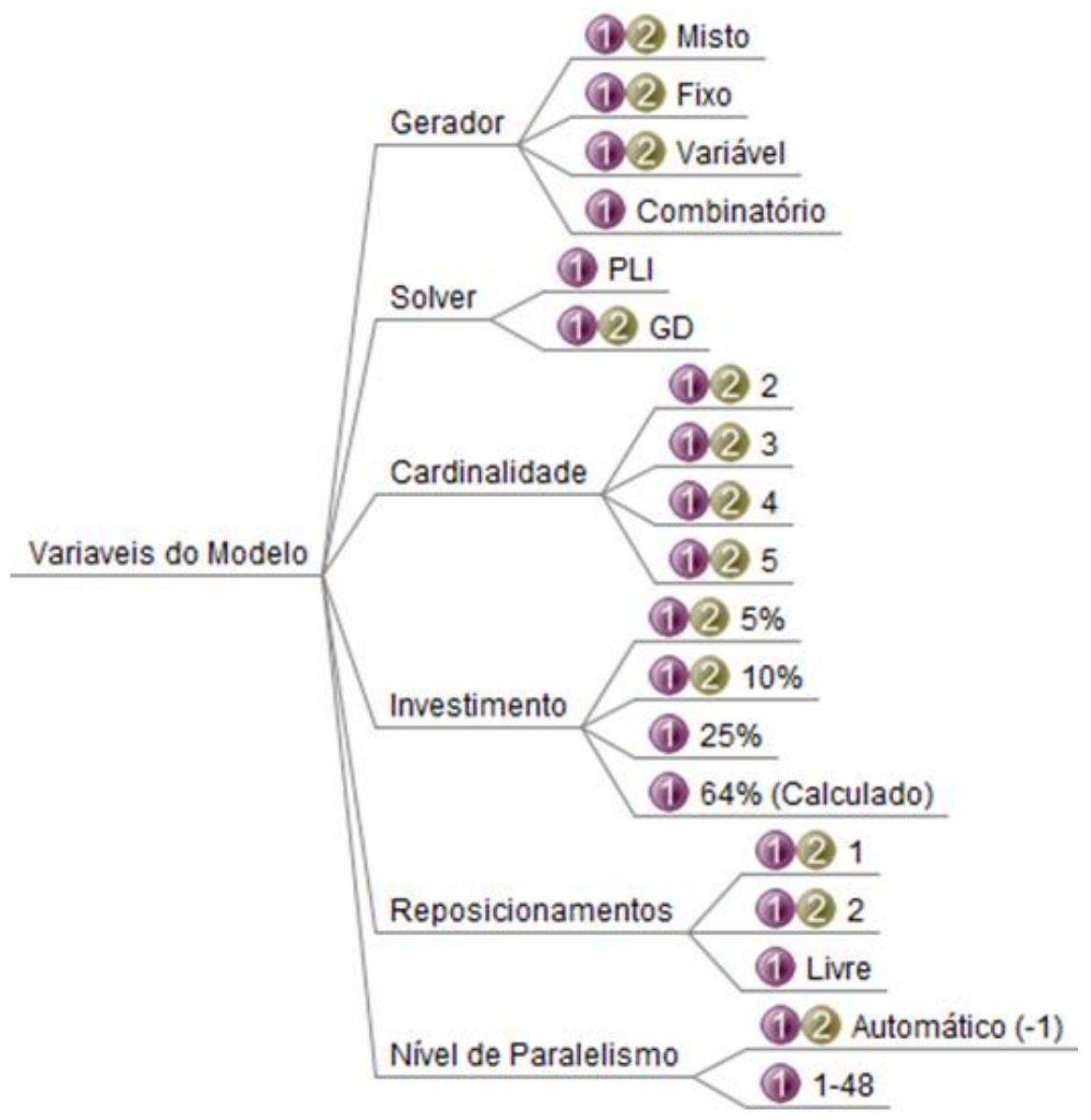

Figura 5.4: Variáveis do Modelo.

Realizados todos os testes, levando em consideração as variáveis do modelo, escolheu-se algumas linhas de análise, conforme Fig. (5.5), para comparar e descrever o funcionamento da proposta. Dentre as linhas de análise: o tempo de execução para chegar ao resultado é uma variável muito importante, pois pode inviabilizar a solução e por isso é foco neste trabalho uma heurística voltada a instâncias de grande escala; a quantidade de caminhos gerados, pois tem como resultado o tempo do gerador e impacta diretamente no tempo do solver; a qualidade da solução, pois para atingir maiores escalas a heurística deixa de encontrar a melhor solução para encontrar uma solução otimizada com melhor benefício tempo x economia. 


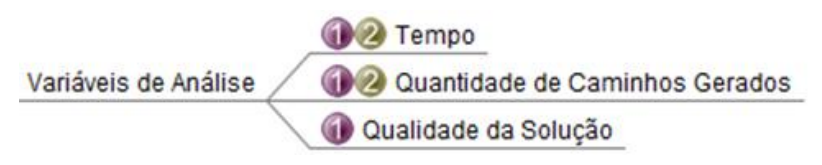

Figura 5.5: Linhas de Análise.

\subsection{Aplicação do Gerador de Caminhos}

O Gerador de caminhos tem um papel fundamental na solução, dado que ele determina quais caminhos vão concorrer para estar na solução final. O gerador de caminhos precisa ser assertivo ao criar os caminhos que serão variáveis de entrada para o solver, pois entregar todas as opções possíveis combinatoriamente ao solver é proibitivo, como será visto. Dessa forma, o trade-off do Gerador de Caminhos é gerar o menor número possível de caminhos sem impactar muito na economia do resultado final, ou seja, gerar somente os caminhos viáveis mais econômicos. A qualidade dos caminhos gerados (ou seja, avaliar o potencial de economia dos caminhos gerados) na seção 5.4.3.

Inicia-se pela análise da quantidade de caminhos gerados, em seguida a análise do tempo de execução e depois a análise da qualidade dos caminhos gerados. Diretamente relacionado ao tempo de execução do gerador e também do solver, está a quantidade de caminhos gerados, que será nossa primeira análise.

\subsubsection{Análise do Total de Ciclos Gerados}

Nesta seção será mostrada as quantidades de caminhos gerados em cada tipo de gerador. A quantidade de caminhos gerados é diretamente proporcional ao tempo que o solver vai levar para selecionar e atribuir demandas aos caminhos, pois cada caminho gerado é uma variável de decisão no solver. Essa quantidade também impacta o próprio gerador de caminhos, pois quanto mais caminhos mais tempo foi gasto para criá-los.

Não foi possível analisar o Gerador Combinatório para as instâncias escolhidas devido ao custo computacional, como vimos na seção 3.4.1 , para 100 demandas distintas esse gerador gera quase 80 milhões de caminhos e o custo computacional explode com isso. Durante a execução da instância de 100 arcos com demanda para cardinalidade máxima igual a 4, o processo não chegou a concluir, pois a quantidade de memória RAM excedeu os limites do computador, como pode ser visto na Fig. (5.6) a quandidade de memória requerida chegou perto dos 48 GB do computador. 


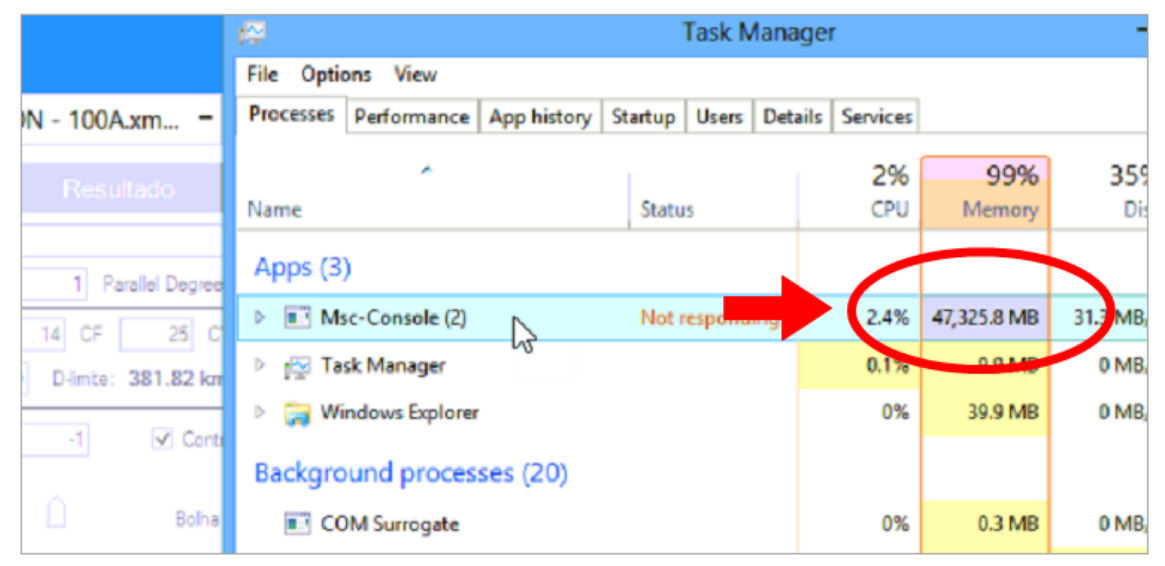

Figura 5.6: Monitoramento de Memória durante a Execução.

A seguir serão expostos todos os resultados dos geradores de caminhos executados sobre as seis amostras selecionadas para avaliar os algoritmos.

Como mencionado, não foi possível executar o algoritmo gerador combinatório, pois o custo computacional cresce muito e não foi possível executar nem mesmo para a menor das amostras (100 arcos). Para ter as quantidades referentes ao gerador combinatório, foi utilizada a equação Eq. (3.8), deduzida na seção 3.4.1 . Isso valoriza a abordagem heurística proposta, pois como será observado, foi possível resolver problemas de escalas maiores que problemas com 100 arcos.

Seguem os resultados obtidos pelas heurísticas e calculados para o gerador combinatório. Nas tabelas a seguir (5.2 a 5.8) foi simulado para todas as seis instâncias a geração para cardinalidade máxima (Kmax): 2, 3, 4 e 5. Para cada gerador foi testado dois cenários de reposicionamento máximo: $R=1$ e $R=2$. No caso do Gerador com Raio Variável, foram testados dois percentuais de custo core: $5 \%$ e $10 \%$.

Tabela 5.2: Quantidade de Caminhos Calculada para o Gerador Combinatório.

\begin{tabular}{|c|c|c|c|c|}
\hline \multicolumn{5}{|c|}{ Quantidade de Caminhos Gerados: Combinatório (Calculado) } \\
\hline Qtd $\operatorname{Arcos} \backslash K \max$ & $\mathrm{Kmax}=2$ & $\mathrm{Kmax}=3$ & $\mathrm{Kmax}=4$ & $\mathrm{Kmax}=5$ \\
\hline 100 & 5.050 & 166.750 & 4.087 .975 & 79.375 .495 \\
\hline 200 & 20.100 & 1.333 .500 & 66.018 .450 & 2.601 .668 .490 \\
\hline 500 & 125.250 & 20.833 .750 & 2.593.864.875 & 257.838 .552 .475 \\
\hline 1000 & 500.500 & 166.667 .500 & 41.583 .792 .250 & 8.291 .875 .042 .450 \\
\hline 3000 & 4.501 .500 & 4.500 .002 .500 & 3.372 .754 .126 .750 & 2.021 .630 .625 .377 .350 \\
\hline 5000 & 12.502 .500 & 20.833 .337 .500 & 26.031 .261 .461 .250 & 26.015 .651 .042 .712 .200 \\
\hline
\end{tabular}


Tabela 5.3: Quantidade de Caminhos Gerados com Gerador de Raio de Investimento Misto com no máximo um reposicionamento.

\begin{tabular}{|c|c|c|c|c|}
\hline \multicolumn{5}{|c|}{ Quantidade de Caminhos Gerados: Raio de Investimento Misto ( $R=1, p=64 \%)$} \\
\hline Qtd $\operatorname{Arcos} \backslash$ Kmax & $\mathrm{Kmax}=2$ & $\mathrm{Kmax}=3$ & $\mathrm{Kmax}=4$ & $\mathrm{Kmax}=5$ \\
\hline 100 & 100 & 100 & 100 & 107 \\
\hline 200 & 200 & 207 & 229 & 253 \\
\hline 500 & 500 & 628 & 939 & 1.379 \\
\hline 1000 & 1.000 & 1.629 & 3.841 & 9.403 \\
\hline 3000 & 3.000 & 8.308 & 50.090 & 171.718 \\
\hline 5000 & 4.998 & 18.106 & 115.877 & - \\
\hline
\end{tabular}

Tabela 5.4: Quantidade de Caminhos Gerados com Gerador de Raio de Investimento Misto com no máximo dois reposicionamentos.

\begin{tabular}{|c|c|c|c|c|}
\hline \multicolumn{5}{|c|}{ Quantidade de Caminhos Gerados: Raio de Investimento Misto ( $R=2, p=64 \%)$} \\
\hline Qtd $\operatorname{Arcos} \backslash K \max$ & $\mathrm{Kmax}=2$ & $\mathrm{Kmax}=3$ & $\mathrm{Kmax}=4$ & $\mathrm{Kmax}=5$ \\
\hline 100 & 100 & 100 & 148 & 347 \\
\hline 200 & 200 & 207 & 456 & 1.614 \\
\hline 500 & 500 & 628 & 3.368 & 27.244 \\
\hline 1000 & 1.000 & 1.629 & 14.168 & 181.514 \\
\hline 3000 & 4.998 & - & - & - \\
\hline 5000 & - & - & - & - \\
\hline
\end{tabular}

Tabela 5.5: Quantidade de Caminhos Gerados com Gerador de Raio de Investimento Variável de um reposicionamento e 10\% do custo core.

\begin{tabular}{|c|c|c|c|c|}
\hline \multicolumn{5}{|c|}{ Quantidade de Caminhos Gerados: Raio de Investimento Variável ( $R=1, p=10 \%$ ) } \\
\hline Qtd $\operatorname{Arcos} \backslash \mathrm{Kmax}$ & $\mathrm{Kmax}=2$ & $\mathrm{~K} \max =3$ & $\mathrm{Kmax}=4$ & $\mathrm{~K} \max =5$ \\
\hline 100 & 100 & 100 & 100 & 100 \\
\hline 200 & 200 & 200 & 200 & 203 \\
\hline 500 & 500 & 500 & 556 & 632 \\
\hline 1000 & 1.000 & 1.099 & 1.436 & 2.491 \\
\hline 3000 & 3.000 & 3.765 & 10.596 & 83.290 \\
\hline 5000 & - & - & - & - \\
\hline
\end{tabular}

Tabela 5.6: Quantidade de Caminhos Gerados com Gerador de Raio de Investimento Variável de dois reposicionamentos e 10\% do custo core.

\begin{tabular}{|c|c|c|c|c|}
\hline \multicolumn{5}{|c|}{ Quantidade de Caminhos Gerados: Raio de Investimento Variável ( $R=2, p=10 \%$ ) } \\
\hline Qtd $\operatorname{Arcos} \backslash K \max$ & $\mathrm{Kmax}=2$ & $\mathrm{Kmax}=3$ & $\mathrm{Kmax}=4$ & $\mathrm{~K} \max =5$ \\
\hline 100 & 100 & 100 & 100 & 101 \\
\hline 200 & 200 & 200 & 204 & 221 \\
\hline 500 & 500 & 500 & 601 & 1.002 \\
\hline 1000 & 1.000 & 1.099 & 1.705 & 6.153 \\
\hline 3000 & 3.000 & 3.862 & 12.625 & 104.222 \\
\hline 5000 & - & - & - & - \\
\hline
\end{tabular}


Tabela 5.7: Quantidade de Caminhos Gerados com Gerador de Raio de Investimento Variável de um reposicionamento e 5\% do custo core.

\begin{tabular}{|c|c|c|c|c|}
\hline \multicolumn{5}{|c|}{ Quantidade de Caminhos Gerados: Raio de Investimento Variável ( $R=1, p=5 \%$ ) } \\
\hline Qtd $\operatorname{Arcos} \backslash K \max$ & $\mathrm{Kmax}=2$ & $\mathrm{Kmax}=3$ & $\mathrm{Kmax}=4$ & $\mathrm{Kmax}=5$ \\
\hline 100 & 100 & 100 & 100 & 100 \\
\hline 200 & 200 & 200 & 200 & 200 \\
\hline 500 & 500 & 500 & 500 & 527 \\
\hline 1000 & 1.000 & 1.019 & 1.088 & 1.385 \\
\hline 3000 & 3.000 & 3.189 & 5.404 & 15.264 \\
\hline 5000 & 4.998 & 5.647 & 12.018 & 214.481 \\
\hline
\end{tabular}

Tabela 5.8: Quantidade de Caminhos Gerados com Gerador de Raio de Investimento Variável de dois reposicionamentos e 5\% do custo core.

\begin{tabular}{|c|c|c|c|c|}
\hline \multicolumn{5}{|c|}{ Quantidade de Caminhos Gerados: Raio de Investimento Variável ( $R=2, p=5 \%$ ) } \\
\hline Qtd $\operatorname{Arcos} \backslash K \max$ & $\mathrm{Kmax}=2$ & $\mathrm{Kmax}=3$ & $\mathrm{Kmax}=4$ & $\mathrm{Kmax}=5$ \\
\hline 100 & 100 & 100 & 100 & 100 \\
\hline 200 & 200 & 200 & 200 & 200 \\
\hline 500 & 500 & 500 & 503 & 565 \\
\hline 1000 & 1.000 & 1.019 & 1.110 & 1.672 \\
\hline 3000 & 3.000 & 3.189 & 5.351 & 44.216 \\
\hline 5000 & 4.998 & 5.777 & 18.840 & 219.596 \\
\hline
\end{tabular}

Comparadas as quantidades de caminhos gerados entre o Gerador Combinatório e o Gerador Guiado por Raio de Investimento, nota-se que a quantidade gerada na heurística é muito menor e com o crescimento das instâncias a diferença é mais significativa ainda, chegando a bilhões de vezes menor.

Entre mesmas abordagens, variando somente a quantidade de reposicionamentos, observa-se uma diferença muito menor que entre o gerador combinatório e gerador guiado, mas porém significativa. Para o Gerador de Raio Misto, as quantidades geradas com dois reposicionamentos foram em torno de 10 a 100 vezes maiores que as com um reposicionamento apenas e a proporção cresce com o aumento das amostras. Para as amostras com Raio Variável a diferença entre as quantidades de caminhos gerados com um ou dois reposicionamentos não foram representativas (ficando em torno de 1 a 1,5 vezes maior a de dois reposicionamentos) e também não houve variação representativa com o crescimento das amostras (Quantidade de Arcos). A variação das quantidades de caminhos gerados entre Raios Variáveis de 5\% e 10\% também não foi representativa (em torno de 1,2 a 1,7 vezes maior a de $10 \%)$. 


\subsubsection{Análise do Tempo de Execução}

O objetivo desta seção é analisar o tempo de execução das abordagens propostas neste trabalho e analisar também o impacto de parâmetros como cardinalidade máxima e percentual do custo core (para Gerador com Raio Variável) no tempo de execução.

Para comparar o tempo de execução das várias abordagens, nos restringimos a analisar somente o Grupo 1 (100, 200, 500), devido a restrições de tempo de processamento. No entanto, para abordagens de larga escala, aqui representadas pelo gerador de raio variável com $5 \%$ e 10\% do custo core, será feita uma análise mais adiante.

Seguem os resultados obtidos pelas abordagens aplicadas ao Grupo 1, nas figuras: 5.7 a 5.12, estruturadas em gráficos de instâncias X tempo (ms) divididos por cardinalidade máxima $(\mathrm{K})$.

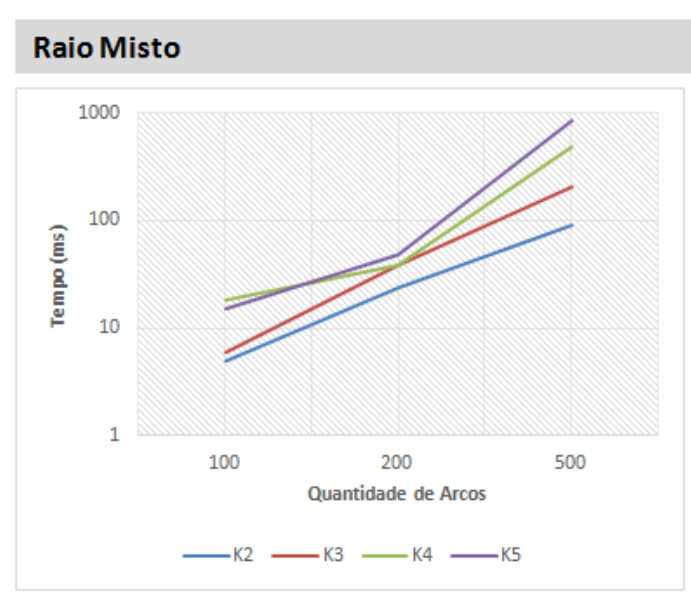

Reposição $=1$

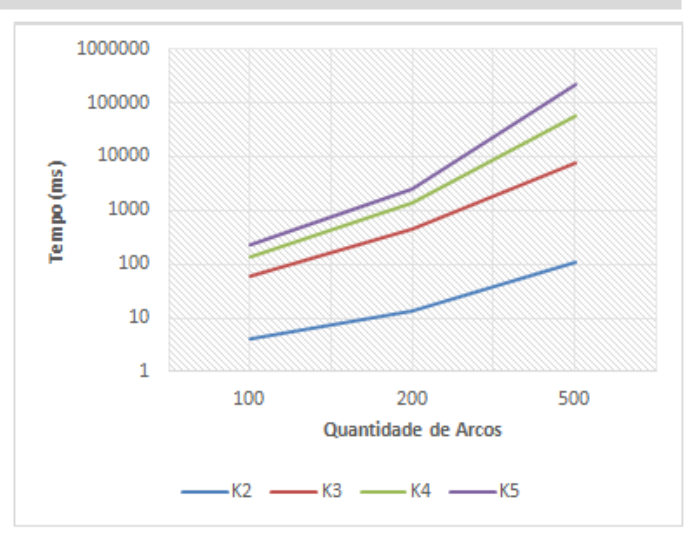

Reposição $=2$

Figura 5.7: Gráfico de Tempo do Gerador (ms) de Raio Misto para o Grupo 1.

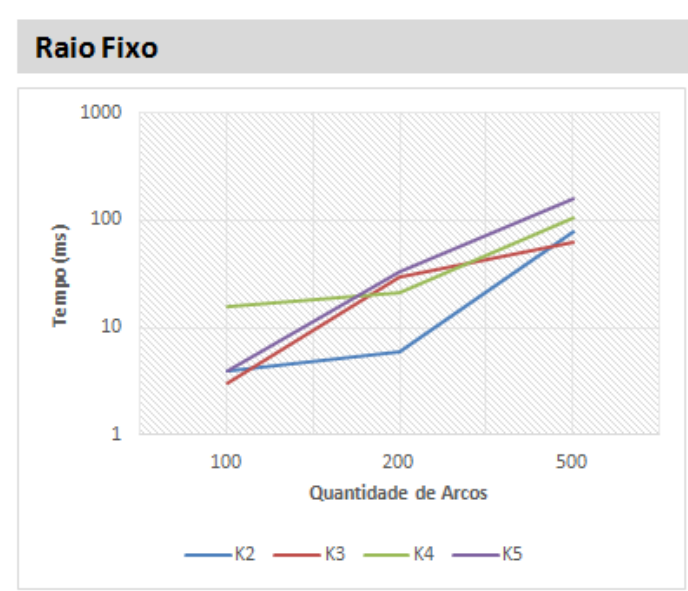

Reposição $=1$

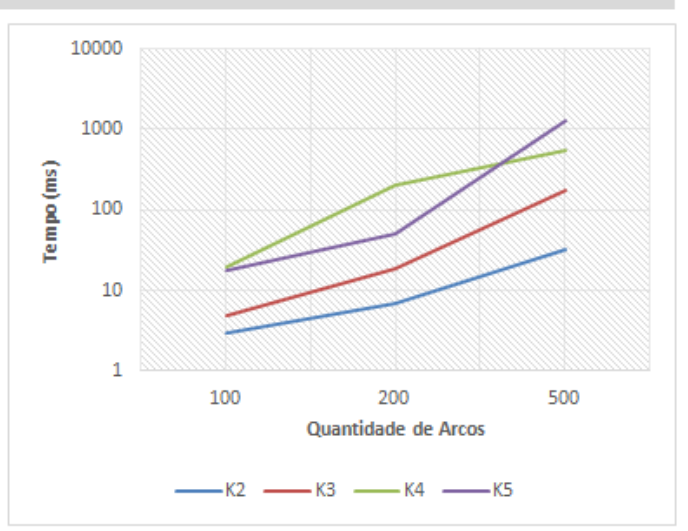

Reposição $=2$

Figura 5.8: Gráfico de Tempo do Gerador (ms) de Raio Fixo para o Grupo 1. 


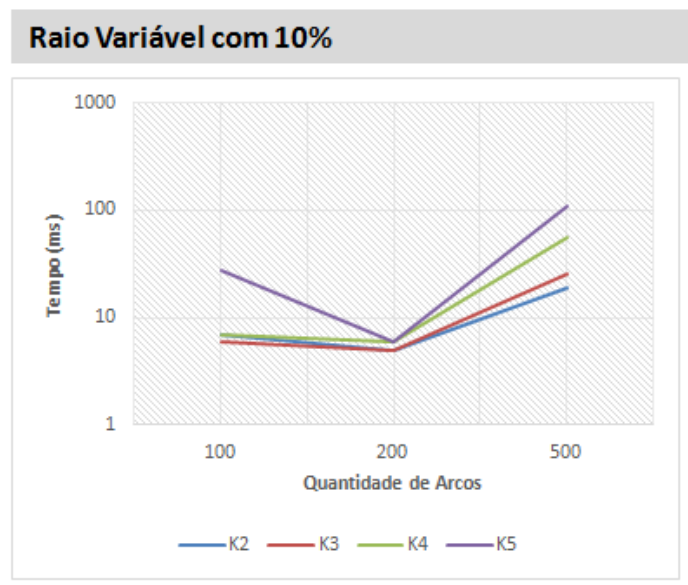

Reposição $=1$

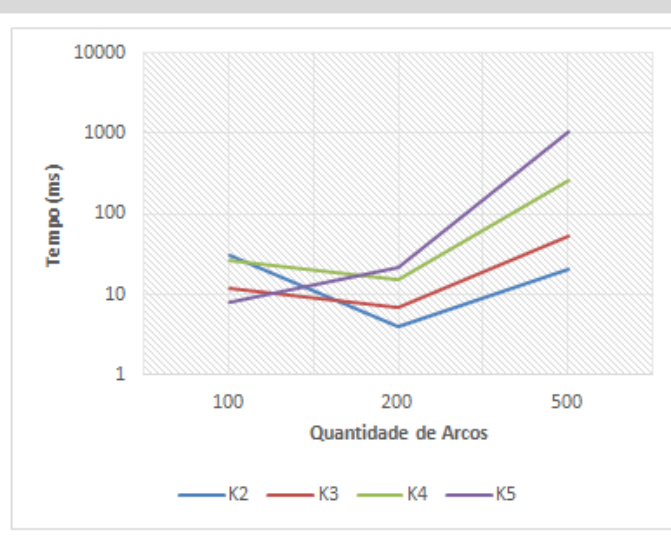

Reposição $=2$

Figura 5.9: Gráfico de Tempo do Gerador (ms) de Raio Variável de 10\% para o Grupo 1.

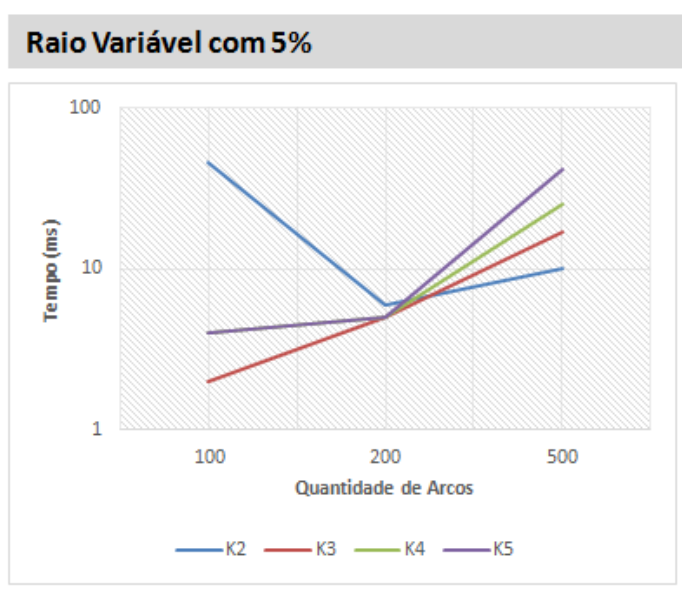

Reposição $=1$

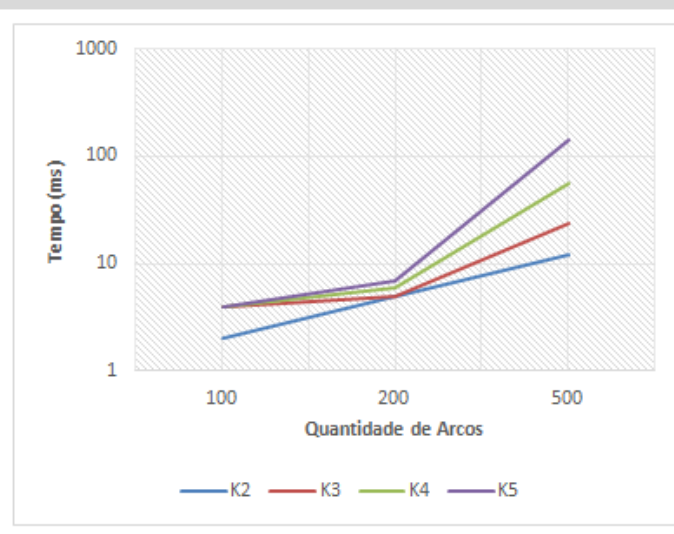

Reposição $=2$

Figura 5.10: Gráfico de Tempo do Gerador (ms) de Raio Variável de $5 \%$ para o Grupo 1.

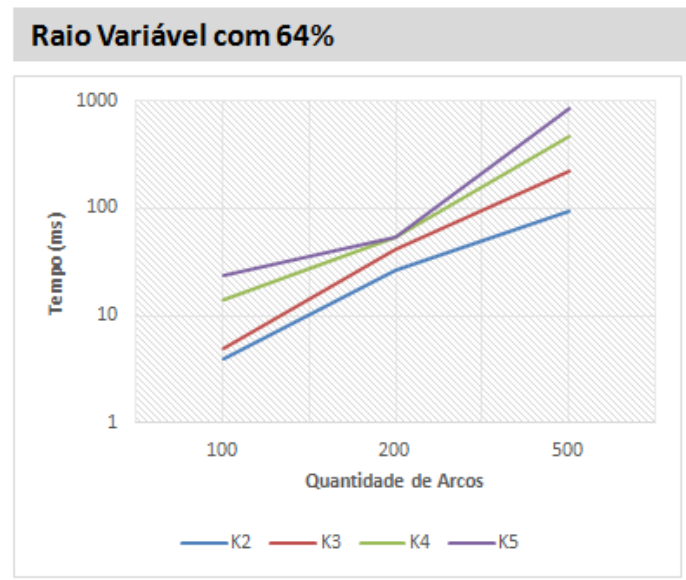

Reposição $=1$

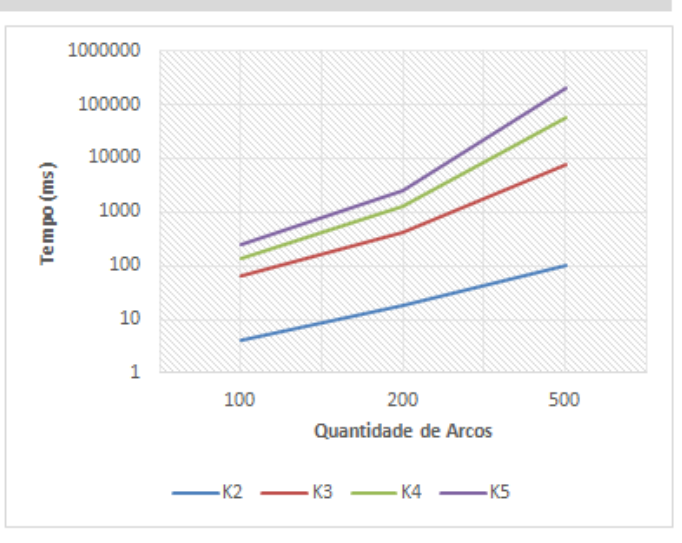

Reposição $=2$

Figura 5.11: Gráfico de Tempo do Gerador (ms) de Raio Variável de $64 \%$ para o Grupo 1. 
Mesmo com poucas amostras é possível notar uma redução de pelo menos 10 vezes no tempo de execução das abordagens de raio variável com $5 \%$ e 10\%. O gráfico de 64\%, percentual calculado pela Eq. (5.4) para se aproximar do gerador de raio misto, mostra que no tempo de execução também se aproxima do gerador de raio misto, conforme Fig. (5.12).

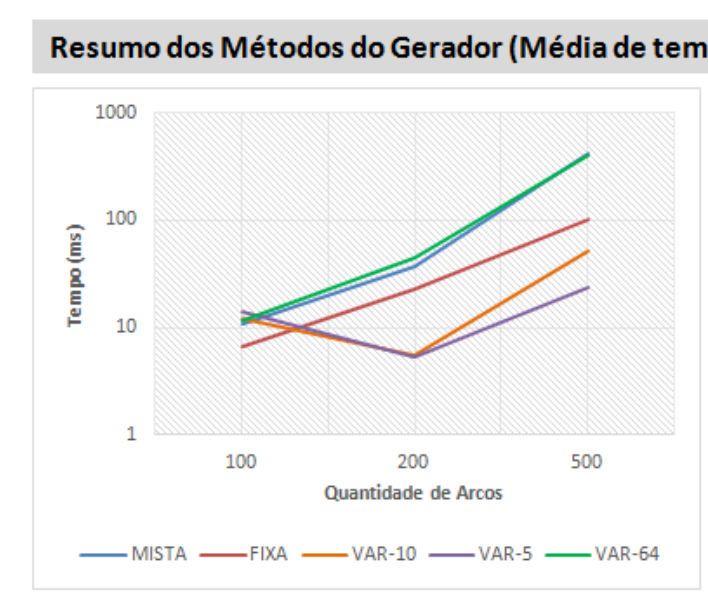

Reposição $=1$

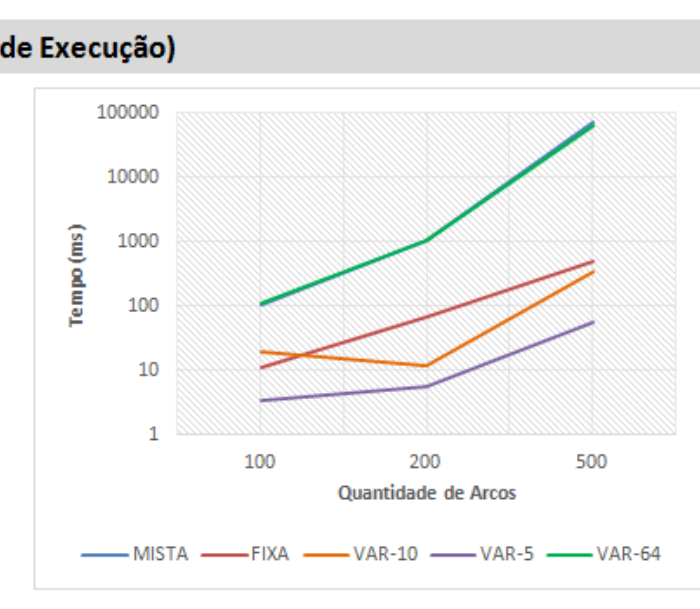

Reposição $=2$

Figura 5.12: Gráfico Resumo dos Tempos (ms) dos Métodos do Gerador para o Grupo 1.

Considerando a abordagem para larga escala, com raios de investimentos variáveis com $5 \%$ e $10 \%$ do custo core, a Fig. (5.13) representa o crescimento em função do tamanho da instância (agora incluindo o Grupo 2). Para chegar ao gráfico da Fig. (5.13) foi feito uma média das amostras de reposicionamento $R=1 \mathrm{e}$ $\mathrm{R}=2$. Visando obter melhores resultados de tempo, foi utilizado particionamento automático para processamento paralelo.

Ao observar os gráficos da Fig. (5.13), é possível inferir um crescimento exponencial tanto para o crescimento das amostras (pela linearidade do gráficos em escala $\log 10$ ) quanto para o crescimento em função da cardinalidade máxima (expresso pela função da linha de tendência com aproximadamente $99 \%$ de aderência).

Para avaliar o impacto do processamento paralelo, foi feita uma média do tempo de execução para as instâncias 100, 200, 500 e 1000 para particionamentos de 1 a 48, conforme Fig. (5.14) . Observou-se um ganho representativo na redução do tempo de execução, principalmente para o particionamento com 8 partes paralelas executando simultaneamente. 


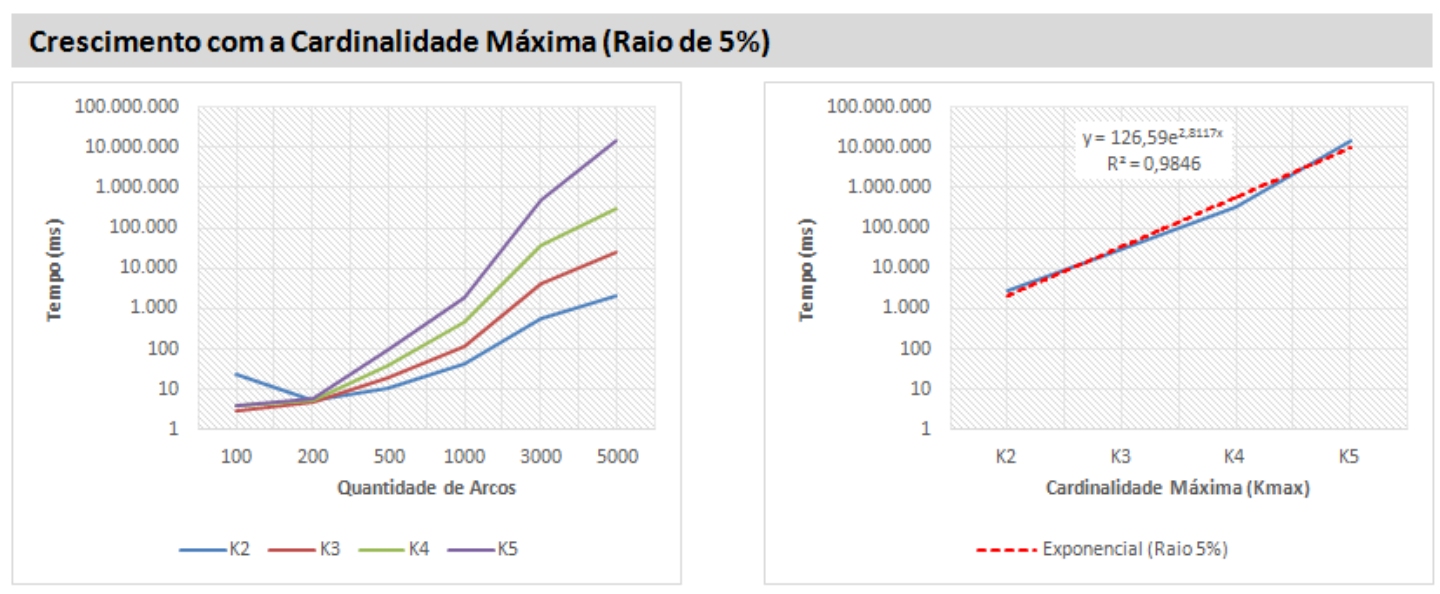

\section{Crescimento com a Cardinalidade Máxima (Raio de 10\%)}
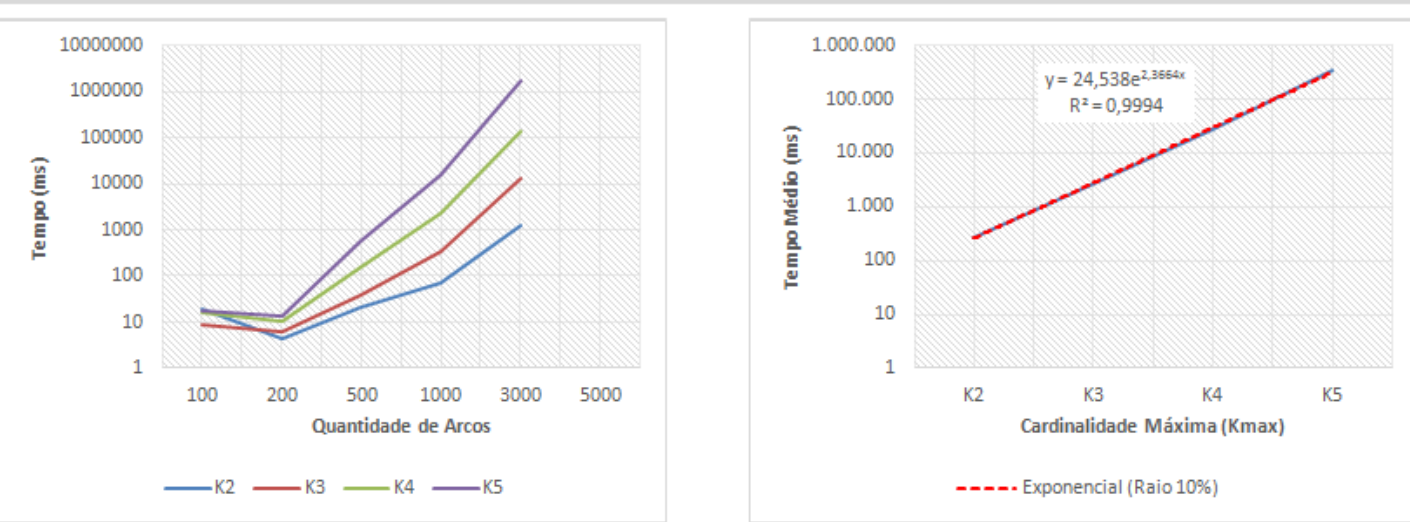

Figura 5.13: Gráfico do Tempo de Gerador (ms) em Função da Cardinalidade (K) Máxima.

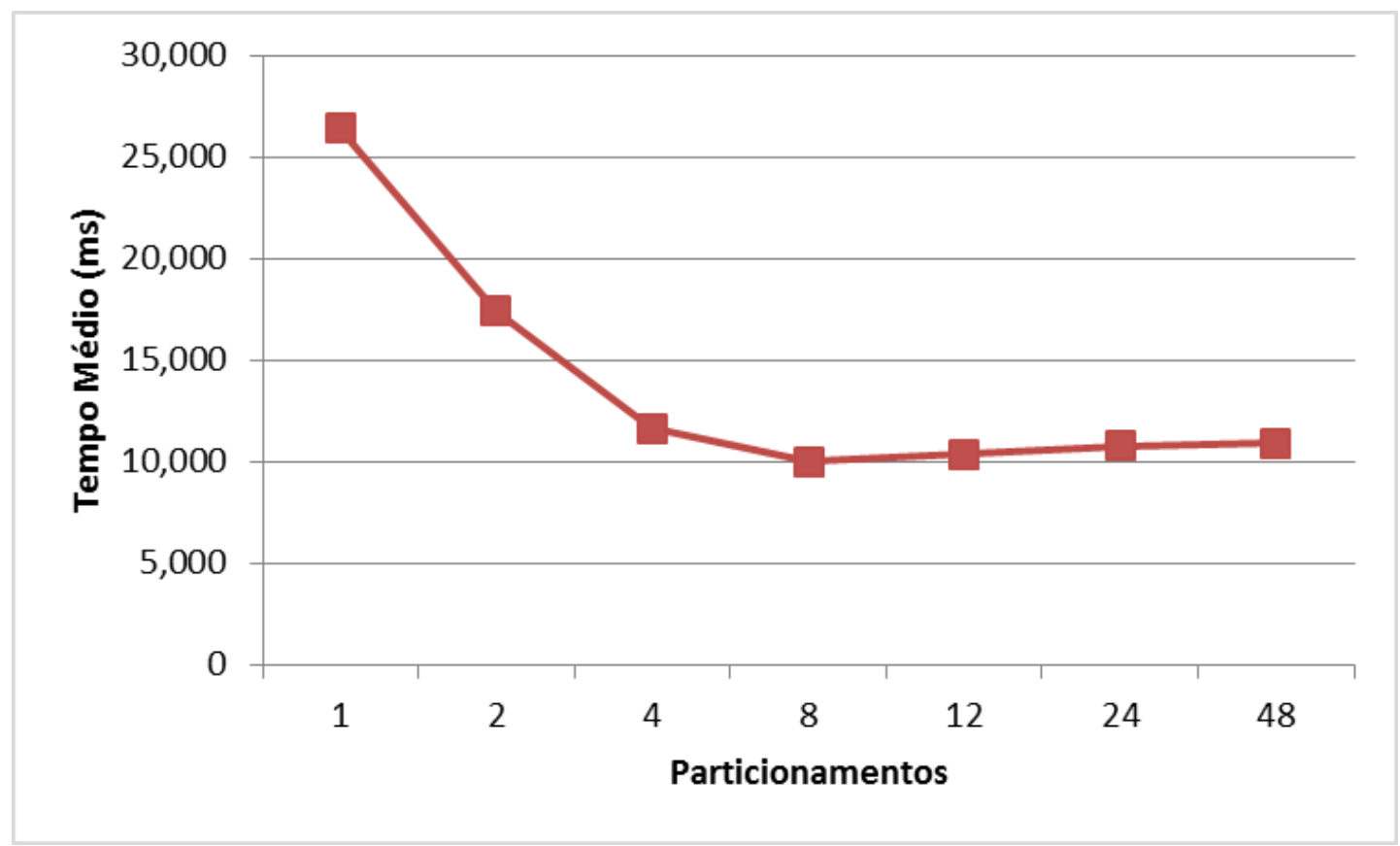

Figura 5.14: Gráfico de Tempo do Gerador um Função de Particionamentos Paralelos.

Durante as execuções para avaliar o impacto dos particionamentos paralelos 
observou-se no monitoramento das variáveis que a coleção de caminhos coletados impactava bastante o tempo de execução devido à concorrência de acessos e adição de novos caminhos. Embora todos os objetos do modelo, no momento geração, sejam independentes e, portanto totalmente paralelos, a gravação e consulta na coleção de caminhos onerou o tempo de execução devido a concorrência de dados.

\subsubsection{Análise da Qualidade dos Caminhos Gerados}

Para analisar a qualidade dos caminhos gerados, foi utilizado o gerador combinatório como referência, dado que esse gerador teoricamente gera o máximo de caminhos possíveis. Do ponto de vista de desempenho ele é o pior, no entanto do ponto de vista de qualidade de caminhos gerados ele é o melhor, pois se existem caminhos que podem chegar a máxima economia esses caminhos estão no imenso conjunto de caminhos gerados por esse gerador.

Como foi comentado na seção 5.4.1, o gerador combinatório consome muitos recursos computacionais e nem sempre consegue concluir sua função por causa disso. Para as amostras selecionadas, de 100 arcos em diante, esse gerador não consegue operar com recursos computacionais e tempo limitados, portanto para seguir com essa análise serão utilizadas instâncias menores (10, 20, 30, 40 e 50 arcos) para avaliar a qualidade dos caminhos gerados pelas heurísticas guiadas por raio de investimento (proposta neste trabalho).

Tabela 5.9: Análise da Qualidade dos Caminhos Gerados para a Instância com 10 Arcos

\begin{tabular}{|c|c|c|c|c|}
\hline $\begin{array}{l}\text { Model - } 20130221082312 \text { - Uniforme - } \\
\text { STD } 1000-20 \mathrm{~N}-10 \mathrm{~A}\end{array}$ & Solução & Dif $\%$ Custo C1 & Dif \% Custo Core & $\begin{array}{c}\text { Dif \% Custo } \\
\text { Combinatório-PLI }\end{array}$ \\
\hline \multicolumn{5}{|l|}{ 1-Referência } \\
\hline Custo Core & $1,163,576.74$ & $-45.0 \%$ & $0.0 \%$ & $-21.4 \%$ \\
\hline Custo $\mathrm{C} 1$ & $2,115,153.49$ & $0.0 \%$ & $81.8 \%$ & $42.8 \%$ \\
\hline Custo $\mathrm{CO}$ & $1,534,576.74$ & $-27.4 \%$ & $31.9 \%$ & $3.6 \%$ \\
\hline Combinatorio & $1,480,807.95$ & $-30.0 \%$ & $27.3 \%$ & $0.0 \%$ \\
\hline 2-Solver PLI & & $-29.1 \%$ & $28.9 \%$ & $1.3 \%$ \\
\hline Bolha de Investimento - Variada - 5 & $1,534,576.74$ & $-27.4 \%$ & $31.9 \%$ & $3.6 \%$ \\
\hline Bolha de Investimento - Variada - 10 & $1,492,309.32$ & $-29.4 \%$ & $28.3 \%$ & $0.8 \%$ \\
\hline Bolha de Investimento - Mista & $1,480,807.95$ & $-30.0 \%$ & $27.3 \%$ & $0.0 \%$ \\
\hline Bolha de Investimento - Fixa & $1,492,309.32$ & $-29.4 \%$ & $28.3 \%$ & $0.8 \%$ \\
\hline 3-Heuristica GD & & $-28.9 \%$ & $29.2 \%$ & $1.5 \%$ \\
\hline Bolha de Investimento - Variada - 5 & $1,534,576.74$ & $-27.4 \%$ & $31.9 \%$ & $3.6 \%$ \\
\hline Bolha de Investimento - Variada - 10 & $1,492,309.32$ & $-29.4 \%$ & $28.3 \%$ & $0.8 \%$ \\
\hline Bolha de Investimento - Mista & $1,492,309.32$ & $-29.4 \%$ & $28.3 \%$ & $0.8 \%$ \\
\hline Bolha de Investimento - Fixa & $1,492,309.32$ & $-29.4 \%$ & $28.3 \%$ & $0.8 \%$ \\
\hline
\end{tabular}


Tabela 5.10: Análise da Qualidade dos Caminhos Gerados para a Instância com 20 Arcos.

\begin{tabular}{lcccc}
$\begin{array}{c}\text { Model - 20130221 082317 - Uniforme - } \\
\text { STD 1000 - 20N - 20A }\end{array}$ & Solução & Dif \% Custo C1 & Dif \% Custo Core & $\begin{array}{c}\text { Dif \% Custo } \\
\text { Combinatório-PLI }\end{array}$ \\
\hline $\begin{array}{l}\text { 1-Referência } \\
\text { Custo Core }\end{array}$ & $3,367,600.76$ & $-46.6 \%$ & $0.0 \%$ & $-11.8 \%$ \\
\hline Custo C1 & $6,302,201.53$ & $0.0 \%$ & $87.1 \%$ & $65.1 \%$ \\
\hline Custo C0 & $4,125,350.76$ & $-34.5 \%$ & $22.5 \%$ & $8.1 \%$ \\
\hline Combinatorio & $3,816,655.04$ & $-39.4 \%$ & $13.3 \%$ & $0.0 \%$ \\
\hline 2-Solver PL & & $-\mathbf{3 9 . 3} \%$ & $\mathbf{1 3 . 6 \%}$ & $\mathbf{0 . 2 \%}$ \\
\hline Bolha de Investimento - Variada - 5 & $3,831,150.71$ & $-39.2 \%$ & $13.8 \%$ & $0.4 \%$ \\
\hline Bolha de Investimento - Variada - 10 & $3,816,938.06$ & $-39.4 \%$ & $13.3 \%$ & $0.0 \%$ \\
\hline Bolha de Investimento - Mista & $3,816,655.04$ & $-39.4 \%$ & $13.3 \%$ & $0.0 \%$ \\
\hline Bolha de Investimento - Fixa & $3,831,150.71$ & $-39.2 \%$ & $13.8 \%$ & $0.4 \%$ \\
\hline 3-Heuristica GD & & $-\mathbf{3 8 . 6 \%}$ & $\mathbf{1 4 . 9 \%}$ & $\mathbf{1 . 4 \%}$ \\
\hline Bolha de Investimento - Variada - 5 & $3,870,372.83$ & $-38.6 \%$ & $14.9 \%$ & $1.4 \%$ \\
\hline Bolha de Investimento - Variada - 10 & $3,870,372.83$ & $-38.6 \%$ & $14.9 \%$ & $1.4 \%$ \\
\hline Bolha de Investimento - Mista & $3,870,372.83$ & $-38.6 \%$ & $14.9 \%$ & $1.4 \%$ \\
\hline Bolha de Investimento - Fixa & $3,870,372.83$ & $-38.6 \%$ & $14.9 \%$ & $1.4 \%$ \\
\hline
\end{tabular}

Tabela 5.11: Análise da Qualidade dos Caminhos Gerados para a Instância com 30 Arcos.

\begin{tabular}{lcccc}
$\begin{array}{c}\text { Model - 20130221 082335 - Uniforme - } \\
\text { STD 1000 - 20N - 30A }\end{array}$ & Solução & Dif \% Custo C1 & Dif \% Custo Core & $\begin{array}{c}\text { Dif \% Custo } \\
\text { Combinatório-PLI }\end{array}$ \\
\hline $\begin{array}{l}\text { 1-Referência } \\
\text { Custo Core }\end{array}$ & $4,914,382.56$ & $-46.1 \%$ & $0.0 \%$ & $-10.1 \%$ \\
\hline Custo C1 & $9,121,165.13$ & $0.0 \%$ & $85.6 \%$ & $66.9 \%$ \\
\hline Custo CO & $6,152,682.56$ & $-32.5 \%$ & $25.2 \%$ & $12.6 \%$ \\
\hline Combinatorio & $5,464,061.50$ & $-40.1 \%$ & $11.2 \%$ & $0.0 \%$ \\
\hline 2-Solver PL & & $-39.4 \%$ & $\mathbf{1 2 . 6 \%}$ & $\mathbf{1 . 2 \%}$ \\
\hline Raio de Investimento - Variado - 5\% & $5,582,667.31$ & $-38.8 \%$ & $13.6 \%$ & $2.2 \%$ \\
\hline Raio de Investimento - Variado - 10\% & $5,522,852.57$ & $-39.5 \%$ & $12.4 \%$ & $1.1 \%$ \\
\hline Raio de Investimento - Misto & $5,463,485.58$ & $-40.1 \%$ & $11.2 \%$ & $0.0 \%$ \\
\hline Raio de Investimento - Fixo & $5,555,563.96$ & $-39.1 \%$ & $13.0 \%$ & $1.7 \%$ \\
\hline 3-Heuristica GD & & $-\mathbf{3 7 . 9} \%$ & $\mathbf{1 5 . 3} \%$ & $\mathbf{3 . 7 \%}$ \\
\hline Raio de Investimento - Variado - 5\% & $5,665,552.73$ & $-37.9 \%$ & $15.3 \%$ & $3.7 \%$ \\
\hline Raio de Investimento - Variado - 10\% & $5,665,552.73$ & $-37.9 \%$ & $15.3 \%$ & $3.7 \%$ \\
\hline Raio de Investimento - Misto & $5,665,552.73$ & $-37.9 \%$ & $15.3 \%$ & $3.7 \%$ \\
\hline Raio de Investimento - Fixo & $5,665,552.73$ & $-37.9 \%$ & $15.3 \%$ & $3.7 \%$ \\
\hline
\end{tabular}


Tabela 5.12: Análise da Qualidade dos Caminhos Gerados para a Instância com 40 Arcos.

\begin{tabular}{lcccc}
$\begin{array}{c}\text { Model - 20130221 082321 - Uniforme - } \\
\text { STD 1000 - 20N - 40A }\end{array}$ & Solução & Dif \% Custo C1 & Dif \% Custo Core & $\begin{array}{c}\text { Dif \% Custo } \\
\text { Combinatório-PLI }\end{array}$ \\
\hline 1-Referência & & & & \\
\hline Custo Core & $4,356,019.76$ & $-44.8 \%$ & $0.0 \%$ & $-13.8 \%$ \\
\hline Custo C1 & $7,897,039.51$ & $0.0 \%$ & $81.3 \%$ & $56.3 \%$ \\
\hline Custo C0 & $5,782,269.76$ & $-26.8 \%$ & $32.7 \%$ & $14.4 \%$ \\
\hline Combinatorio & $5,052,226.80$ & $-36.0 \%$ & $16.1 \%$ & $0.0 \%$ \\
\hline 2-Solver PL & & $-\mathbf{3 3 . 7} \%$ & $\mathbf{2 0 . 3} \%$ & $\mathbf{3 . 7 \%}$ \\
\hline Raio de Investimento - Variado - 5\% & $5,540,376.14$ & $-29.8 \%$ & $27.2 \%$ & $9.7 \%$ \\
\hline Raio de Investimento - Variado - 10\% & $5,232,819.14$ & $-33.7 \%$ & $20.1 \%$ & $3.6 \%$ \\
\hline Raio de Investimento - Misto & $5,052,969.62$ & $-36.0 \%$ & $16.1 \%$ & $0.0 \%$ \\
\hline Raio de Investimento - Fixo & $5,126,236.84$ & $-35.1 \%$ & $17.7 \%$ & $1.5 \%$ \\
\hline 3-Heuristica GD & & $-29.5 \%$ & $\mathbf{2 7 . 7 \%}$ & $\mathbf{1 0 . 1 \%}$ \\
\hline Raio de Investimento - Variado - 5\% & $5,571,765.81$ & $-29.4 \%$ & $27.9 \%$ & $10.3 \%$ \\
\hline Raio de Investimento - Variado - 10\% & $5,561,291.66$ & $-29.6 \%$ & $27.7 \%$ & $10.1 \%$ \\
\hline Raio de Investimento - Misto & $5,561,291.66$ & $-29.6 \%$ & $27.7 \%$ & $10.1 \%$ \\
\hline Raio de Investimento - Fixo & $5,561,291.66$ & $-29.6 \%$ & $27.7 \%$ & $10.1 \%$ \\
\hline
\end{tabular}

Tabela 5.13: Análise da Qualidade dos Caminhos Gerados para a Instância com 50 Arcos.

\begin{tabular}{lcccc}
$\begin{array}{c}\text { Model - 20130221 082343 - Uniforme - } \\
\text { STD 1000 - 20N - 50A }\end{array}$ & Solução & Dif \% Custo C1 & Dif \% Custo Core & $\begin{array}{c}\text { Dif \% Custo } \\
\text { Combinatório-PLI }\end{array}$ \\
\hline $\begin{array}{l}\text { 1-Referência } \\
\text { Custo Core }\end{array}$ & $5,429,639.16$ & $-45.0 \%$ & $0.0 \%$ & $-9.7 \%$ \\
\hline Custo C1 & $9,872,878.32$ & $0.0 \%$ & $81.8 \%$ & $64.2 \%$ \\
\hline Custo CO & $7,155,839.16$ & $-27.5 \%$ & $31.8 \%$ & $19.0 \%$ \\
\hline Combinatorio & $6,012,313.11$ & $-39.1 \%$ & $10.7 \%$ & $0.0 \%$ \\
\hline 2-Solver PL & & $-38.5 \%$ & $\mathbf{1 1 . 9 \%}$ & $\mathbf{1 . 0 \%}$ \\
\hline Raio de Investimento - Variado - 5\% & $6,118,594.17$ & $-38.0 \%$ & $12.7 \%$ & $1.8 \%$ \\
\hline Raio de Investimento - Variado - 10\% & $6,081,622.52$ & $-38.4 \%$ & $12.0 \%$ & $1.2 \%$ \\
\hline Raio de Investimento - Misto & $6,011,885.83$ & $-39.1 \%$ & $10.7 \%$ & $0.0 \%$ \\
\hline Raio de Investimento - Fixo & $6,089,556.88$ & $-38.3 \%$ & $12.2 \%$ & $1.3 \%$ \\
\hline 3-Heuristica GD & & $-\mathbf{3 7 . 1} \%$ & $\mathbf{1 4 . 5 \%}$ & $\mathbf{3 . 4 \%}$ \\
\hline Raio de Investimento - Variado - 5\% & $6,214,945.19$ & $-37.1 \%$ & $14.5 \%$ & $3.4 \%$ \\
\hline Raio de Investimento - Variado - 10\% & $6,214,945.19$ & $-37.1 \%$ & $14.5 \%$ & $3.4 \%$ \\
\hline Raio de Investimento - Misto & $6,214,945.19$ & $-37.1 \%$ & $14.5 \%$ & $3.4 \%$ \\
\hline Raio de Investimento - Fixo & $6,214,945.19$ & $-37.1 \%$ & $14.5 \%$ & $3.4 \%$ \\
\hline
\end{tabular}

Dentre as heurísticas de geração de caminhos, a heurística de geração por raio misto gerou os melhores caminhos a serem utilizados nos solvers, como pode ser visto na linha correspondente ao Solver PLI com Raio de Investimento Variável na Tab. (5.14) e nas demais tabelas, os caminhos gerados não tiveram adicional em relação a referência Combinatório-PLI. Em seguida, o segundo melhor é o gerador com raio de investimento fixo e depois os raios de investimento variável $10 \%$ e $5 \%$. 
Tabela 5.14: Resumo das Diferenças das Soluções Obtidas pelos Solvers.

\begin{tabular}{lc} 
Resumo das Variações em relação ao & Diferença Média \\
\hline 2-Solver PLI & $\mathbf{1 . 5} \%$ \\
\hline Bolha de Investimento - Variada - 5 & $3.5 \%$ \\
\hline Bolha de Investimento - Variada - 10 & $1.3 \%$ \\
\hline Bolha de Investimento - Mista & $0.0 \%$ \\
\hline Bolha de Investimento - Fixa & $1.1 \%$ \\
\hline 3-Heuristica GD & $\mathbf{4 . 0} \%$ \\
\hline Bolha de Investimento - Variada - 5 & $4.5 \%$ \\
\hline Bolha de Investimento - Variada - 10 & $3.9 \%$ \\
\hline Bolha de Investimento - Mista & $3.9 \%$ \\
\hline Bolha de Investimento - Fixa & $3.9 \%$ \\
\hline
\end{tabular}

Das informações contidas na Tab. (5.14), existem dois tipos de avaliação de qualidade, a qualidade dos caminhos gerados comparando com o gerador combinatório e a qualidade da heurística de priorização (HSPC) para encontrar uma solução. Dessa forma, observa-se que os caminhos gerados pelo gerador guiado por raios de investimento proporcionam, através do solver PLI, soluções com custos, em média, 1,5\% maiores que a referência (Gerador Combinatório com Solver PLI). Observou-se também que o Solver por priorização proposto este trabalho (o HSPC) encontra soluções 4\% maiores que o Gerador Combinatório com Solver PLI. Das informações contidas na Tab. (5.14), existem dois tipos de avaliação de qualidade, a qualidade dos caminhos gerados comparando com o gerador combinatório e a qualidade da heurística de priorização (HSPC) para encontrar uma solução. Dessa forma, observa-se que os caminhos gerados pelo gerador guiado por raios de investimento proporcionam, através do solver PLI, soluções com custos, em média, 1,5\% maiores que a referência (Gerador Combinatório com Solver PLI). Observou-se também que o Solver por priorização proposto este trabalho (o HSPC) encontra soluções $4 \%$ maiores, em custo, que o Gerador Combinatório com Solver PLI.

\subsubsection{Discussões sobre o Gerador de Caminhos}

Durante as execuções da análise de particionamentos paralelos foi observado um limite inferior ao esperado nos ganhos com os particionamentos paralelos. Como as informações do modelo não se alteram durante o processamento do gerador de caminhos e os particionamentos geradores são independentes, esperava-se que com o aumento do número de particionamentos o tempo de execução reduzisse, pelo menos até o limite de núcleos de processamento do servidor (neste caso 12 núcleos), e não foi o que ocorreu, pois parou de reduzir o tempo em 8 parti- 
Tabela 5.15: Tempo de Execução do Solver (HSPC) para a Instância de 100 arcos.

\begin{tabular}{|c|c|c|c|c|}
\hline Instâncias e Solvers (Tempo em ms) & 2 & 3 & 4 & 5 \\
\hline \multicolumn{5}{|l|}{100} \\
\hline Heuristica GD & 1.88 & 0.25 & 1.25 & 0.50 \\
\hline Bolha de Investimento - Fixa & 0.00 & 0.00 & 0.50 & 0.50 \\
\hline Bolha de Investimento - Mista & 0.00 & 1.00 & 1.00 & 1.00 \\
\hline Bolha de Investimento - Variada - 5 & 7.50 & 0.00 & 3.50 & 0.00 \\
\hline Bolha de Investimento - Variada - 10 & 0.00 & 0.00 & 0.00 & 0.50 \\
\hline Solver PLI & 218.50 & 96.50 & 125.13 & 145.63 \\
\hline Bolha de Investimento - Fixa & 93.50 & 94.50 & 99.00 & 101.00 \\
\hline Bolha de Investimento - Mista & 93.00 & 100.00 & 132.00 & 276.50 \\
\hline Bolha de Investimento - Variada - 5 & 554.50 & 95.00 & 166.50 & 99.00 \\
\hline Bolha de Investimento - Variada - 10 & 133.00 & 96.50 & 103.00 & 106.00 \\
\hline
\end{tabular}

cionamentos. Como comentado na seção 5.4.2, observou-se no monitoramento um certo "gargalo" na escrita e leitura de caminhos na coleção que armazena os caminhos gerados, que devido a concorrência de acesso e escrita à coleção de caminhos limitou o aproveitamento do processamento paralelo. Neste caso, uma estratégia mais sofisticada de acesso e escrita concorrente poderia trazer ganhos.

\subsection{Aplicação do Solver}

Dado o conjunto de caminhos gerados, o Solver é responsável por escolher os melhores e atribuir as quantidades certas de demandas a cada caminho, visando a máxima economia na rede. É pensando em alocar primeiro recursos para caminhos representativos e econômicos que a heurística HSPC é baseada, priorizando caminhos.

Para analisar a eficiência da heurística serão feitas duas análises: análise do tempo de execução e análise da qualidade da solução encontrada.

\subsubsection{Análise do Tempo de Execução}

Nesta seção será analisado o tempo de execução para as instâncias do Grupo 1 e Grupo 2, onde para o segundo grupo serão analisadas somente as amostras de grande escala (HSPC) sem comparar com o PLI. 
Tabela 5.16: Tempo de Execução do Solver (HSPC) para a Instância de 200 arcos.

\begin{tabular}{lrrrr}
\hline Instâncias e Solvers (Tempo em ms) & $\mathbf{2}$ & $\mathbf{3}$ & $\mathbf{4}$ & $\mathbf{5}$ \\
\hline 200 & & & & $\mathbf{1 . 6 3}$ \\
\hline Heuristica GD & $\mathbf{0 . 5 0}$ & $\mathbf{1 . 8 8}$ & $\mathbf{1 . 8 8}$ \\
\hline Bolha de Investimento - Fixa & 0.00 & 2.00 & 2.00 & 2.00 \\
\hline Bolha de Investimento - Mista & 0.00 & 4.00 & 2.50 & 3.00 \\
\hline Bolha de Investimento - Variada - 5 & 1.50 & 0.50 & 0.50 & 1.00 \\
\hline Bolha de Investimento - Variada - 10 & 0.50 & 1.00 & 1.50 & 1.50 \\
\hline Solver PLI & 398.38 & $\mathbf{4 2 7 . 7 5}$ & $\mathbf{5 1 6 . 5 0}$ & $\mathbf{9 6 9 . 3 8}$ \\
\hline Bolha de Investimento - Fixa & 404.50 & 416.50 & 471.50 & 511.00 \\
\hline Bolha de Investimento - Mista & 384.00 & 474.50 & 768.00 & $2,504.50$ \\
\hline Bolha de Investimento - Variada - 5 & 411.50 & 400.00 & 406.50 & 404.50 \\
\hline Bolha de Investimento - Variada - 10 & 393.50 & 420.00 & 420.00 & 457.50 \\
\hline
\end{tabular}

Tabela 5.17: Tempo de Execução do Solver (HSPC) para a Instância de 500 arcos.

\begin{tabular}{lrrrr}
\hline Instâncias e Solvers (Tempo em ms) & $\mathbf{2}$ & $\mathbf{3}$ & $\mathbf{4}$ & $\mathbf{5}$ \\
\hline $\mathbf{5 0 0}$ & & & $\mathbf{3 . 8 8}$ & $\mathbf{1 0 . 6 3}$ \\
\hline Heuristica GD & $\mathbf{0 . 8 8}$ & $\mathbf{3 . 8 8}$ & $\mathbf{4 . 8 8}$ \\
\hline Bolha de Investimento - Fixa & 1.00 & 4.50 & 3.50 & 4.00 \\
\hline Bolha de Investimento - Mista & 0.50 & 6.00 & 8.50 & $\mathbf{3 2 . 0 0}$ \\
\hline Bolha de Investimento - Variada - 5 & 1.00 & 1.00 & 4.00 & 2.00 \\
\hline Bolha de Investimento - Variada - 10 & 1.00 & 4.00 & 3.50 & 4.50 \\
\hline Solver PLI & $\mathbf{2 , 4 2 7 . 0 0}$ & $\mathbf{2 , 8 0 0 . 2 5}$ & $\mathbf{5 , 4 7 5 . 5 0}$ & $\mathbf{3 3 , 1 5 2 . 2 5}$ \\
\hline Bolha de Investimento - Fixa & $2,265.50$ & $2,708.50$ & $3,650.00$ & $5,656.00$ \\
\hline Bolha de Investimento - Mista & $2,497.00$ & $3,469.50$ & $12,688.00$ & $119,555.50$ \\
\hline Bolha de Investimento - Variada - 5 & $2,534.50$ & $2,492.00$ & $2,587.00$ & $2,853.50$ \\
\hline Bolha de Investimento - Variada - 10 & $2,411.00$ & $2,531.00$ & $2,977.00$ & $4,544.00$ \\
\hline
\end{tabular}

Tabela 5.18: Tempo de Execução do Solver (HSPC) para a Instância de 1000 arcos.

\begin{tabular}{lrrrr}
\hline Instâncias e Solvers (Tempo em ms) & $\mathbf{2}$ & $\mathbf{3}$ & $\mathbf{4}$ & $\mathbf{5}$ \\
\hline $\mathbf{1 0 0 0}$ & & & & \\
\hline Heuristica GD & $\mathbf{1 . 1 8}$ & $\mathbf{4 . 8 2}$ & $\mathbf{4 0 . 2 7}$ & $\mathbf{7 5 9 . 3 0}$ \\
\hline Bolha de Investimento - Fixa & 1.50 & 5.00 & 16.00 & 29.50 \\
\hline Bolha de Investimento - Mista & 1.00 & 5.60 & 70.20 & $1,847.25$ \\
\hline Bolha de Investimento - Variada - 5 & 1.50 & 3.50 & 13.00 & 27.00 \\
\hline Bolha de Investimento - Variada - 10 & 1.00 & 4.00 & 17.00 & $\mathbf{4 5 . 5 0}$ \\
\hline
\end{tabular}


Tabela 5.19: Tempo de Execução do Solver (HSPC) para a Instância de 3000 arcos.

\begin{tabular}{lrrrr}
\hline Instâncias e Solvers (Tempo em ms) & $\mathbf{2}$ & $\mathbf{3}$ & $\mathbf{4}$ & $\mathbf{5}$ \\
\hline $\mathbf{3 0 0 0}$ & & & & \\
\hline Heuristica GD & $\mathbf{9 . 8 0}$ & $\mathbf{1 1 2 . 8 0}$ & $\mathbf{1 , 6 3 1 . 0 0}$ & $\mathbf{1 2 , 2 4 9 . 6 0}$ \\
\hline Bolha de Investimento - Mista & 7.00 & 120.00 & $1,417.00$ & $14,731.00$ \\
\hline Bolha de Investimento - Variada - 5 & 9.50 & 116.50 & $1,531.50$ & $9,612.00$ \\
\hline Bolha de Investimento - Variada - 10 & 11.50 & 105.50 & $\mathbf{1 , 8 3 7 . 5 0}$ & $13,646.50$ \\
\hline
\end{tabular}

Tabela 5.20: Tempo de Execução do Solver (HSPC) para a Instância de 5000 arcos.

\begin{tabular}{lrrrr}
\hline Instâncias e Solvers (Tempo em ms) & $\mathbf{2}$ & $\mathbf{3}$ & $\mathbf{4}$ & $\mathbf{5}$ \\
\hline $\mathbf{5 0 0 0}$ & & & & \\
\hline Heuristica GD & $\mathbf{4 3 . 8 3}$ & $\mathbf{1 , 0 1 1 . 0 0}$ & $\mathbf{3 5 , 7 3 5 . 2 5}$ & $\mathbf{1 4 5 , 5 3 7 . 0 0}$ \\
\hline Bolha de Investimento - Fixa & 27.50 & $1,097.00$ & $33,961.00$ & \\
\hline Bolha de Investimento - Mista & 20.00 & $1,065.00$ & $\mathbf{4 7 , 5 8 8 . 0 0}$ & \\
\hline Bolha de Investimento - Variada - 5 & 84.00 & 941.00 & $30,696.00$ & $\mathbf{1 4 5 , 5 3 7 . 0 0}$ \\
\hline
\end{tabular}

Para o Grupo 1 (100, 200 e 500) é possível notar a diferença no tempo de execução do HSPC e o PLI, de 100 a 2000 vezes maior para o Solver PLI.

\subsubsection{Análise da Qualidade de Solução}

Para analisar a qualidade de uma solução, é necessário comparar com uma solução reconhecida como máximo econômica, dados os parâmetros de entrada (custos e caminhos gerados). Dessa forma, a referência para analisar a qualidade do solver HSPC será o solver PLI, utilizando para ambos a mesma massa de caminhos gerados.

A Tab. (5.21) resume as diferenças entre as soluções do HSPC e o PLI para a avaliação do Solver proposto. 
Tabela 5.21: Diferença entre a Solução do HSPC e PLI para o mesmo conjunto de Caminhos Gerados.

\begin{tabular}{lr}
\hline Cenário & $\begin{array}{c}\text { Diferença Máxima } \\
\text { HSGD x PLI }\end{array}$ \\
\hline Model - 20130211 134207 - Uniforme - STD 1000 - 500N - 100A & $\mathbf{0 . 0 4 7 \%}$ \\
\hline Raio de Investimento - Fixo & $0.000 \%$ \\
\hline Raio de Investimento - Misto & $0.189 \%$ \\
\hline Raio de Investimento - Variado - 10\% & $0.000 \%$ \\
\hline Raio de Investimento - Variado - 5\% & $0.000 \%$ \\
\hline Model - 20130211 134222 - Uniforme - STD 1000 - 500N - 200A & $\mathbf{0 . 1 8 3 \%}$ \\
\hline Raio de Investimento - Fixo & $0.000 \%$ \\
\hline Raio de Investimento - Misto & $0.629 \%$ \\
\hline Raio de Investimento - Variado - 10\% & $0.103 \%$ \\
\hline Raio de Investimento - Variado - 5\% & $0.000 \%$ \\
\hline Model - 20130211 134243 - Uniforme - STD 1000 - 500N - 500A & $\mathbf{2 . 0 1 5 \%}$ \\
\hline Raio de Investimento - Fixo & $2.332 \%$ \\
\hline Raio de Investimento - Misto & $3.514 \%$ \\
\hline Raio de Investimento - Variado - 10\% & $1.798 \%$ \\
\hline Raio de Investimento - Variado - 5\% & $0.416 \%$ \\
\hline Diferença Média Geral & $\mathbf{0 . 7 4 8 \%}$ \\
\hline
\end{tabular}

Observando a Tab. (5.21), será observado uma diferença média de um custo maior que o PLI de $0,748 \%$, o que parece bastante eficiente, dado que o tempo de execução reduziu de 100 a 2000 vezes para as instâncias selecionadas. É importante ressaltar que para os casos de Raio Variável 5\% e $10 \%$ as diferenças médias são baixas porque a massa de caminhos gerados de entrada é muito menor, dando assim um número menor de opções aos dois Solvers. A qualidade dos caminhos gerados foi analisada na seção 5.4 .3 e ficou em média de $3,9 \%$ a $4,5 \%$ maior que o Gerador Combinatório com Solver PLI.

\subsubsection{Discussões sobre o Solver}

A diferença média da qualidade da qualidade da solução, em relação ao solver PLI ficou em torno de 0,784\%, no entanto o tempo de execução teve significativa diferença. Esses dois pontos coloca o solver HSPC como um opção para resolver problemas de grande escala sem perder muito em qualidade da solução encontrada.

Analisando a redução na quantidade dos caminhos gerados, a redução no tempo do gerador (através da heurística de raio de investimento) e a redução no tempo de execução do solver, utilizando o HSPC, chega-se a uma combinação de heurísticas capaz de resolver problemas de grande escala, problemas antes 
impossíveis (para computadores robustos como o utilizado neste trabalho) de serem resolvidos com a abordagem de Gerador Combinatório e Solver PLI.

Como recomendação, pode-se fazer uso das heurísticas e solvers de acordo com o tamanho do problema. Para problemas pequenos (até 50 arcos) é possível utilizar o Gerador Combinatório junto com o Solver PLI. Para problemas médios (de 100 arcos a 500 arcos) o Gerador de Caminhos por Raio de Investimento junto com o PLI. Para os problemas de grande escala (mais de 1000 arcos), a estratégia é já começar com e Gerador de Caminhos por Raio de Investimento e Solver de priorização (HSPC) direto. 


\section{Conclusões}

O texto apresentado teve como objetivo propor uma heurística para achar uma solução viável para o PCR em larga escala (problemas maiores), cujo principal trade-off se dá por ser um problema NP-Difícil. Dada a complexidade, a estratégia para achar a solução (acompanhando a literatura) foi dividir em duas partes a solução, Gerador de Caminhos e Solver, e desenvolver heurísticas especializadas em cada uma das etapas para permitir resolver problemas maiores.

Especificamente para o Gerador de Caminhos, responsável por gerar as variáveis de decisão do modelo, o principal trade-off foi desenvolver uma heurística que reduzisse a quantidade de caminhos gerados sem impactar na seleção dos melhores caminhos (trabalho do solver), ou seja, gerar os caminhos que realmente estariam entre os mais cotados para o solver, evitando gerar caminhos com pouca chance de serem escolhidos.

Olhando para os resultados de desempenho do Gerador de Caminhos, logo no início nos deparamos com a impossibilidade de comparar os resultados com o Gerador Combinatório de Caminhos, pois as instâncias escolhidas para testar a proposta possuíam mais de 100 arcos (quase 80 milhões de caminhos para o gerador combinatório), e observa-se que a quantidade de memória requerida superou o limite do computador (48GB). Para continuar os testes e estimar os ganhos foi preciso gerar instâncias menores (de 10 a 50 arcos). Do ponto de vista de desempenho e possibilidade de resolver problemas maiores, já justificou-se o uso da heurística proposta.

Pensando em problemas maiores, utilizou-se estratégias mais restritivas como Raio Variável com 10\% e 5\% (com impacto estimado na solução de no máximo 4,5\% acima do Custo Ótimo com Gerador Combinatório e Solver PLI) garantindo que o custo ótimo estivesse no máximo igual ao Custo Conjugado C0C1.

Embora durante a geração dos caminhos não exista escrita de informações no modelo, o que permitiria um alto grau de paralelismo, observou-se que a coleção que armazena os caminhos gerados tornou-se um "gargalo" do ponto de vista de 
paralelismo por causa da concorrência dos acessos e escrita, mas isso não evitou ganhos de desempenho com o uso de paralelismo até 8 particionamentos paralelos.

Olhando para o Solver, a estratégia adotada para reduzir o tempo foi a mesma adotada pela literatura, heurística de priorização de caminhos. Nessa estratégia, aloca-se primeiro as demandas aos caminhos mais representativos e evita-se resolver um modelo matemático, que com o aumento do tamanho do problema pode ficar bastante custoso computacionalmente.

A heurística de priorização se mostrou bastante eficiente frente ao solver PLI, sendo de 100 a 2000 vezes mais rápido que o PLI para as instâncias avaliadas com uma diferença média de 0,748\% acima no valor encontrado na solução.

Como estratégia, é possível utilizar, de acordo com o tamanho da instância, até mesmo o Gerador Combinatório com o Solver PLI para instâncias menores (até 50 arcos), deixando as heurísticas propostas neste trabalho para instâncias maiores.

É possível concluir, através dos resultados experimentais, que as heurísticas do Gerador de Caminhos (HGCGRI) e Solver (HSPC) propostas mostraram-se úteis para resolver problemas maiores sem muito impacto na economia gerada na solução final.

\subsection{Trabalhos Futuros}

Como possível próximo passo, o desenvolvimento de uma estratégia de paralelização mais sofisticada para as heurísticas propostas poderia trazer mais benefícios, pois foi observado um "gargalo" em concorrência de acessos na coleção de caminhos gerados. Dada a independência dos dados durante a geração (exceto para a coleção de caminhos gerados), é possível utilizar estratégias mistas de processamento paralelo, como por exemplo, processamento distribuído entre vários computadores e processamento paralelo através de threads nos computadores finais. Uma estratégia de particionamento para essa abordagem seria particionar por "Nó inicial", pois dadas as características das heurísticas propostas o "Nó Inicial" seria a unidade atômica de particionamento. 


\section{Referências}

1 WEISSTEIN, E. W. Hamiltonian Cycle. Nov 2012. http://mathworld. wolfram.com/HamiltonianCycle.html. [Online; acesso em 01-Nov-2012].

2 GOMES, M. J. N.; JÚNIOR, W. R. C.; PALHANO, A. W. C.; COUTINHO, E. F.; CASTRO, G. A.; GOMES, F. J. N.; BARCELlOS, G. C.; REZENDE, B. F.; PEREIRA, L. W. O problema do carteiro chinês, algoritmos exatos e um ambiente mvi para análise de suas instâncias: sistema xnÊs. Pesquisa Operacional, 209, v. 29, p. p.323-363, 209.

3 GOldBARG, M. C.; LUNA, H. P. L. Otimização Combinatória e Programação Linear: modelos e algoritmos. [S.l.]: Rio de Janeiro: Campus, 2000 .

4 GUROBI. Mixed Integer Programming Basics. Dezembro 2012. Http://www.gurobi.com/resources/getting-started/mip-basics. [Online; acesso em 01-Dez-2012].

5 SAVELSBERGH, M.; ERGUN, O.; KUYZU, G. Collaborative Logistics. Jan 2013. <http://www2. isye.gatech. edu/ jswann/teaching/6230S06.htm>. [Online; acesso em 01-Nov-2012].

6 LIMA, M. O Custeio do Transporte Rodoviário de Cargas. Janeiro 2013. <http://www . portalntc.org.br/index.php?option=com _ remository\&Itemid $=388 \&$ f unc $=$ startdown\&id=332>. [Online; acesso em 01-Jan-2013].

7 FIGUEIREDO, R.; EIRAS, J. Transporte Colaborativo: conceituação, benefícios e práticas (parte 1). 2007. http://www.ilos.com.br/index.php? option=com_docman\&task=doc_details\&gid=14\&itemid=44. [Online; acesso em 19-Set-2010].

8 CUNHA, C. B.; SILVA, M. R. A genetic algorithm for the problem of configuring a hub-and-spoke network for a ltl trucking company in brazil. European Journal of Operational Research, 2007, p. 747-758, 2007.

9 EnGEVAlL, S.; GOOTHE-LUndGREN, M.; VARBRAND, P. The heterogeneous vehicle-routing game. Transportation Science, 2004, p. 71-85, 2004 .

10 ERGUN, O.; KUYZU, G.; SAVELSBERGH, M. Reducing truckload transportation costs through collaboration. Transportation Science, 2007, p. 206-221, 2007.

11 STRINGHER, F. G. Designação de rotas para frota dedicada em uma rede de distribuição de linha branca. Dissertação (Mestrado) - Dissertação (Mestrado em Engenharia de Sistemas Logísticos) - Escola Politécnica, Universidade de São Paulo, São Paulo, 2004, 2004. 
12 MOORE, E.; WARMKE, J.; GORBAN, L. The indispensable role of management science in centralizing freight operations at reynoldsmetals-company. INTERFACES, 1991, INST OPERATIONS RESEARCH MANAGEMENT SCIENCES, 901 ELKRIDGE LANDING RD, STE 400, LINTHICUM HTS, MD 21090-2909, 21, n. 1, p. 107-129, JAN-FEB 1991. ISSN 0092-2102.

13 ALVAREnGA, A. C.; NOVAES, A. G. Logística Aplicada - Suprimentos e Distribuição Física. [S.l.]: 3. ed. São Paulo: Editora Edgard Blucher, 2000.

14 YEUN, L. C. e. a. Vehicle routing problem: Models and solutions. Journal of Quality Measurement and Analysis, 2008, v. 4(1), p. 205-218, 2008.

15 EULER, L. Solutio problematis ad geometrian situs pertinentis. Commentarii academiae scientarum petropolitanae 8, 1736, p. 128-140, 1736.

16 SHERAFAT, H. Algoritmos heurísticos de cobertura de arcos. Universidade Federal de Santa Catarina. Centro Tecnológico. Programa de Pós-Graduação em Engenharia de Produção., 2004. Disponível em: $<$ http://books.google.com.br/books?id=pMxWkgEACAAJ >.

17 BELFIORE, P. P. Scatter Search para problemas de roteirização de veículos com frota heterogênea, janelas de tempo e entregas fracionadas. [S.1.]: São Paulo: [s.n.], 2006.

18 HILLIER, F. S.; LIEBERMAN, G. J. Introduction operations research. [S.l.]: 8. ed. McGraw-Hill, 2006.

19 PAPADIMITRIOU, C.; STEIGLITZ, K. Combinatorial Optimization: Algorithms and Complexity. Dover Pub., 1998. (Dover Books on Computer Science Series). ISBN 9780486402581. Disponível em: $<$ http://books.google.com.br/books?id=u1RmDoJqkF4C $>$.

20 ERGUN, O.; KUYZU, G.; SAVELSBERGH, M. The lane covering problem. Manuscript. 2003.

21 AGARWAL, R. e. a. Optimization and logistics challenges in the enterprise. In: . [S.l.]: Springer-Verlag, 2006. cap. Collaboration in Cargo Transportation, p. 373-409.

22 ERGUN, O.; KUYZU, G.; SAVELSBERGH, M. Shipper collaboration. Computers \& Operations Research, 2007, p. 1551-1560, 2007.

23 THOMASSEN, C. On the complexity of finding a minimum cycle cover of a graph. SIAM JOURNAL ON COMPUTING, 1997, SIAM PUBLICATIONS, 3600 UNIV CITY SCIENCE CENTER, PHILADELPHIA, PA 19104-2688, 26, n. 3, p. 675-677, JUN 1997. ISSN 0097-5397.

24 GUAN, M. G.; FLEISCHNER, H. On the minimum weighted cycle covering problem for planar graphs. Ars Combinatoria, 1985, v. 20, p. 61-68, 1985.

25 KESEL'MAN, D. Covering the edges of a graph by circuits. Kibernetica, 1987, Kluwer Academic Publishers-Plenum Publishers, v. 3, p. 16-22, 1987. ISSN 0011-4235. Disponível em: <http://dx.doi.org/10.1007/BF01074821>. 
26 FERRI, E. B. Uma proposta de heurística para solução do problema de cobertura de rotas com cardinalidade restrita. Dissertação (Mestrado) - Escola Politécnica da Universidade de São Paulo, São Paulo, 2009.

27 OEZENER, O. O.; ERGUN, O. Allocating costs in a collaborative transportation procurement network. TRANSPORTATION SCIENCE, 2008, INFORMS, 7240 PARKWAY DR, STE 310, HANOVER, MD 21076-1344 USA, 42, n. 2, p. 146-165, MAY 2008. ISSN 0041-1655.

28 NADARAJAH, S. Collaborative Logistics in Vehicle Routing. Tese (Doutorado) — Waterloo, 2008.

29 DIAS, G. M.; TSUZUKI, M. S. G. Modelagem para colaboração entre embarcadores. In: SAE International. [S.l.: s.n.], 2010.

30 MATTSOn, T.; SANDERS, B.; MASSInGILL, B. Patterns for parallel programming. [S.l.]: Boston: Pearson, 1985. (Software patterns series).

31 BOTTER, R. C.; TACLA, D.; HINO, C. M. Estudo e aplicação de transporte colaborativo para cargas de grande volume. Pesquisa Operacional, 2006, v. 26, p. 25-49, 2006.

32 DIAS, G.; ARAÚJO, M. Portal para otimização de redes logísticas. Trabalho de Graduação - Escola Politécnica da Universidade de São Paulo. 


\section{Apêndice A - Aplicação da Proposta ao Transporte Colaborativo}

A forte pressão por redução de custos, aumento da competitividade e exigência por níveis de serviços agressivos têm forçado empresas a focarem suas energias em melhorias operacionais, tais como eficiência e agilidade da cadeia de suprimentos. Nesse cenário, a logística colaborativa é vista por diversos autores como uma oportunidade para atingir esses objetivos, reduzindo custos que não poderiam ser otimizados individualmente pelas empresas. Apresentado pela primeira vez no ano de 2000 pelo Comitê de Logística do VICS (Voluntary Interindustry Commerce Standards Association), o termo Transporte Colaborativo (CTM - Collaborative Transportation Management) é definido pelo Sub-Comitê de Logística do VICS (retirado de Figueiredo e Eiras ${ }^{[7]}$ ): "um processo holístico que une parceiros de uma cadeia de suprimentos e provedores de serviços logísticos no intuito de eliminar as ineficiências do planejamento e da execução do transporte, e tendo como objetivo principal otimizar o desempenho operacional de todas as partes envolvidas na colaboração".

Esse mesmo Sub-Comitê de Transporte Colaborativo do VICS fez um estudo, sobre iniciativas-piloto começadas em 1999 por empresas nos Estados Unidos e, de acordo com resultados apresentados em ${ }^{[7]}$, experimentaram uma série de benefícios aos embarcadores e transportadores, relacionados a produtividade de ativos de transporte, Redução de Custos e Nível de Serviço, como pode ser visto na Tabela A.1. 
Tabela A.1: Benefícios do Transporte Colaborativo (Figueiredo e Eiras ${ }^{[7]}$ ).

Benefícios para o Embarcador

\begin{tabular}{lll}
\hline \multirow{2}{*}{ Nível de Serviço } & Pontualidade das entregas & Aumento de até 35\% \\
\cline { 2 - 3 } & Lead-time das entregas & Redução de até $\mathbf{7 5 \%}$ \\
\hline \multirow{3}{*}{ Custos Logísticos } & Estoques & Redução de até $\mathbf{5 0 \%}$ \\
\cline { 2 - 3 } & Transporte de Cargas Urgentes & Redução de até $\mathbf{2 0 \%}$ \\
\cline { 2 - 3 } & Custos Administrativos & Redução de até $\mathbf{2 0 \%}$ \\
\hline
\end{tabular}

Benefícios para o Transportador

\begin{tabular}{lll}
\hline \multirow{3}{*}{ Produtividade } & Trechos vazios (reposicionamentos) & Redução de até 15\% \\
\cline { 2 - 3 } & Tempo de espera & Redução de até 15\% \\
\cline { 2 - 3 } & Utilização da Frota & Aumento de até 33\% \\
\hline
\end{tabular}

Segundo (Browning, 2001) apud Botter, Tacla e Hino ${ }^{[31]}$, operacionalmente o transporte colaborativo acontece com o aproveitamento ou compartilhamento do mesmo equipamento de transporte para um ciclo fechado de movimentação de cargas. A proposta deste trabalho busca sinergia de demandas em busca de maior produtividade dos ativos de transporte. Ou seja, a proposta busca reduzir os deslocamentos vazios (reposicionamento do veículo) através de sinergia de demandas, que podem ser de vários embarcadores e é onde encaixa o conceito de transporte colaborativo.

Visando ilustrar a aplicação da proposta como ferramenta de planejamento de transporte colaborativo, será apresentado a seguir um exemplo de aplicação extraído de ${ }^{[32]}$.

\section{A.1 Exemplo de aplicação em Transporte Cola- borativo}

Dias e Araújo ${ }^{[32]}$, utilizando a abordagem de gerador de caminhos combinatória e solver PLI, muito próxima da abordagem utilizada neste trabalho, propôs um exemplo de colaboração entre duas empresas que será apresentado a seguir. Para exemplificar os resultados de uma operação colaborativa, será apresentado este caso de duas empresas fictícias, Empresa A e Empresa B, que possuem demandas distintas e um potencial de otimização de suas próprias operações e também de uma operação colaborativa.

Primeiramente, serão apresentadas as demandas de transporte da Empresa A, através da tabela e do mapa da Fig. (A.1). 
A Empresa A poderia contratar transportadoras independentes para cada demanda específica ou considerar sua rede logística como um todo e otimizála através da utilização de circuitos logísticos. Os custos relativos à operação individual, sem colaboração, dessa empresa são, R $\$ 203.978,85$ para operação não otimizada (uma contratação para cada demanda) e R \$138.647,10 para operação otimizada (sem colaboração com outra empresa). Para a operação isolada, ou seja, sem colaborar com a Empresa B, a Empresa A consegue otimizar seus custos em $32 \%$, conforme Fig. (A.2) .
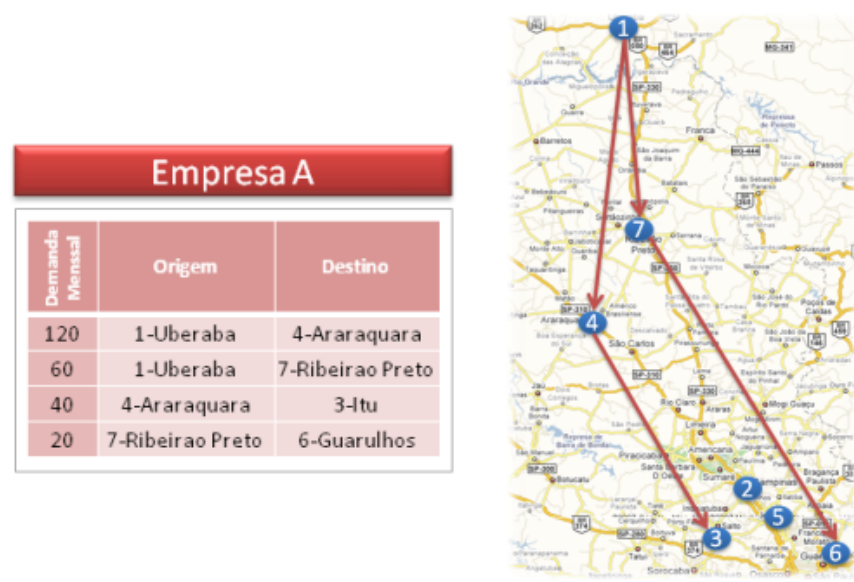

Figura A.1: Rede Logística da Empresa A.

A Empresa A poderia contratar transportadoras independentes para cada demanda específica ou considerar sua rede logística como um todo e otimizála através da utilização de circuitos logísticos. Os custos relativos à operação individual, sem colaboração, dessa empresa são, R\$203.978,85 para operação não otimizada (uma contratação para cada demanda) e $\mathrm{R} \$ 138.647,10$ para operação otimizada (sem colaboração com outra empresa). Para a operação isolada, ou seja, sem colaborar com a Empresa B, a Empresa A consegue otimizar seus custos em $32 \%$, conforme Fig. (A.2).

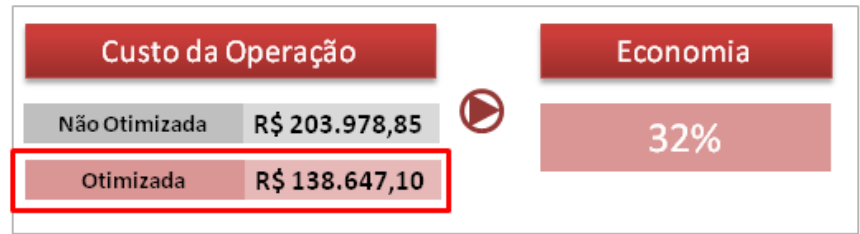

Figura A.2: Comparativo de Custos (Empresa A).

Do mesmo modo, a Empresa B, cujas demandas estão representadas na Fig. (A.3), poderia optar pelos mesmos tipos de serviços citados acimas, cujos custos estão apresentados na Fig. (A.4). E seguindo o mesmo raciocínio aplicado na Empresa A, a Empresa B experimenta uma economia de $9 \%$ sem colaboração. 

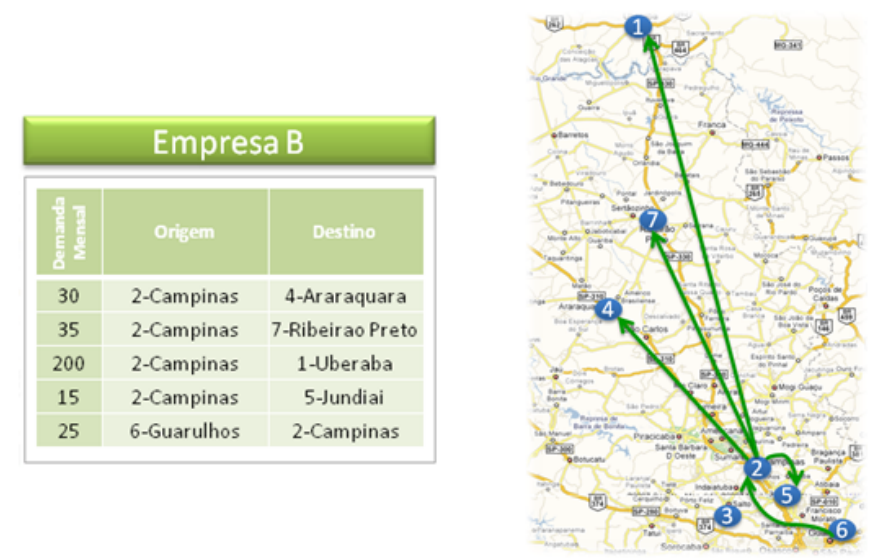

Figura A.3: Comparativo de Custos (Empresa B).

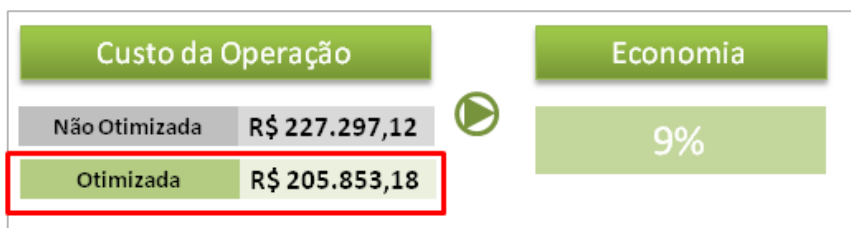

Figura A.4: Comparativo de Custos (Empresa B).

Nota-se que a otimização da malha gera ganhos significativos, mesmo quando realizada dentro dos domínios de uma única organização. Entretanto, como será visto, poderia obter uma economia ainda maior com a participação de mais embarcadores na colaboração. Na Fig. (A.5), temos a apresentação dos resultados obtidos através da colaboração entre as empresas A e B.

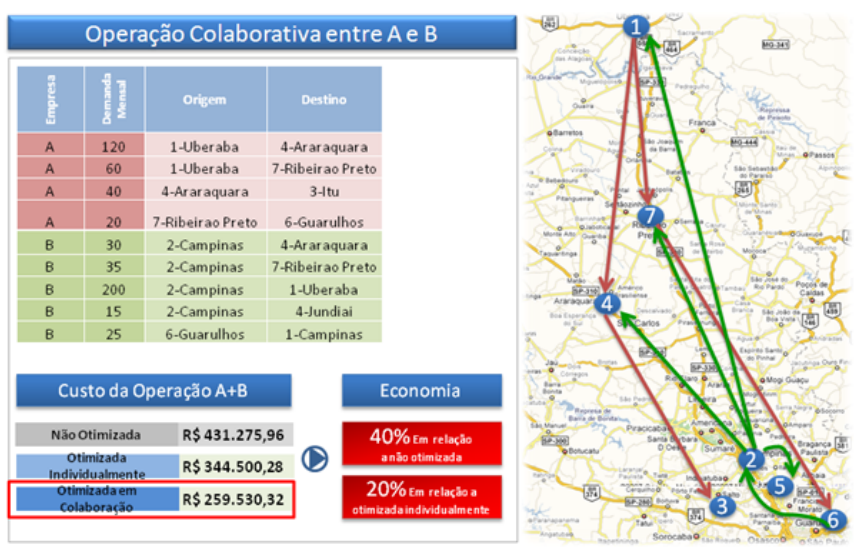

Figura A.5: Operação Colaborativa entre A e B.

Nota-se que somados individualmente (sem colaboração) os cenários de A e B, com operação individual otimizada obteve uma economia de $40 \%$ em relação a operação individual não otimizada. Para a operação colaborativa entre A e B, oteve-se mais $20 \%$ de economia em relação a operação individual otimizada, totalizando uma economia de $52 \%$ (40\% mais $20 \%$ acumulativa) no exemplo apresentado. 


\section{Apêndice B - Aplicação da Proposta à Modelo com Dados FIPE/IDET}

Visando mostrar uma aplicação de grande escala (729 arcos $=27$ UFs origens x 27 UFs destinos) e com dados reais, foi elaborado neste trabalho um modelo baseado em dados da FIPE/IDET para Jan/2010, apresentados nas tabelas do Anexo A. Além da aplicação prática das heurísticas, é possível extrair desse modelo estimativas importantes para a economia brasileira, como por exemplo o potencial de economia com sinergias de transporte através de rotas contínuas.

Como comentado por Ferri ${ }^{[26]}$, o Brasil possui um desbalanceamento nos vetores de cargas, onde a maior parte das cargas possuem origem no interior do país e destino sentido ao litoral, mais representativamente rumo ao estado de São Paulo e principal origem no estado do Mato Grosso, conforme Tabela B.1. Esse desbalanceamento prejudica o aproveitamento dos veículos de transporte, dado que a carga de retorno não existe para todos, fazendo-se necessários deslocamentos de reposicionamento dos veículos. 
Tabela B.1: Desbalanceamento dos Vetores de Cargas no Brasil (Fonte: FIPE/IDET para Jan/2010).

\begin{tabular}{lrrr}
\hline UF-REGIAO & \multicolumn{1}{c}{ SAINDO } & \multicolumn{1}{c}{ ENTRANDO } & DESBALANCEAMENTO \\
\hline SP & $12,198,017,162$ & $14,203,232,547$ & $2,005,215,385$ \\
\hline RS & $3,451,626,691$ & $4,770,950,966$ & $1,319,324,275$ \\
\hline CE & $309,467,461$ & $953,718,982$ & $644,251,521$ \\
\hline SC & $1,419,010,611$ & $1,986,577,174$ & $567,566,563$ \\
\hline PE & $664,472,342$ & $1,022,447,552$ & $357,975,210$ \\
\hline SE & $148,060,171$ & $472,516,923$ & $324,456,752$ \\
\hline MG & $3,111,216,414$ & $3,331,378,688$ & $220,162,274$ \\
\hline PI & $95,398,982$ & $295,878,447$ & $200,479,465$ \\
\hline EF & $105,272,905$ & $290,665,018$ & $185,392,113$ \\
\hline MS & $447,094,249$ & $617,400,319$ & $170,306,070$ \\
\hline PB & $334,001,507$ & $473,527,441$ & $139,525,934$ \\
\hline AL & $86,788,846$ & $221,140,318$ & $134,351,472$ \\
\hline RN & $89,438,005$ & $216,536,473$ & $127,098,468$ \\
\hline RJ & $165,758,618$ & $220,782,065$ & $55,023,447$ \\
\hline MA & $2,135,187,447$ & $2,144,347,200$ & $9,159,753$ \\
\hline GO & $320,886,228$ & $297,956,175$ & $-22,930,053$ \\
\hline BA & $1,136,557,476$ & $773,878,352$ & $-362,679,124$ \\
\hline PR & $2,493,307,905$ & $2,088,867,953$ & $-404,439,952$ \\
\hline NORTE & $2,873,474,110$ & $2,253,575,117$ & $-619,898,993$ \\
\hline MT & $2,204,269,299$ & $1,268,531,597$ & $-935,737,702$ \\
\hline & $5,144,906,601$ & $1,030,303,723$ & $-4,114,602,878$ \\
\hline
\end{tabular}

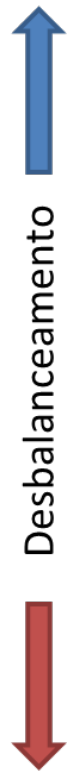

\section{Premissas e Parâmetros}

Para modelar esse cenário assumiu-se algumas premissas para simplificar a análise:

- Cargas interestaduais foram concentradas em um ponto de origem e destino por estado, pois as informações das tabelas FIPE/IDET não possuem informações de cidades de origem e destino, Fig. (B.1) no Google Maps e Fig. (B.2) modelado no Software.

- Para a região Norte não havia informações por estado e para obter um rateio entre os estados, utilizou-se como proporção o PIB de cada estado.

- Para a modelagem de custos utilizou-se os seguintes parâmetros: $C_{V}=$ $25 R \$ / k m, C_{F}=0,5 R \$ / h, T_{\text {carga }}=T_{\text {descarga }}=4$ horas.

- Não permitiu-se a utilização de contratações spot (C0), dado que o desbalanceamento não pode ser corrigido por tempo de espera. 


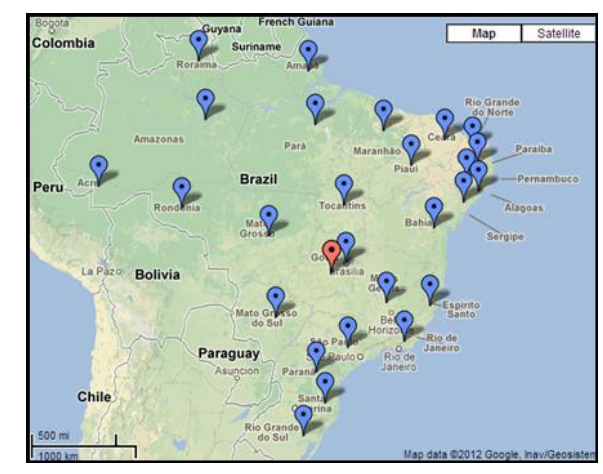

Figura B.1: Representação dos pontos no Google Maps.

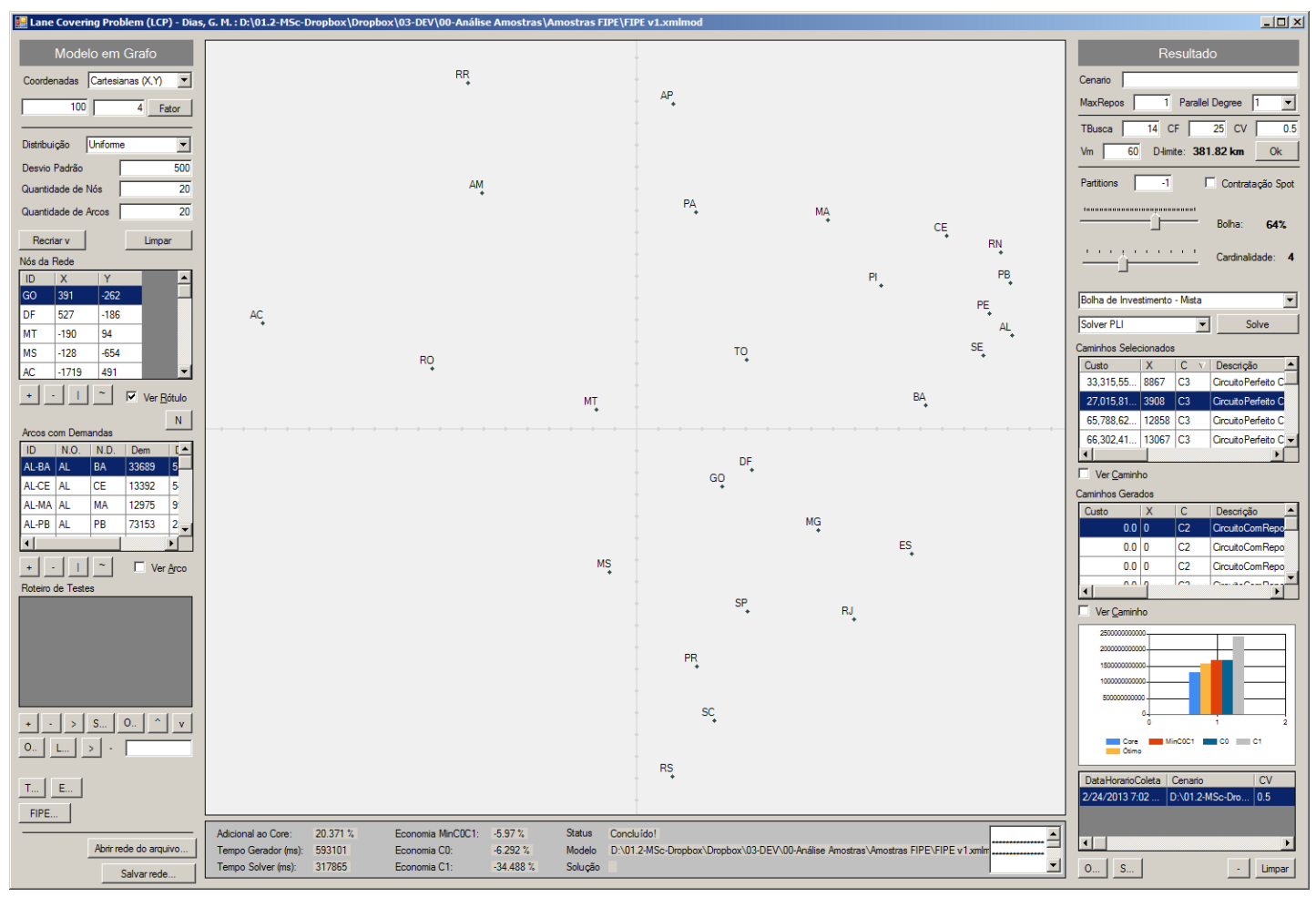

Figura B.2: Representação dos Pontos no Software

\section{Aplicação das Heurísticas e Análise dos Resultados}

Após executar o modelo com 729 arcos com Raio de Investimento Misto, Cardinalidade Máxima igual a 4 e com no máximo dois reposicionamentos, obteve-se os valores da solução representados na Tabela B.2. Dado que para esta análise não considerou-se as contratações spot ( $\mathrm{C} 0)$, pois não fazem sentido para as hipóteses da modelagem, podemos notar na Tabela B.2 que os custos encontrados pela solução são maiores que os custos de uma operação C0, no entanto como era de se esperar, o custo ótimo é menor que custo de operação C1.

Do ponto de vista de desempenho, este modelo razoavelmente grande (729 
arcos) demorou aproximadamente 15 min para encontrar a solução e gerou aproximadamente 19 mil caminhos candidatos, o que numa abordagem de Gerador Combinatório com Solver PLI não seria possível resolver com o computador utilizado.

Do ponto de vista de análise do caso, podemos chegar, com as análises a seguir, a algumas conclusões interessantes sobre o cenário de transporte rodoviário no Brasil.

Tabela B.2: Custos Associados a Rede Modelada.

\begin{tabular}{|l|rr|}
\hline Custos & Custo Estimado (R\$) & $\begin{array}{c}\text { Adicional ao Custo } \\
\text { Core }\end{array}$ \\
\hline Custo C1 & $\mathbf{2 . 1 5 3 . 5 1 1 . 8 6 0 8 7 6 , 0 0}$ & $\mathbf{8 1 , 9 \%}$ \\
\hline Custo C0 & $\mathbf{1 . 5 7 . 6 5 6 . 0 9 4 . 0 4 2 , 0 0}$ & $\mathbf{3 1 , 6 \%}$ \\
\hline Custo Total Ótimo & $1.731 .473 .421 .619,00$ & $46,3 \%$ \\
\hline Custo Core & $\mathbf{1 . 1 8 3 . 6 2 2 . 6 3 3 . 4 6 1 , 0 0}$ & \\
\hline
\end{tabular}

Analisando os $46,3 \%$ de adicional ao custo core é possível concluir que o Brasil, na melhor das hipóteses (pois analisamos o cenário otimizado), gasta pelo menos mais 46,3\% mais com veículos rodando vazio. De acordo com a Fig. (B.3), quase $70 \%$ dos custos do modelo estão associados a rotas com retorno vazio (C1), o que nos confirma o desbalanceamento de vetores de cargas citado por Ferri em $[26]$.

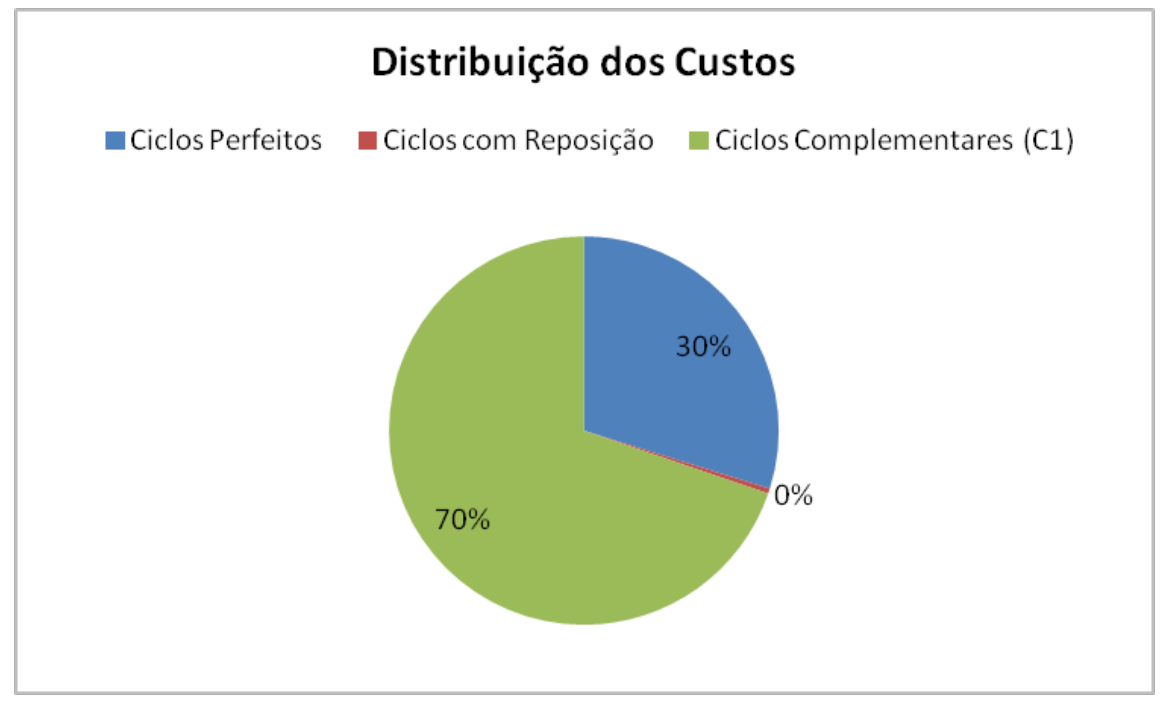

Figura B.3: Distribuição dos Custos encontrados pela Solução.

Partindo para uma análise em TKUs (toneladas transportadas por quilômetro útil), podemos notar o tamanho do desbalanceamento dos vetores de cargas no Brasil (vide Fig. (B.4)) e ainda é possível concluir que, no melhor cenário, os veículos de transporte rodam pelo menos $36 \%$ do tempo vazio. 


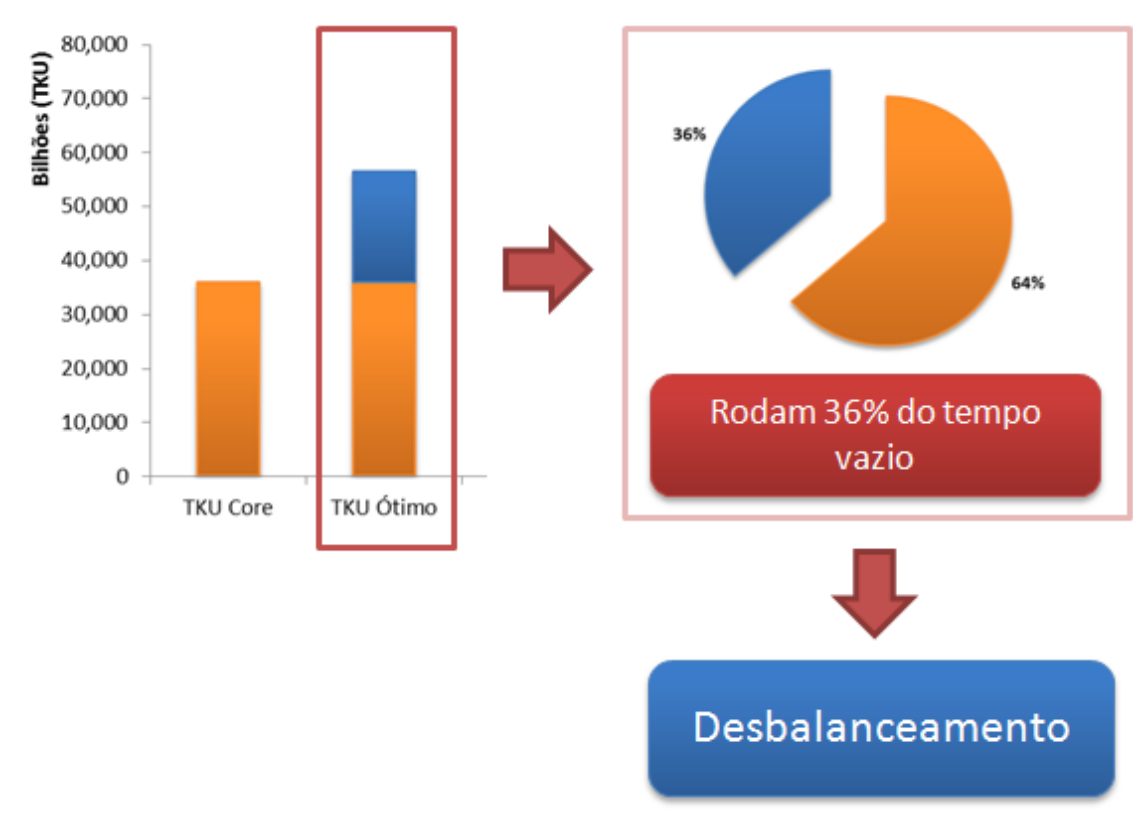

Figura B.4: Desbalanceamento dos vetores de cargas no Brasil. 


\section{Anexo A - Tabelas de Movimentação de Cargas FIPE/IDET em Jan/2010 e PIB da Região Norte (2010)}

Como não havia informações individuais sobre os estados do Norte, a título de modelagem foi feito um rateio do somatório proporcional ao PIB de cada estado, conforme Tabela A.1. Todos os valores com origem ou destino nos estados da Região Norte foram calculados seguindo essa premissa.

Tabela A.1: PIB dos estados da Região Norte em $2010\left(\mathrm{R} \$ 10^{6}\right)$

\begin{tabular}{|c|r|}
\hline \multicolumn{1}{|c|}{} & PIB 2010 \\
\hline Norte & 201.512 \\
\hline AC & 8.477 \\
\hline AM & 59.779 \\
\hline AP & 8.266 \\
\hline PA & 77.848 \\
\hline RO & 6.341 \\
\hline RR & 23.561 \\
\hline TO & 17.240 \\
\hline
\end{tabular}


Tabela A.2: Tabela FIPE/IDET Cargas Movimentadas (ton) - Janeiro2010 entre Regiões.

\begin{tabular}{|c|c|c|c|c|c|c|}
\hline$O \backslash D-T O N$ & NORTE & NORDESTE & CENTRO-OESTE & SUDESTE & SUL & BRASIL \\
\hline$A C$ & $31.509 .159,18$ & $3.458 .442,22$ & $1.424 .278,86$ & $77.434 .682,48$ & $10.409 .535,02$ & $124.236 .097,76$ \\
\hline AM & $222.199 .602,05$ & $24.388 .606,53$ & $10.043 .879,43$ & $546.062 .036,56$ & $73.407 .053,69$ & $876.101 .178,26$ \\
\hline AP & $30.724 .868,44$ & $3.372 .358,55$ & $1.388 .827,30$ & $75.507 .265,00$ & $10.150,432,52$ & $121.143 .751,81$ \\
\hline PA & $289.362 .395,16$ & $31.760 .388,11$ & $13.079 .775,94$ & $711.116 .569,74$ & $95.595 .314,66$ & $1.140 .914 .443,62$ \\
\hline RO & $23.569 .609,34$ & $2.586 .998,01$ & $1.065 .394,86$ & $57.923 .005,97$ & $7.786 .582,70$ & $92.931 .590,88$ \\
\hline$R R$ & $87.576 .654,41$ & $9.612 .405,00$ & $3.958 .645,06$ & $215.222 .195,81$ & $28.932 .293,81$ & $345.302 .194,10$ \\
\hline TO & $64.081 .385,42$ & $7.033 .566,58$ & $2.896 .610,54$ & $157.481 .883,44$ & $21.170 .270,59$ & $252.663 .716,58$ \\
\hline NORTE & $749.023 .674,00$ & $82.212 .764,00$ & $33.857 .412,00$ & $1.840 .747 .639,00$ & $247.451 .484,00$ & $2.953 .292 .973,00$ \\
\hline$A L$ & $2.636 .598,00$ & $57.088 .865,00$ & $1.430 .748,00$ & $25.528 .036,00$ & $2.753 .758,00$ & $89.438 .005,00$ \\
\hline $\mathrm{BA}$ & $11.015 .960,00$ & $718.135 .382,00$ & $6.084 .203,00$ & $1.548 .602 .322,00$ & $209.470 .041,00$ & $2.493 .307 .908,00$ \\
\hline $\mathrm{CE}$ & $47.337 .765,00$ & $164.522 .746,00$ & $43.541 .846,00$ & $44.064 .837,00$ & $10.000 .267,00$ & $309.467 .461,00$ \\
\hline MA & $2.478 .240,00$ & $242.228 .864,00$ & $4.954 .158,00$ & $69.985 .075,00$ & $1.239 .894,00$ & $320.886 .231,00$ \\
\hline PB & $3.329 .375,00$ & $67.598 .568,00$ & $4.266 .188,00$ & $9.986 .753,00$ & $1.607 .964,00$ & $86.788 .848,00$ \\
\hline $\mathrm{PE}$ & $27.687 .102,00$ & $224.189 .769,00$ & $73.184 .942,00$ & $315.566 .062,00$ & $23.844 .467,00$ & $664,472.342,00$ \\
\hline PI & $2.488 .031,00$ & $81.004 .109,00$ & $2.709 .169,00$ & $3.869 .093,00$ & $5.328 .582,00$ & $95.398 .984,00$ \\
\hline $\mathrm{RN}$ & $23.336 .324,00$ & $97.601 .307,00$ & $5.551 .409,00$ & $37.991 .210,00$ & $1.278 .369,00$ & $165.758 .619,00$ \\
\hline $\mathrm{SE}$ & $2.554 .910,00$ & $61.258 .604,00$ & $10.910 .254,00$ & $64.614 .661,00$ & $8.721 .740,00$ & $148.060 .169,00$ \\
\hline NORDESTE & $122.864 .304,00$ & $1.713 .628 .213,00$ & $152.632 .917,00$ & $2.120 .208 .049,00$ & $264.245 .082,00$ & $4.373 .578 .565,00$ \\
\hline DF & $27.945 .498,00$ & $10.607 .652,00$ & $38.697 .841,00$ & $26.956 .500,00$ & $1.065 .417,00$ & $105.272 .908,00$ \\
\hline GO & $8.806 .488,00$ & $214.142 .314,00$ & $420.408 .967,00$ & $451.236 .332,00$ & $41.963 .375,00$ & $1.136 .557 .476,00$ \\
\hline MS & $2.516 .984,00$ & $11.723 .234,00$ & $270.345 .225,00$ & $44.423 .465,00$ & $4.992 .600,00$ & $334.001 .508,00$ \\
\hline MT & $181.697 .238,00$ & $4.480 .044,00$ & $372.475 .702,00$ & $4.453 .462 .067,00$ & $132.791 .552,00$ & $5.144 .906 .603,00$ \\
\hline CENTRO-OESTE & $220.966 .209,00$ & $240.953 .244,00$ & $1.101 .927 .735,00$ & $4.976 .078 .364,00$ & $180.812 .944,00$ & $6.720 .738 .496,00$ \\
\hline ES & $3.418 .671,00$ & $43.620 .884,00$ & $6.008 .698,00$ & $374.029 .168,00$ & $20.016 .826,00$ & $447.094 .247,00$ \\
\hline MG & $72.687 .283,00$ & $461.589 .920,00$ & $163.362 .617,00$ & $2.194 .407 .564,00$ & $219.169 .027,00$ & $3.111 .216 .411,00$ \\
\hline RJ & $109.283 .855,00$ & $121.983 .130,00$ & $113.730 .780,00$ & $1.139 .241 .440,00$ & $650.948 .239,00$ & $2.135 .187 .444,00$ \\
\hline SP & $685.114 .558,00$ & $2.415 .845 .222,00$ & $711.843 .530,00$ & $4.963 .191 .109,00$ & $3.422 .022 .745,00$ & $12.198 .017 .164,00$ \\
\hline SUDESTE & $870.504 .368,00$ & $3.043 .039 .156,00$ & $994.945 .625,00$ & $8.670 .869 .281,00$ & $4.312 .156 .837,00$ & $17.891 .515 .267,00$ \\
\hline PR & $44.877 .423,00$ & $205.851 .207,00$ & $25.971 .486,00$ & $729.334 .147,00$ & $1.867 .439 .847,00$ & $2.873 .474 .110,00$ \\
\hline RS & $3.668 .490,00$ & $374.663 .403,00$ & $211.616 .277,00$ & $1.567 .856 .680,00$ & $1.293 .821 .841,00$ & $3.451 .626 .691,00$ \\
\hline $\mathrm{SC}$ & $5.650 .804,00$ & $129.496 .906,00$ & $47.423 .087,00$ & $391.264 .594,00$ & $845.175 .222,00$ & $1.419 .010 .613,00$ \\
\hline SUL & $54.196 .717,00$ & $710.011 .515,00$ & $285.010 .850,00$ & $2.688 .455 .420,00$ & $4.006 .436 .910,00$ & $7.744 .111 .412,00$ \\
\hline BRASIL & $2.017 .555 .271,00$ & $5.789 .844 .893,00$ & $2.568 .374 .538,00$ & $20.296 .358 .754,00$ & $9.011 .103 .257,00$ & $39.683 .236 .713,00$ \\
\hline
\end{tabular}

Tabela A.3: Tabela FIPE/IDET Cargas Movimentadas (ton) - Janeiro2010 Destino: Região Norte.

\begin{tabular}{|c|c|c|c|c|c|c|c|c|c|c|}
\hline O\D - TON & NORTE & AL & $B A$ & $C E$ & MA & $\mathrm{PB}$ & $P E$ & PI & $R N$ & SE \\
\hline$A C$ & $31.509 .159,18$ & $180.291,27$ & $716.146,14$ & $415.528,98$ & $417.611,76$ & $134.612,00$ & \begin{tabular}{|l|}
$550.929,49$ \\
\end{tabular} & $499.327,28$ & $215.572,96$ & $328.422,33$ \\
\hline AM & $222.199 .602,05$ & $1.271 .396,91$ & $5.050 .194,66$ & $2.930 .270,99$ & $2.944 .958,54$ & $949.271,07$ & $3.885 .102,51$ & $3.521 .208,62$ & $1.520 .200,09$ & $2.316 .003,14$ \\
\hline AP & $30.724 .868,44$ & $175.803,66$ & $698.320,63$ & $405.186,10$ & $407.217,04$ & $131.261,39$ & \begin{tabular}{|l|}
$537.216,37$ \\
\end{tabular} & $4866.898,58$ & $210.207,16$ & $320.247,61$ \\
\hline$P A$ & $289.362 .395,16$ & $1.655 .693,59$ & $6.576 .683,35$ & $3.815 .984,47$ & $3.835 .111,53$ & $1.236 .200,91$ & $5.059 .426,56$ & $4.585 .540,88$ & $1.979 .700,85$ & $3.016 .045,97$ \\
\hline RO & $.569 .609,34$ & $134.862,21$ & $535.694,55$ & $310.825,68$ & $312,383,65$ & $100.693,02$ & $412,108,52$ & $373.508,82$ & $161.253,76$ & $245.667,81$ \\
\hline$R R$ & $87.576 .654,41$ & $501.102,10$ & $1.990,458,80$ & $1.154 .922,54$ & $1.160 .711,42$ & $374.141,01$ & $1.531 .255,13$ & $1.387 .831,78$ & $599.164,16$ & $912.818,05$ \\
\hline Tо & $64.081 .385,42$ & $366.665,26$ & $1.456,453,87$ & $845.077,23$ & $849.313,06$ & $273.765,59$ & $1.120 .446,43$ & $1.015 .501,04$ & $438.419,00$ & $667.925,09$ \\
\hline NORTE & $749.023 .674,00$ & $4.285 .815,00$ & $17.023 .952,00$ & $9.877 .796,00$ & $9.927 .307,00$ & $3.199 .945,00$ & $13.096 .485,00$ & $11.869 .817,00$ & $5.124 .518,00$ & $7.807 .130,00$ \\
\hline AL & $2.636 .598,00$ & $49.071 .032,00$ & $926.459,00$ & $368.290,00$ & $356.825,00$ & $2.011 .711,00$ & $1.452 .968,00$ & $355.981,00$ & $354.696,00$ & $2.190 .903,00$ \\
\hline $\mathrm{BA}$ & $11.015 .960,00$ & $106.546 .009,00$ & $541.989 .826,00$ & $4.422 .317,00$ & $406.276,00$ & $10.875 .017,00$ & $12.438 .904,00$ & $405,439,00$ & $2.052 .173,00$ & $38.999 .419,00$ \\
\hline $\mathrm{CE}$ & $47.337 .765,00$ & $422,892,00$ & $1.759 .605,00$ & $139.608 .992,00$ & $689.150,00$ & $629.020,00$ & $3.611 .411,00$ & $4.628 .264,00$ & $12.297 .286,00$ & $876.126,00$ \\
\hline MA & $478.240,00$ & $359.253,00$ & $362.941,00$ & $1.967 .962,00$ & $165.789 .282,00$ & $4.391 .026,00$ & $66.241 .541,00$ & $452.393,00$ & $2.307 .821,00$ & $356.643,00$ \\
\hline$P B$ & $3.329 .375,00$ & $480.450,00$ & $1.453 .368,00$ & $2.153 .917,00$ & $1.071 .239,00$ & $55.701 .122,00$ & $4.522 .407,00$ & $1.026 .574,00$ & $793.419,00$ & $396.072,00$ \\
\hline PE & $27.687 .102,00$ & $5.398 .235,00$ & $32.560 .601,00$ & $11.392 .216,00$ & $5.028 .960,00$ & \begin{tabular}{|l|}
$15.602 .676,00$ \\
\end{tabular} & $139.165 .288,00$ & $1.724 .078,00$ & $9.771 .835,00$ & $3.545 .880,00$ \\
\hline PI & $2.488 .031,00$ & $355.981,00$ & $364.845,00$ & $1.898 .026,00$ & $463.692,00$ & $365.538,00$ & $355.789,00$ & $76.488 .583,00$ & $355.855,00$ & $355.799,00$ \\
\hline$R N$ & $336.324,00$ & $354.696,00$ & $401.288,00$ & $4.628 .377,00$ & $372.253,00$ & $590.767,00$ & $6.718 .625,00$ & $1.538 .397,00$ & $2.614 .035,00$ & $382.868,00$ \\
\hline SE & 00 & $1.222 .575,00$ & 00 & $434.003,00$ & $461.627,00$ & $354.771,00$ & $418.405,00$ & $451.304,00$ & $\begin{array}{l}376.028,00 \\
\end{array}$ & $52.996 .889,00$ \\
\hline NORDESTE & $122.864 .304,00$ & $164.211 .123,00$ & $84.361 .937,00$ & 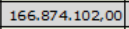 & \begin{tabular}{|l|l|}
$174.639 .305,00$ \\
\end{tabular} & $90.521 .648,00$ & $254.925 .338,00$ & $87.071 .013,00$ & $90.923 .148,00$ & $100.100 .600,00$ \\
\hline $\mathrm{DF}$ & $27.945 .498,00$ & $353.588,00$ & \begin{tabular}{|l|}
$353.588,00$ \\
\end{tabular} & $353.588,00$ & $3.535 .884,00$ & \begin{tabular}{|l|}
$353.588,00$ \\
\end{tabular} & $4.596 .649,00$ & $353.588,00$ & $353.588,00$ & $353.588,00$ \\
\hline Go & $8.806 .488,00$ & $981.854,00$ & $.679 .928,00$ & $5.774 .563,00$ & $2.351 .452,00$ & $6.157 .547,00$ & $61.049 .356,00$ & $419.897,00$ & $10.025 .274,00$ & $40.702 .443,00$ \\
\hline MS & $2.516 .984,00$ & $359.638,00$ & $358.724,00$ & $360.184,00$ & $359.355,00$ & $360.251,00$ & $360.039,00$ & $359.224,00$ & $8.846 .716,00$ & $359.104,00$ \\
\hline MT & $181.697 .238,00$ & $359.655,00$ & $1.619 .552,00$ & $360.182,00$ & $353.588,00$ & $353.588,00$ & $360.056,00$ & $359.222,00$ & $360.612,00$ & $353.588,00$ \\
\hline CENTRO-OESTE & $220.966 .209,00$ & $2.054 .736,00$ & $39.011 .793,00$ & $56.848 .517,00$ & $6.600 .280,00$ & $7.224 .976,00$ & $66.366 .099,00$ & $1.491 .931,00$ & $19.586 .190,00$ & $41.768 .723,00$ \\
\hline ES & $3.418 .671,00$ & $393.290,00$ & $859.452,00$ & $2.836 .468,00$ & $619.882,00$ & $30.372 .110,00$ & $1.808 .468,00$ & $404.771,00$ & $5.466 .109,00$ & $860.335,00$ \\
\hline MG & $.687 .283,00$ & $10.302 .350,00$ & $1.862 .818,00$ & $51.084 .314,00$ & $23.248 .637,00$ & $9.582 .736,00$ & $69.312 .571,00$ & $7.628 .740,00$ & $211.509,00$ & $153.356 .247,00$ \\
\hline $\mathrm{RJ}$ & $109.283 .855,00$ & $2.816 .808,00$ & $16.706 .716,00$ & $15.863 .157,00$ & \begin{tabular}{|l|}
$8.405 .062,00$ \\
\end{tabular} & $6.378 .223,00$ & $34.609 .696,00$ & $2.202 .865,00$ & $5.067 .911,00$ & $29.932 .693,00$ \\
\hline SP & $685.114 .558,00$ & $10.236 .093,00$ & \begin{tabular}{|l|}
$1.027 .680 .346,00$ \\
\end{tabular} & $623.430 .605,00$ & $63.987 .205,00$ & $53.047 .581,00$ & $483.498 .077,00$ & $25.690 .905,00$ & $54.452 .109,00$ & $73.822 .300,00$ \\
\hline SUDESTE & $870.504 .368,00$ & $23.748 .540,00$ & \begin{tabular}{|l|}
$1.177 .109 .331,00$ \\
\end{tabular} & 693.214.544,00 & $96.260 .785,00$ & $99.380 .650,00$ & $589.228 .812,00$ & $35.927 .282,00$ & $70.197 .637,00$ & $257.971 .575,00$ \\
\hline$P R$ & $44.877 .423,00$ & $4.022 .190,00$ & $10.096 .869,00$ & $12.173 .538,00$ & $2.822 .793,00$ & $4.455 .865,00$ & $9.033 .848,00$ & \begin{tabular}{|l|}
$100.257 .287,00$ \\
\end{tabular} & $20.351 .588,00$ & $42.637 .230,00$ \\
\hline RS & $3.668 .490,00$ & $12.423 .669,00$ & $226.353 .638,00$ & $9.956 .118,00$ & $5.020 .905,00$ & $9.029 .575,00$ & $37.707 .277,00$ & $55.582 .955,00$ & $11.431 .383,00$ & $7.157 .882,00$ \\
\hline sc & $5.650 .804,00$ & $5.790 .400,00$ & $34.910 .434,00$ & $4.774 .369,00$ & $2.684 .801,00$ & $7.327 .661,00$ & $52,089.692,00$ & $3.678 .163,00$ & $3.167 .600,00$ & $15.073 .784,00$ \\
\hline 80 & $54.196 .717,00$ & $22.236 .259,00$ & $271.360 .941,00$ & $26.904,025,00$ & $10.528 .498,00$ & $20.813 .101,00$ & $98.830 .817,00$ & \begin{tabular}{|l}
$159.518 .406,00$ \\
\end{tabular} & $34.950 .571,00$ & \\
\hline BRASIL & $55.271,00$ & 1,00 & $67.955,00$ & $353.718 .983,00$ & $97.956 .175,00$ & $221.140 .321,00$ & $022.447 .551,00$ & 295.8 & 0644,00 & 772 \\
\hline
\end{tabular}


Tabela A.4: Tabela FIPE/IDET Cargas Movimentadas (ton) - Janeiro2010 Destino: Região Centro-Oeste.

\begin{tabular}{|c|c|c|c|c|c|c|}
\hline O\D - TON & NORTE & DF & GO & MS & MT & CENTRO-OESTE \\
\hline $\mathrm{AC}$ & $31.509 .159,18$ & $379.521,80$ & $602.284,73$ & $134.866,17$ & $307.606,16$ & $1.424 .278,86$ \\
\hline AM & $222.199 .602,05$ & $2.676 .351,74$ & $4.247 .254,76$ & $951.063,44$ & $2.169 .209,49$ & $10.043 .879,43$ \\
\hline AP & $30.724 .868,44$ & $370.075,17$ & $587.293,33$ & $131.509,23$ & $299.949,57$ & $1.388 .827,30$ \\
\hline PA & $289.362 .395,16$ & $3.485 .314,75$ & $5.531 .044,15$ & $1.238 .535,05$ & $2.824 .881,99$ & $13.079 .775,94$ \\
\hline RO & $23.569 .609,34$ & $283.891,44$ & $450.523,47$ & $100.883,14$ & $230.096,81$ & $1.065 .394,86$ \\
\hline$R R$ & $87.576 .654,41$ & $1.054 .844,06$ & $1.673 .992,03$ & $374.847,45$ & $854.961,52$ & $3.958 .645,06$ \\
\hline TO & $64.081 .385,42$ & $771.848,04$ & $1.224 .889,54$ & $274.282,50$ & $625.590,45$ & $2.896 .610,54$ \\
\hline NORTE & $749.023 .674,00$ & $9.021 .847,00$ & $14.317 .282,00$ & $3.205 .987,00$ & $7.312 .296,00$ & $33.857 .412,00$ \\
\hline $\mathrm{AL}$ & $2.636 .598,00$ & $353.588,00$ & $357.867,00$ & $359.638,00$ & $359.655,00$ & $1.430 .748,00$ \\
\hline $\mathrm{BA}$ & $11.015 .960,00$ & $2.738 .383,00$ & $1.921 .196,00$ & $358.724,00$ & $1.065 .899,00$ & $6.084 .203,00$ \\
\hline $\mathrm{CE}$ & $47.337 .765,00$ & $8.394 .266,00$ & $34.414 .025,00$ & $366.779,00$ & $366.775,00$ & $43.541 .846,00$ \\
\hline MA & $2.478 .240,00$ & $353.588,00$ & $357.508,00$ & $353.588,00$ & $3.889 .473,00$ & $4.954 .158,00$ \\
\hline PB & $3.329 .375,00$ & $353.588,00$ & $1.424 .137,00$ & $360.251,00$ & $2.128 .211,00$ & $4.266 .188,00$ \\
\hline $\mathrm{PE}$ & $27.687 .102,00$ & $53.821 .360,00$ & $3.715 .929,00$ & $382.325,00$ & $15.265 .328,00$ & $73.184 .942,00$ \\
\hline PI & $2.488 .031,00$ & $353.588,00$ & $1.648 .403,00$ & $353.588,00$ & $353.588,00$ & $2.709 .169,00$ \\
\hline RN & $23.336 .324,00$ & $353.588,00$ & $940.731,00$ & $360.594,00$ & $3.896 .496,00$ & $5.551 .409,00$ \\
\hline SE & $2.554 .910,00$ & $372.499,00$ & $9.819 .531,00$ & $359.104,00$ & $359.121,00$ & $10.910 .254,00$ \\
\hline NORDESTE & $122.864 .304,00$ & $67.094 .450,00$ & $54.599 .328,00$ & $3.254 .592,00$ & $27.684 .546,00$ & $152.632 .917,00$ \\
\hline DF & $27.945 .498,00$ & $18.890 .873,00$ & $8.259 .119,00$ & $356.778,00$ & $11.191 .071,00$ & $38.697 .841,00$ \\
\hline GO & $8.806 .488,00$ & $7.695 .264,00$ & $406.245 .394,00$ & $2.788 .086,00$ & $3.680 .224,00$ & $420.408 .967,00$ \\
\hline MS & $2.516 .984,00$ & $354.945,00$ & $447.645,00$ & $264.149 .194,00$ & $5.393 .440,00$ & $270.345 .225,00$ \\
\hline MT & $181.697 .238,00$ & $4.166 .949,00$ & $7.139 .182,00$ & $2.651 .667,00$ & $358.517 .903,00$ & $372.475 .702,00$ \\
\hline CENTRO-OESTE & $220.966 .209,00$ & $31.108 .031,00$ & $422.091 .341,00$ & $269.945 .724,00$ & $378.782 .638,00$ & $1.101 .927 .735,00$ \\
\hline ES & $3.418 .671,00$ & $1.747 .580,00$ & $3.528 .203,00$ & $364.576,00$ & $368.339,00$ & $6.008 .698,00$ \\
\hline MG & $72.687 .283,00$ & $34.775 .276,00$ & $99.606 .521,00$ & $3.364 .039,00$ & $25.616 .782,00$ & $163.362 .617,00$ \\
\hline RJ & $109.283 .855,00$ & $13.395 .325,00$ & $29.473 .683,00$ & $29.325 .869,00$ & $41.535 .904,00$ & $113.730 .780,00$ \\
\hline SP & $685.114 .558,00$ & $117.544 .316,00$ & $129.448 .882,00$ & $140.832 .837,00$ & $324.017 .495,00$ & $711.843 .530,00$ \\
\hline SUDESTE & $870.504 .368,00$ & $167.462 .496,00$ & $262.057 .288,00$ & $173.887 .320,00$ & $391.538 .520,00$ & $994.945 .625,00$ \\
\hline PR & $44.877 .423,00$ & $1.939 .788,00$ & $2.731 .783,00$ & $4.355 .063,00$ & $16.944 .851,00$ & $25.971 .486,00$ \\
\hline RS & $3.668 .490,00$ & $11.308 .481,00$ & $6.782 .090,00$ & $17.060 .484,00$ & $176.465 .221,00$ & $211.616 .277,00$ \\
\hline sc & $5.650 .804,00$ & $2.729 .926,00$ & $11.299 .241,00$ & $1.818 .270,00$ & $31.575 .651,00$ & $47.423 .087,00$ \\
\hline SUL & $54.196 .717,00$ & $15.978 .194,00$ & $20.813 .115,00$ & $23.233 .817,00$ & $224.985 .723,00$ & $285.010 .850,00$ \\
\hline BRASIL & $2.017 .555 .271,00$ & $290.665 .020,00$ & $773.878 .354,00$ & $473.527 .441,00$ & $1.030 .303 .723,00$ & $2.568 .374 .538,00$ \\
\hline
\end{tabular}


Tabela A.5: Tabela FIPE/IDET Cargas Movimentadas (ton) - Janeiro2010 Destino: Região Sudeste.

\begin{tabular}{|c|c|c|c|c|c|}
\hline O\D - TON & ES & MG & RJ & SP & SUDESTE \\
\hline $\mathrm{AC}$ & $124.093,87$ & $14.272 .545,59$ & $25.223 .889,06$ & $37.814 .153,95$ & $77.434 .682,48$ \\
\hline AM & $875.098,20$ & $100.648 .637,85$ & $177.876 .473,30$ & $266.661 .827,21$ & $546.062 .036,56$ \\
\hline AP & $121.005,06$ & $13.917 .289,36$ & $24.596 .044,23$ & $36.872 .926,34$ & $75.507 .265,00$ \\
\hline PA & $139.608,31$ & $131.071 .030,95$ & $231.642 .009,62$ & $347.263 .920,85$ & $711.116 .569,74$ \\
\hline Ro & $92.825,20$ & $10.676 .207,57$ & $18.868 .076,03$ & $28.285 .897,16$ & $57.923 .005,97$ \\
\hline$R R$ & $344.906,89$ & $39.669 .157,34$ & $70.107 .355,21$ & $105.100 .776,38$ & $215.222 .195,81$ \\
\hline TO & $252.374,46$ & $29.026 .623,34$ & $51.298 .790,54$ & $76.904 .095,10$ & $157.481 .883,44$ \\
\hline NORTE & $2.949 .912,00$ & $339.281 .492,00$ & $599.612 .638,00$ & $898.903 .597,00$ & $1.840 .747 .639,00$ \\
\hline AL & $356.848,00$ & $8.012 .106,00$ & $1.538 .742,00$ & $15.620 .341,00$ & $25.528 .036,00$ \\
\hline $\mathrm{BA}$ & $1.754 .187,00$ & $42.054 .771,00$ & $110.435 .533,00$ & $1.384 .357 .831,00$ & $1.548 .602 .322,00$ \\
\hline $\mathrm{CE}$ & $471.614,00$ & $8.214 .782,00$ & $3.576 .751,00$ & $31.801 .691,00$ & $44.064 .837,00$ \\
\hline MA & $399.008,00$ & $8.356 .025,00$ & $53.309 .389,00$ & $7.920 .653,00$ & $69.985 .075,00$ \\
\hline PB & $365.209,00$ & $5.765 .502,00$ & $1.354 .687,00$ & $2.501 .354,00$ & $9.986 .753,00$ \\
\hline $\mathrm{PE}$ & $492.287,00$ & $5.873 .547,00$ & $26.542 .999,00$ & $282.657 .229,00$ & $315.566 .062,00$ \\
\hline $\mathrm{PI}$ & $374.602,00$ & $2.542 .803,00$ & $474.860,00$ & $476.828,00$ & $3.869 .093,00$ \\
\hline RN & $446.345,00$ & $3.436 .783,00$ & $5.024 .067,00$ & $29.084 .015,00$ & $37.991 .210,00$ \\
\hline $\mathrm{SE}$ & $356.314,00$ & $14.750 .239,00$ & $8.958 .333,00$ & $40.549 .775,00$ & $64.614 .661,00$ \\
\hline NORDESTE & $15.016 .414,00$ & $99.006 .558,00$ & $211.215 .361,00$ & $1.794 .969 .717,00$ & $2.120 .208 .049,00$ \\
\hline $\mathrm{DF}$ & $353.588,00$ & $354.473,00$ & $361.902,00$ & $25.886 .537,00$ & $26.956 .500,00$ \\
\hline GO & $2.892 .520,00$ & $284.587 .280,00$ & $48.417 .019,00$ & $115.339 .512,00$ & $451.236 .332,00$ \\
\hline MS & $357.251,00$ & $708.136,00$ & $737.037,00$ & $42.621 .041,00$ & $44.423 .465,00$ \\
\hline MT & $12.957 .626,00$ & $17.615 .082,00$ & $183.299 .370,00$ & $4.239 .589 .989,00$ & $4.453 .462 .067,00$ \\
\hline CENTRO-OESTE & $16.560 .986,00$ & $303.264 .972,00$ & $232.815 .327,00$ & $4.423 .437 .079,00$ & $4.976 .078 .364,00$ \\
\hline ES & 106.098.196,00 & $12.107 .131,00$ & $17.856 .985,00$ & $237.966 .856,00$ & $374.029 .168,00$ \\
\hline MG & $23.114 .883,00$ & $1.236 .737 .024,00$ & $92.670 .136,00$ & $841.885 .521,00$ & $2.194 .407 .564,00$ \\
\hline RJ & $30.624 .759,00$ & $309.857 .161,00$ & $132.009 .717,00$ & $666.749 .804,00$ & $1.139 .241 .440,00$ \\
\hline SP & $164.262 .118,00$ & $670.209 .607,00$ & $500.170 .940,00$ & $3.628 .548 .443,00$ & $4.963 .191 .109,00$ \\
\hline SUDESTE & \begin{tabular}{|l|}
$324.099 .956,00$ \\
\end{tabular} & $2.228 .910 .923,00$ & $742.707 .778,00$ & $5.375 .150 .624,00$ & $8.670 .869 .281,00$ \\
\hline $\mathrm{PR}$ & $186.138 .958,00 \mid$ & $66.380 .427,00$ & $91.191 .619,00$ & $385.623 .143,00$ & $729.334 .147,00$ \\
\hline RS & $57.389 .556,00$ & $203.799 .699,00$ & $209.567 .405,00$ & $1.097 .100 .021,00$ & $1.567 .856 .680,00$ \\
\hline SC & $15.244 .538,00$ & $90.734 .618,00$ & $57.237 .071,00$ & $228.048 .366,00$ & $391.264 .594,00$ \\
\hline SUL & $258.773 .052,00$ & $360.914 .744,00$ & $357.996 .095,00$ & $1.710 .771 .529,00$ & $2.688 .455 .420,00$ \\
\hline BRASIL & \begin{tabular}{|l|}
$617.400 .320,00$ \\
\end{tabular} & $3.331 .378 .689,00$ & $2.144 .347 .199,00$ & $14.203 .232 .547,00$ & $20.296 .358 .754,00$ \\
\hline
\end{tabular}


Tabela A.6: Tabela FIPE/IDET Cargas Movimentadas (ton) - Janeiro2010 Destino: Região Sul.

\begin{tabular}{|c|c|c|c|c|}
\hline O\D - TON & PR & RS & SC & SUL \\
\hline $\mathrm{AC}$ & $5.384 .858,60$ & $4.180 .669,35$ & $844.007,07$ & $10.409 .535,02$ \\
\hline AM & $37.973 .512,14$ & $29.481 .683,77$ & $5.951 .857,78$ & $73.407 .053,69$ \\
\hline $\mathrm{AP}$ & $5.250 .824,73$ & $4.076 .608,81$ & $822.998,99$ & $10.150 .432,52$ \\
\hline PA & $49.451 .512,62$ & $38.392 .915,87$ & $7.750 .886,18$ & $95.595 .314,66$ \\
\hline RO & $4.028 .003,82$ & $3.127 .241,28$ & $631.337,60$ & $7.786 .582,70$ \\
\hline RR & $14.966 .692,64$ & $11.619 .765,32$ & $2.345 .835,85$ & $28.932 .293,81$ \\
\hline TO & $10.951 .393,45$ & $8.502 .387,60$ & $1.716 .489,54$ & $21.170 .270,59$ \\
\hline NORTE & $128.006 .798,00$ & $99.381 .272,00$ & $20.063 .413,00$ & $247.451 .484,00$ \\
\hline $\mathrm{AL}$ & $359.146,00$ & $374.482,00$ & $2.020 .129,00$ & $2.753 .758,00$ \\
\hline BA & $73.376 .175,00$ & $76.195 .658,00$ & $59.898 .208,00$ & $209.470 .041,00$ \\
\hline $\mathrm{CE}$ & $2.496 .677,00$ & $4.541 .053,00$ & $2.962 .537,00$ & $10.000 .267,00$ \\
\hline MA & $359.841,00$ & $361.121,00$ & $518.932,00$ & $1.239 .894,00$ \\
\hline $\mathrm{PB}$ & $401.799,00$ & $825.591,00$ & $380.574,00$ & $1.607 .964,00$ \\
\hline $\mathrm{PE}$ & $8.459 .617,00$ & $12.478 .850,00$ & $2.906 .000,00$ & $23.844 .467,00$ \\
\hline PI & $359.673,00$ & $419.863,00$ & $4.549 .047,00$ & $5.328 .582,00$ \\
\hline RN & $366.616,00$ & $443.599,00$ & $468.154,00$ & $1.278 .369,00$ \\
\hline SE & $1.259 .970,00$ & $1.788 .176,00$ & $5.673 .594,00$ & $8.721 .740,00$ \\
\hline NORDESTE & $87.439 .515,00$ & $97.428 .393,00$ & $79.377 .174,00$ & $264.245 .082,00$ \\
\hline DF & $353.588,00$ & $356.297,00$ & $355.532,00$ & $1.065 .417,00$ \\
\hline GO & $10.918 .935,00$ & $6.733 .547,00$ & $24.310 .893,00$ & $41.963 .375,00$ \\
\hline MS & $658.913,00$ & $3.547 .545,00$ & $786.141,00$ & $4.992 .600,00$ \\
\hline MT & $26.684 .247,00$ & $69.050 .025,00$ & $37.057 .280,00$ & $132.791 .552,00$ \\
\hline CENTRO-OESTE & $38.615 .683,00$ & $79.687 .414,00$ & $62.509 .846,00$ & $180.812 .944,00$ \\
\hline ES & $1.310 .552,00$ & $18.093 .432,00$ & $612.843,00$ & $20.016 .826,00$ \\
\hline MG & $28.383 .875,00$ & $187.315 .828,00$ & $3.469 .324,00$ & $219.169 .027,00$ \\
\hline RJ & $178.067 .304,00$ & $258.525 .733,00$ & $214.355 .202,00$ & $650.948 .239,00$ \\
\hline SP & $525.878 .109,00$ & $2.643 .400 .262,00$ & $252.744 .374,00$ & $3.422 .022 .745,00$ \\
\hline SUDESTE & $733.639 .840,00$ & $3.107 .335 .255,00$ & $471.181 .742,00$ & $4.312 .156 .837,00$ \\
\hline PR & $1.015 .082 .809,00$ & $165.565 .309,00$ & $686.791 .729,00$ & $1.867 .439 .847,00$ \\
\hline RS & $76.160 .569,00$ & $1.099 .722 .509,00$ & $117.938 .764,00$ & $1.293 .821 .841,00$ \\
\hline SC & $174.629 .904,00$ & $121.830 .814,00$ & $548.714 .504,00$ & $845.175 .222,00$ \\
\hline SUL & $1.265 .873 .281,00$ & $1.387 .118 .632,00$ & $1.353 .444 .997,00$ & $4.006 .436 .910,00$ \\
\hline BRASIL & $2.253 .575 .118,00$ & $4.770 .950 .967,00$ & $1.986 .577 .172,00$ & $9.011 .103 .257,00$ \\
\hline
\end{tabular}

